\title{
TFOS DEWS II Tear Film Report
}

\author{
Willcox, Mark D. P.
}

2017-07

Willcox , M D P , Argueso , P , Georgiev , G A , Holopainen , J M , Laurie , G W , Millar , T J , Papas , E B , Rolland, J P , Schmidt , T A , Stahl , U, Suarez , T , Subbaraman , L N , Ucakhan , O O \& Jones , L 2017 , ' TFOS DEWS II Tear Film Report ' , Ocular Surface, vol. 15 , no. 3 , pp. 366-403 . https://doi.org/10.1016/j.jtos.2017.03.006

http://hdl.handle.net/10138/297896

https://doi.org/10.1016/j.jtos.2017.03.006

publishedVersion

Downloaded from Helda, University of Helsinki institutional repository.

This is an electronic reprint of the original article.

This reprint may differ from the original in pagination and typographic detail.

Please cite the original version. 


\title{
TFOS DEWS II Tear Film Report
}

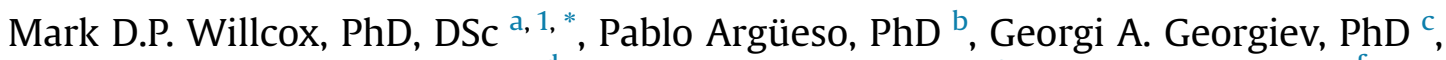 \\ Juha M. Holopainen, MD, PhD ${ }^{\mathrm{d}}$, Gordon W. Laurie, PhD ${ }^{\mathrm{e}}$, Tom J. Millar, PhD ${ }^{\mathrm{f}}$, \\ Eric B. Papas, BScOptom, PhD ${ }^{\text {a }}$, Jannick P. Rolland, PhD ${ }^{g}$, Tannin A. Schmidt, PhD ${ }^{\mathrm{h}}$, \\ Ulrike Stahl, BScOptom, PhD ${ }^{i}$, Tatiana Suarez, $\mathrm{PhD}^{\mathrm{j}}$, \\ Lakshman N. Subbaraman, BS Optom, PhD ${ }^{\mathrm{i}}$, Omür Ö. Uçakhan, MD ${ }^{\mathrm{k}}$, \\ Lyndon Jones, FCOptom, PhD ${ }^{\mathrm{i}}$
}

a School of Optometry and Vision Science, University of New South Wales, Sydney, Australia

${ }^{\mathrm{b}}$ Schepens Eye Research Institute, Harvard Medical School, Boston, USA

${ }^{\mathrm{c}}$ Biointerfaces and Biomaterials Laboratory, Department of Optics and Spectroscopy, School of Optometry, Faculty of Physics, St. Kliment Ohridski University of Sofia, Sofia, Bulgaria

d Helsinki University Eye Hospital, University of Helsinki, Finland

e Departments of Cell Biology, Ophthalmology and Biomedical Engineering, University of Virginia, Charlottesville, VA, USA

${ }^{\mathrm{f}}$ School of Science and Health, Western Sydney University, Australia

${ }^{\mathrm{g}}$ Institute of Optics, University of Rochester, New York, USA

${ }^{\mathrm{h}}$ Faculty of Kinesiology and Schulich School of Engineering, University of Calgary, Canada

${ }^{\mathrm{i}}$ Centre for Contact Lens Research, School of Optometry and Vision Science, University of Waterloo, Canada

${ }^{\mathrm{j}}$ Bioftalmik Applied Research, Bizkaia, Spain

${ }^{\mathrm{k}}$ Department of Ophthalmology, Ankara University Faculty of Medicine, Ankara, Turkey

\section{A R T I C L E I N F O}

\section{Article history:}

Received 25 March 2017

Accepted 27 March 2017

\section{Keywords:}

Dry eye disease

Evaporation

Lipidome

Mucin

Osmolarity

Proteome

Tear film

Tear film stability

Tears

\begin{abstract}
A B S T R A C T
The members of the Tear Film Subcommittee reviewed the role of the tear film in dry eye disease (DED) The Subcommittee reviewed biophysical and biochemical aspects of tears and how these change in DED. Clinically, DED is characterized by loss of tear volume, more rapid breakup of the tear film and increased evaporation of tears from the ocular surface. The tear film is composed of many substances including lipids, proteins, mucins and electrolytes. All of these contribute to the integrity of the tear film but exactly how they interact is still an area of active research. Tear film osmolarity increases in DED. Changes to other components such as proteins and mucins can be used as biomarkers for DED. The Subcommittee recommended areas for future research to advance our understanding of the tear film and how this changes with DED. The final report was written after review by all Subcommittee members and the entire TFOS DEWS II membership.
\end{abstract}

๑) 2017 Elsevier Inc. All rights reserved.

\section{Overview of the tear film in health}

A stable preocular tear film is a hallmark of ocular health, largely because it forms the primary refracting surface for light entering the visual system and it protects and moisturizes the cornea. The three layered model of the tear film proposed by Wolff $[1,2]$ has had

\footnotetext{
* Corresponding author.

E-mail address: m.willcox@unsw.edu.au (M.D.P. Willcox).

1 Subcommittee Chair
}

an overwhelming allure because it is simple and logical: a mucin layer covering the ocular surface and lowering the supposed hydrophobicity of the epithelial cells; an aqueous layer to nurse the exposed ocular epithelium by providing lubricity, some nutrients, antimicrobial proteins and appropriate osmolarity; and a lipid layer to prevent loss of the aqueous layer through overspill and evaporation. There is a continual return to this three layered model, despite Doane stating over 20 years ago that the three layered structure "is a considerable simplification of reality" [3]. This has generally limited novel perspectives that might lead to a clearer understanding of the dynamics, structure and function of the tear 
film and the changes that occur to cause dry eye. The precorneal tear film behaves as a single dynamic functional unit [4] with different compartments.

Laxity of terminology means that there is ready acceptance of information that may not be entirely correct. For instance, "tear osmolarity is approximately $302 \mathrm{mOsm} / \mathrm{L}$ " is often accepted terminology, but in reality such a value is for tears sampled from within the lower tear meniscus. While it may represent the osmolarity of the tear film spread over the ocular surface, there is no evidence of this. A consequence of being aware of where the samples being measured are coming from and how they are collected may lead to a more cautious approach to extrapolating data to the tear film that covers the ocular surface and, ultimately, a better understanding of its composition, structure and spatial distribution. Optical coherence tomography (OCT) has allowed non-invasive measurements of both the upper and lower menisci in terms of height, area, and curvature of the surface and while the upper and lower meniscus in an individual appear to be identical in these parameters, none of these parameters correspond to central tear film thickness [5], but lower meniscus height seems to correspond to the volume of mucoaqueous tears $[6,7]$.

When the eyes are open the tears are distributed in three compartments, which are the fornical compartment (which occupies the fornix and retrotarsal space), the tear menisci and the preocular tear film. The fornical compartment is assumed to be narrowest in the region of the lid wiper of the lid margin, which is directly apposed to the globe. The preocular tear film overlies the exposed conjunctiva and cornea [8]. The precorneal tear film follows the contours of the cornea, and is usually highly stable [9]. The pre-bulbar film follows the varying contours of the bulbar conjunctiva. The preocular tear film is the whole tear component that is spread over the exposed surface of the eye. Results from studies using ultrahigh resolution OCT has resolved the debate over the thickness of the tear film. It is extraordinarily thin, $2-5.5 \mu \mathrm{m}$ thick over the corneal region (precorneal tear film), and these data concur with estimates of tear film thickness using interferometry techniques [8-10]. The tear film is so thin that the roughness of the corneal surface $(\sim 0.5 \mu \mathrm{m})$ cannot be ignored [11]. Neither the tear film thickness over the conjunctival region, nor the roughness of the conjunctival surface has been measured. Water has a high surface tension and therefore to form such a thin film of water without it collapsing onto the surface or forming lenses, the surface on which it spreads has to have similar properties to water and the surface tension of the water at the air interface has to be lowered $[12,13]$.

The apical surfaces of the corneal and conjunctival epithelia have transmembrane mucins [14], which increase the adhesion tension for water, facilitating the spread of the tears across the ocular surface. Transmembrane mucins attached to the microplicae of the epithelial cells extend up to $500 \mathrm{~nm}(0.5 \mu \mathrm{m})$ into the tear film $[15,16]$. They also constitute a line of defense for the epithelial cells against infection and injury $[17,18]$.

Much remains to be learned about the mucoaqueous component of the preocular tear film and whether it is the same within all compartments. In addition to oxygen, metabolites and electrolytes, the tear film contains antimicrobial peptides, proteins and soluble immunoglobulins that protect the ocular surface from infection. The sensitivity of modern proteomics techniques has allowed the identification of more than 1500 proteins [19], and more than 200 peptides originating from several of those proteins [20]. The nature of the vast majority of these proteins and peptides reflects that tears are also a mechanism for removal of cellular debris that occurs due to the turnover of ocular epithelial cells. In addition, sensitive lipid studies also show that tears contain a lipid profile similar in ratio to meibomian lipids, but with a relative abundance of phospholipids [21].

Shortly after a blink, the mucoaqueous component of the preocular tear film is believed to become physically isolated from the upper and lower menisci, such that diffusion between these compartments does not occur [22,23]. This isolation has been observed as a black line at the ocular margins in fluorescein-labeled tears.

The tear film lipid layer is approximately $40 \mathrm{~nm}$ thick [24], lowers the surface tension at the air interface of the preocular tear film and results in spreading of the tear film over the ocular surface. A feature of the preocular tear film is that it resists evaporation, and it is purported that the tear film lipid layer is responsible for this $[25-27,67]$. The complete nature of the tear film lipid layer is unknown, but it is likely it has surfactant molecules at the mucoaqueous interface and lipophilic molecules at the air interface. Unlike the aqueous component of the preocular tear film, which appears to be isolated shortly after a blink, the lipid layer of the tear film appears to be continuous over the menisci and indeed continues to move upwards over the ocular surface following a blink. Observations using various interference techniques at different magnifications show that the lipid layer is variable in thickness across the ocular surface. This movement and continuum from the meibomian gland orifices, and direct observation of secretions from the meibomian glands onto the ocular surface, indicate that the tear film lipid layer is almost entirely derived from meibomian gland secretions. It is unknown if lipids from the tear film lipid layer move into the mucoaqueous compartment of the preocular tear film, or if lipids from other ocular tissues (origin unknown) transverse the mucoaqueous compartment and adsorb to the tear film lipid layer. By examining the shear rheology of films of meibomian lipids in vitro and comparing them with other lipids, there is evidence that meibomian lipid films spread over a mucoaqueous subphase, causing the subphase to resist collapse as it thins [28]. Dilatational rheology studies also confirmed that the viscoelastic films of tear lipids, meibum and contact lens lipid extracts are predominantly elastic, which may enhance their capability to stabilize the air/tear surface [29-31].

\section{Biophysical measurements of the tear film}

\subsection{Tear film structure and dynamics}

There is evidence that, in the above described three layer structure of the tear film, the mucin layer has a decreasing gradient of concentration from the epithelium towards the aqueous layer [32]. It is also commonly considered that the aqueous and mucin layers are a single layer of mucoaqueous gel (referred to hereafter as the mucoaqueous layer) [33].

The tear film lipid layer is derived from meibum secreted from the lid margins and is spread onto the tear film with each blink, driven by surface tension forces. It plays an important role in stabilizing the tear film and in the past has been thought to play a key role in retarding tear evaporation [25-27,67]. The lipid layer can be investigated with interferometry techniques. The color and brightness of the interference images are analyzed to yield lipid layer thickness [24,34-37]. The thickness of the lipid layer has been reported to be from 15 to $157 \mathrm{~nm}$, with a mean of $42 \mathrm{~nm}$ [24].

Evidence from reflection spectra of the precorneal tear film suggested the tear film has a thickness of approximately $2 \mu \mathrm{m}$ [9]. OCT techniques find the thickness of the tear film to range from 2 to $5.5 \mu \mathrm{m}[10,38-42]$.

To elucidate the structure of the tear film, studies have made use of multiple methods. These include combining a wavefront sensor with OCT [43], using fluorescein tear breakup time (TBUT) and Schirmer test [43], applying fluorescein and assessing using a 
rotating Scheimpflug camera (Pentacam, Oculus, Germany) [44], simultaneously recording videos of fluorescence and imaging tear film lipid layer [45], and using dual thermal-fluorescent imaging [46].

The bulk of the tear volume and flow is via secretion from the lacrimal gland [47,48], with a smaller portion secreted by the conjunctiva [49]. In animal studies, tears can be produced by the accessory lacrimal glands in the conjunctiva even after removal of the main gland [50]. Both parasympathetic and sympathetic nerves innervate the main lacrimal glands [51,52] and a few sensory nerves have also been identified [51]. The nerves are located in close proximity to acinar, ductal, and myoepithelial cells as well as being close to blood vessels [51,52]. Stimulation of the lacrimal gland and secretion occur via the cornea -trigeminal nerve-brainstem-facial nerve-lacrimal gland reflex arc. Afferent sensory nerves of the cornea and conjunctiva are activated by stimulation of the ocular surface. Efferent parasympathetic and sympathetic nerves are then activated to stimulate secretion from acinar and tubular cells in the lacrimal gland [53].

Tears have been classified into four broad types - basal, reflex, emotional and closed-eye. (see review by Craig et al.) [54]. Basal tears (sometimes referred to as open-eye tears) are tears that constitutively coat the eye and are deficient in dry eye. Reflex tears are produced upon stimulation of the ocular surface (for example by onion vapor) or stimulation of the reflex arc (for example by nasal stimulation of the sneeze reflex). Emotional tears are also produced upon stimulation, but in this case via emotions such as sadness. Closed-eye tears are those that can be collected from the ocular surface immediately after a period of sleep. Basal, reflex and emotional tears are produced mainly from the lacrimal glands via the neural arc [55], but differ in their constitution, for example, the concentration of various proteins change [54]. Secretion from the lacrimal gland is greatly reduced during sleep, and so the constitution of closed-eye tears is somewhat different to that of other types with, for example, an increased amount of serum-derived proteins leaking from the conjunctival blood vessels [54].

A two-step process of tear film deposition through a blink has been proposed [56]. In the first step, the upper lid pulls a layer of tears over the cornea by capillary action; in the second step, the lipid layer drifts upward, which may drag up aqueous tears along with it. The upward drift of the lipid layer can be observed using interferometry imaging approaches [57]. After the blink, tear film redistribution occurs due to the negative hydrostatic pressure within the nascent menisci. This draws liquid from the forming tear film and eventually causes the precorneal portion to separate from the menisci. The boundary can be observed as a black line of reduced fluorescence in the fluorescein-stained tear film, indicating where the aqueous layer is thin but the lipid layer remains intact [58,59].

Tears flow from the supply region towards the puncta, located on the lids near the nasal canthi, to facilitate their turnover and removal $[60,61]$. Tear turnover rate has been estimated to be $16 \pm 5 \% / \mathrm{min}$ [62-64]. Between blinks, thinning of the tear film occurs, which can be observed using several different approaches $[40,57,65,66]$. Most of the observed tear thinning between blinks is due to evaporation $[25-27,57,65,67,68]$.

Tear production, turnover and volume can be estimated by several methods, but there is limited correlation between different tests [69]. Accordingly, a combination of tests should provide a more reliable diagnosis and increase the specificity and sensitivity of dry eye diagnosis [70]. The phenol red thread test (Hamano test) [71] is a measurement of tear volume or change in tear volume with time, by observation of the amount of wetting of a phenol red dye impregnated cotton thread placed over the inferior eyelid. The Schirmer test [72] is a measure of tear production and is undertaken by observing the wetting of a standardized paper strip. Historically, the Schirmer I test is performed without anesthesia and thus measures predominantly reflex tearing. A variation on the Schirmer I test involves use of topical anesthesia and claims to reflect the basal secretion of tears, although a contribution from reflex tearing cannot be discounted [626]. Tear volume can also be measured by fluorophotometric assessment, and demonstrates an apparent normal human volume of approximately $8 \pm 3 \mu \mathrm{l}[47,62]$ Tear meniscus height (TMH) is linearly proportional to the lacrimal secretory rate [47]. Differences in TMH and radius of curvature can be used to aid diagnosis of dry eye $[7,73,74]$. Tear clearance rate is the rate at which the preocular tear film or an instilled marker of the tears is removed from the tear film by dilution or drainage from the tear volume [75]. Tear clearance rate measurement is seldom performed in the clinical setting. Tear dynamics can be estimated by dividing the value of the Schirmer test with anesthesia by the tear clearance rate, giving the Tear Function Index [76]. This value has been shown to have greater sensitivity for detecting dry eye than either one of these tests alone [76].

\subsection{Tear film stability on eye and ocular surface wettability}

A stable precorneal tear film has long been viewed as one of the hallmarks of ocular health, largely because it provides the primary refracting surface for light entering the visual system as well as creating a protective and lubricated environment for the tissues of the palpebral and bulbar surfaces. Unlike some other species, whose tears can remain stable for many minutes [77], the human tear film tends to collapse or "break up" in under half a minute or so, unless it is re-established by the act of blinking. While all individuals will manifest this behavior if blinking is prevented for long enough, rapid appearance of regions of localized drying is viewed as evidence for tear film disorder, particularly in dry eye, and so observations of stability are commonly and frequently performed as a diagnostic aid.

Experiments have shown that tear film thinning and breakup occur mainly as a result of evaporation from the tear film, rather than due to fluid flow, whether that be tangentially within the film itself, or radially across the ocular surface $[78,79]$. Using reflectivity and tear fluorescein as respective indicators for lipid and mucoaqueous layer thickness, King-Smith et al. suggested a lack of correspondence between dry eye and both lipid layer thickness and thinning rate [45]. Further, thinning rate was not affected by apparent thickening of the lipid layer with lipid emulsion-based eye drops [24], suggesting that the lipid was a poor barrier to evaporation [45]. Perhaps it is the whole healthy preocular tear film that resists evaporation from the ocular surface, and hence thinning? Measurement of TBUT may provide a better indicator of the ability of the preocular tear film to prevent evaporative losses.

Acquiring a TBUT is a relatively simple task, but interpreting the result is not straightforward because of its inherent variability [80,81]. A number of approaches to improving repeatability have been suggested, including taking multiple readings and averaging or selecting a subset of values [82,83], minimizing the amount of fluorescein instilled [84-86] and, most significantly, eliminating the use of fluorescein altogether. This last approach, via a number of different methods, provides a non-invasive breakup time (NIBUT) value. Tear film additives are avoided, the examination environment should ideally introduce no additional sources of heat, air movement, humidity etc., and head posture and blinking behavior are standardized. Inevitably however, the extent to which these conditions are achieved varies somewhat between methods.

Early efforts in acquiring a NIBUT projected a grid pattern $[87,88]$ or keratometry mires $[89,90]$ onto the surface of the tear film and viewed their distortion in time after a blink. While it is still 
possible to use keratometer-based methods in clinical situations, a degree of subjectivity is involved in judging when the image distortion first occurs. Increasing sophistication in both image capture and computational capability has led to a refinement of the technique, using both automated detection and more detailed targets. In most cases, these targets are identical to those originally developed and used for measuring corneal shape (keratoscopes) and consist of multiple concentric rings whose angular subtense is sufficient to cover more or less all of the visible cornea. The image of this target is reflected from the anterior surface of the tear film and captured for subsequent analysis [91-98]. Typically, multiple, sequential images are acquired during the inter-blink period and image analysis software utilized to automatically detect the onset of areas of breakup.

Although repeatability has not been reported for all the devices using this approach, the available data are in reasonable agreement that they operate with a coefficient of variation of around $10 \%$ $[92,94]$, which is roughly three times better than traditional TBUT measurement [92]. Despite this improvement, the range of values reported for normal individuals is broad, being from about 4 to $19 \mathrm{~s}$ (Table 1). It may be that this reflects the different algorithms being used to extract breakup data among the various instruments, a suspicion that is strengthened by the observation that the corresponding dry eye breakup times are consistently about half those given for normal eyes. Thus, while inter-instrument comparisons are likely to be difficult to interpret, data derived from a given instrument type appear reasonably reliable and offer quite good sensitivity and specificity in distinguishing dry-eyed individuals from normals (Table 1). Further details may be obtained from the Tear Film and Ocular Surface Society's Dry Eye Workshop II (TFOS DEWS II) Diagnostic Methodology report [99].

Ocular surface thermography has been used to measure NIBUT, on the principle that breakup is associated with evaporative cooling and therefore thinning areas in the tear film show up as cool spots in the thermograph [46]. The technique is suggested to be reliable [100], although test-retest confidence intervals have not been made available so far. While data are limited to a single study, NIBUT derived from this method appear similar to those from the lower end of the videokeratoscopy range. Again, dry-eyed subjects yield breakup times that are about half those of normals, with levels of sensitivity and specificity being similar to those from videokeratoscopy (Table 1 ).

All the systems discussed so far are commercially available and so could feasibly be used in routine clinical practice. The following discussion deals with instruments that are more complex and/or unlikely to be applicable outside a research setting. Recently, lateral shearing interferometry has been used to monitor changes in tear film stability. This instrument uses an optical wedge to laterally shift the wavefront reflected from the tear film surface and rotate it so that it can be made to interfere with itself [101,102]. Information about the shape of the reflecting surface is contained in this wavefront and can be extracted from the resulting interference pattern. Note that this differs from colored fringe methods, such those of Guillon [103], or the interferometer developed by Doane [104], both of which rely on interference between light reflected from different surfaces within the tear film, such as the front and back of the lipid layer. Using fast Fourier transformation, images derived with the shearing technique can be processed to generate a surface stability index parameter (M2). Sequential image acquisition allows M2 to be followed over the blink cycle, in real time, at a resolution determined by the video frame rate. It is claimed that this method is relatively insensitive to eye movements and the degree of dryness of the surface being measured [105] and is better able to discriminate dry eyed subjects from normal than either dynamic area high speed videokeratoscopy or wavefront sensing [106].

Another technique that may be developed for clinical application is the use of double pass methods. The basis for double pass methods is that the view of the retina obtained using a double pass optical system, in which the image forming light traverses all the optical surfaces of the eye twice (once on entry and again on exit), will be affected by scattering from all these surfaces, including the tear film. Thus, analysis of double-pass retinal images on the time scale of the blink cycle may provide an indirect measure of tear film stability. Deteriorations in image quality metrics such as intensity distribution index [107], Strehl ratio, modulation transfer function cut-off frequency and objective scattering index [108] are observed in dry eye. More data are needed to establish the diagnostic ability of this approach for discriminating dry eye.

\subsection{Vision quality}

An association between dry eye and compromised visual acuity postulated by Rieger [110] is poorly documented using high contrast letter acuity [111]. However, based on the measurement of "functional visual acuity", whereby acuity is measured after suspension of blinking for several seconds, dry eyed subjects do significantly worse than normals [111]. Delayed blinking generates subtle wavefront aberrations that more rapidly give rise to higher order aberrations after the blink in dry eye individuals [112]. In an effort to directly link tear film changes to visual loss, a three channel optical system that allowed concurrent measurement of letter contrast acuity, TBUT and refractive aberrations was constructed. Although the data reported were for contact lens wearing eyes only, progression of TBUT was clearly associated with both visual performance reduction and declining optical quality [113].

Table 1

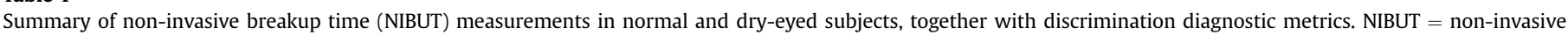
breakup time; AUC = area under the curve of a receiver operating characteristic graph plotting sensitivity vs. 1-specificity.

\begin{tabular}{|c|c|c|c|c|c|c|c|}
\hline Author (Reference) & NIBUT Normal (sec) & NIBUT Dry Eye (sec) & AUC & Sensitivity & Specificity & Instrument & Principle \\
\hline Hong et al. 2013[94] & $\begin{array}{l}4.3 \pm 0.3 \\
\mathrm{n}=41\end{array}$ & $\begin{array}{l}2.0 \pm 0.2 \\
\mathrm{n}=44\end{array}$ & 0.83 & 84.1 & 75.6 & Oculus keratograph & Videokeratoscopy \\
\hline Gumus et al. 2011[97] & $\begin{array}{l}4.9 \pm 1.6 \\
n=25\end{array}$ & $\begin{array}{l}2.4 \pm 2.5 ; \text { Mild } n=23 \\
1.2 \pm 1.8 ; \text { Moderate } n=11 \\
0.4 \pm 0.5 ; \text { Severe } n=11\end{array}$ & & 82.2 & 88.0 & Tomey RT7000 & Videokeratoscopy \\
\hline Downie 2015 [92] & $\begin{array}{l}19.4 \pm 5.3 \\
n=17\end{array}$ & $\begin{array}{l}7.9 \pm 4.9 \\
\mathrm{n}=28\end{array}$ & 0.92 & 81.5 & 94.4 & Medmont E300 & Videokeratoscopy \\
\hline Koh et al. 2016[95] & $\begin{array}{l}9.7 \pm 6.7 \\
n=31\end{array}$ & $\begin{array}{l}4.6 \pm 1.3 \\
n=49\end{array}$ & & & & Keratograph M5 & Videokeratoscopy \\
\hline Su et al. 2016[109] & $\begin{array}{l}4.5 \pm 0.9 \\
\mathrm{n}=31\end{array}$ & $\begin{array}{l}2.1 \pm 1.1 \\
\mathrm{n}=42\end{array}$ & 0.88 & 80.0 & 89.0 & IT-85, United Integrated Services Co & Thermography \\
\hline
\end{tabular}




\subsection{Tear osmolarity}

Tear film osmolarity has been described as a single measurement that gives insight into the balance between tear production, evaporation, drainage and absorption [114]. In the 1995 National Eye Institute/Industry Workshop [115], tear hyperosmolarity was included as a global feature of dry eye and in the 2007 TFOS DEWS definition and classification report [116] tear film hyperosmolarity was identified as one of the two core mechanisms of dry eye and included in the definition. This section will mainly focus on new knowledge gained since the 2007 reports.

The terms tear film osmolarity and osmolality have frequently been employed interchangeably, with osmolarity being the more common term, and is the term used throughout this manuscript $[117,118]$. Both refer to the amount of osmotically active particles, although with small differences [119] that are clinically irrelevant. Previously, tear film osmolarity was primarily measured via freezing point depression or vapor pressure osmometry, but a series of factors have limited their usage in clinical settings [118-121]. Clinical evaluation of tear osmolarity has increased with the introduction of a new osmometer that collects a $50 \mathrm{~nL}$ tear sample and analyzes its electrical impedance (TearLab, San Diego, CA, USA).

Mean tear film osmolarity values in normal participants range from 270 to $315 \mathrm{mOsm} / \mathrm{L}$ [122-137], with an overall average of 300 $\mathrm{mOsm} / \mathrm{L}$, which is similar to the value stated by Tomlinson et al., who reviewed studies between 1978 and 2004 [138]. There seems to be no statistical or clinically relevant effect on tear osmolarity of age $[128,139-141]$, race $[140,142,143]$, hormonal fluctuation in women with a regular menstrual cycle $[131,144]$, or oral contraceptive pill use [131,144]. Vehof et al. investigated the influence of genetic factors on dry eye in female twins and found an estimated heritability of $40 \%$ for osmolarity [145]. Variation between normal right and left eyes is $6.9 \pm 5.9 \mathrm{mOsm} / \mathrm{L}$ [146]. Data on the effect of sex on tear osmolarity remain equivocal, with Lemp et al. [128] and Versura et al. [126] reporting no significant effect of sex, which is in agreement with a previous review of the literature [54], whilst Fuerst et al. [140] show significantly higher tear film osmolarity in men (311.8 vs. $302.3 \mathrm{mOsm} / \mathrm{L}$ ). An increase in tear osmolarity has been observed after sleep deprivation, exposure to high altitude and religious fasting $[135,147,148]$. In accordance with previous studies, prolonged eye closure has been found to lead to tear hypoosmolarity but data about diurnal variations are equivocal $[130,134,139,142,149]$. Some authors $[130,142]$ show a shift towards lower values mid-day, followed by an increase, whilst others $[134,139,149]$ show no significant effect of time. There is a positive relationship between plasma osmolarity and tear osmolarity and both are raised in patients with dry eye disease or with systemic dehydration [150-152].

The concentration of electrolytes in the mucoaqueous layer mainly determines the osmolarity of the normal tear film, and secretion mechanisms and contribution to tear film osmolarity have been previously summarized [117,119]. Various mathematical models, as summarized and furthered by Braun et al., have stated that the osmolarity across the ocular surface is different to that measured in the tear meniscus [153]. During the blink interval the tear film thins over the cornea, mainly due to evaporation, leading to a hyperosmotic shift $[153,154]$. The level of hyperosmotic shift depends on the thinning rate, which is driven by the evaporation rate [154]. In the event of a low thinning rate, such as $1 \mu \mathrm{m} / \mathrm{min}$, tear film osmolarity over the ocular surface will increase from 300 $\mathrm{mOsm} / \mathrm{L}$ to $332 \mathrm{mOsm} / \mathrm{L}$ over a $25 \mathrm{~s}$ period, but will increase to 1830 $\mathrm{mOsm} / \mathrm{L}$ in the case of a rapid thinning rate of $20 \mu \mathrm{m} / \mathrm{min}$ [153]. During tear film breakup, local spikes of tear osmolarity around
$1900 \mathrm{mOsm} / \mathrm{L}$ have been predicted [153]. Those rates are significantly higher than those observed in the tear meniscus, partly due to the mixing of the tear fluid from the ocular surface with that in the meniscus during the blink and secretion of new tears. In the non-dry eye, the predicted osmolarity difference between the tear film over the ocular surface and in the tear meniscus is fairly small, but is predicted to increase in dry eye, particularly when there is increased evaporation with reduced TMH [68]. The peak in tear film osmolarity during tear film breakup is supported by studies investigating ocular comfort sensations. A slow increase in ocular discomfort has been demonstrated during tear thinning, with a sharp increase at tear film breakup or before a blink [155,156]. Liu et al. evaluated the subjective response during tear film breakup and tried to match the experienced sensation by instilling hyperosmolar drops [157]. The detection threshold for $\mathrm{NaCl}$ drops was $454 \pm 14 \mathrm{mOsm} / \mathrm{kg}$, with overall discomfort increasing as osmolarity increased. On average, a salt solution with $809 \mathrm{mOsm} / \mathrm{kg}$ was needed to evoke the same ocular response as during TBUT, ranging from 696 to $972 \mathrm{mOsm} / \mathrm{kg}$ [157]. The link between tear evaporation, tear thinning and tear film osmolarity is further supported in clinical studies showing a significant correlation between increased evaporation, tear film osmolarity and decreased tear stability, or automated measures of tear film surface quality breakup time being a clinical marker for tear hyperosmolarity in moderate to severe dry eye $[92,158]$.

As summarized in the 2007 TFOS DEWS report, tear hyperosmolarity in dry eye has been attributed to increased evaporation or a higher impact of evaporation in low volume [116,159]. Mean tear film osmolarity values for dry eye in studies until 2008 ranged between 311 and $360 \mathrm{mOsm} / \mathrm{L}$, with an average of $326.9 \mathrm{mOsm} / \mathrm{L}$ $[119,138]$. Table 2 summarizes the values obtained in studies since 2009 that aimed to establish osmolarity values in dry eye or investigated the feasibility of osmolarity measurements in the diagnosis or treatment success of dry eye. Using different degrees of dry eye severity and etiologies, mean values range between 297 and $337 \mathrm{mOsm} / \mathrm{L}$, with an overall mean of 315. Higher tear film osmolarity values have been reported with increased dry eye severity grade [126,128,160-164]. For example, normal, mild/moderate, and severe dry eyes have average tear osmolarity values of $302 \pm 8$ $\mathrm{mOsm} / \mathrm{L}, 315 \pm 11 \mathrm{mOsm} / \mathrm{L}$ and $336 \pm 22 \mathrm{mOsm} / \mathrm{L}$, respectively [162]. Suzuki et al. and Sullivan et al. found a significant correlation between dry eye severity scores and measured tear film osmolarity ( $r=0.47$ and $r=0.74$, respectively) $[160,162]$. Despite similar outcomes, it must be noted that the criteria for dry eye severity were not uniform among studies, with authors using different cutoff values, different calculation of scores and different decisions about the inclusion of tear film osmolarity as a diagnostic factor for dry eye severity, which could have introduced selection bias [116].

Although there can be large within-subject fluctuations $[130,137,141,149]$, Eperjesi et al. proposed that changes of $33 \mathrm{mOsm} /$ L or higher can be considered clinically relevant [141]. The instability of osmolarity readings has been attributed to compromised homeostasis of the dry eye tear film. Differences between readings can be considered a marker for tear film instability $[128,133,146]$. Such interpretation may be supported by studies showing higher variability between measurements or eyes with higher osmolarity values or more severe dry eye $[128,133,137,139,165]$.

Despite a general shift in tear film osmolarity with dry eye, there is a large overlap in osmolarity values between normal and dry eye participants. Sensitivity and specificity measurements of osmolarity for dry-eye diagnosis using a threshold of $294 \mathrm{mOsm} / \mathrm{L}$ were $67 \%$ and $46 \%$ respectively [143], $40 \%$ and $100 \%$ using a threshold of $>310$ mOsm/L and Sjögren syndrome patients [166]. For a more in-depth analysis of statistical measures of performance and potential 
Table 2

Tear film osmolarity values in dry eye and non-dry eye subjects.

\begin{tabular}{|c|c|c|c|c|c|c|}
\hline Author & Testing Method & $\begin{array}{l}\text { Measurement from } \\
\text { one eye, combined } \\
\text { eyes, or worst eye }\end{array}$ & $\begin{array}{l}\text { Non-Dry Eye } \\
(\mathrm{mOsm} / \mathrm{L})\end{array}$ & $\begin{array}{l}\text { Dry Eye } \\
(\mathrm{mOsm} / \mathrm{L})\end{array}$ & Change \% & Dry Eye Group Definition \\
\hline $\begin{array}{l}\text { Khanal et al., } 2009 \\
\text { [123] }\end{array}$ & $\begin{array}{l}\text { Freezing point } \\
\text { depression }\end{array}$ & NK & $308.39 \pm 9.29$ & $\begin{array}{l}330.01 \pm 13.34 \\
325.57 \pm 14.76\end{array}$ & $\begin{array}{l}6.6 \\
5.3\end{array}$ & $\begin{array}{l}\text { Aqueous deficient; TFOS DEWS } \\
\text { Evaporative dry eye; TFOS DEWS }\end{array}$ \\
\hline $\begin{array}{l}\text { Messmer et al., } \\
\quad 2010[122]^{\text {a }}\end{array}$ & $\begin{array}{l}\text { Electrical } \\
\text { impedance }\end{array}$ & One eye & $307.1 \pm 11.3$ & $308.9 \pm 14.0$ & $0.6^{\mathrm{b}}$ & $\begin{array}{l}\geq 3 \text { of the following criteria were fulfilled:( } 1) \text { ocular } \\
\text { surface disease index (OSDI) }>15 ;(2) \text { staining of the } \\
\text { cornea in the typical interpalpebral area; ( } 3 \text { ) staining of } \\
\text { the conjunctiva in the typical interpalpebral area; }(4) \\
\text { tear film breakup time }<7 \mathrm{~s} \text {; (5) Schirmer test }<7 \mathrm{~mm} \text { in } \\
5 \mathrm{~min} \text {; (6) the presence of blepharitis or meibomitis. }\end{array}$ \\
\hline $\begin{array}{l}\text { Suzuki et al., } 2010 \\
\qquad[160]^{\text {a }}\end{array}$ & $\begin{array}{l}\text { Freezing point } \\
\text { depression }\end{array}$ & One eye & - & $309.7 \pm 22.3$ & & Modified TFOS DEWS Grades $1-4$ \\
\hline \multirow[t]{2}{*}{$\begin{array}{l}\text { Tomlinson et al., } \\
2010 \text { [125] }^{\mathrm{a}}\end{array}$} & $\begin{array}{l}\text { Electrical } \\
\text { impedance }\end{array}$ & One eye & $308 \pm 6.2$ & $321 \pm 7.2$ & 4.1 & \multirow[t]{2}{*}{$\begin{array}{l}\text { NIBUT }<10 \mathrm{~s} \text {, Schirmer I test }<5 \mathrm{~mm} \text {, and positive } \\
\text { symptoms }\end{array}$} \\
\hline & $\begin{array}{l}\text { Freezing point } \\
\text { depression }\end{array}$ & & $310 \pm 7.2$ & $323 \pm 14.7$ & 4.0 & \\
\hline \multirow[t]{3}{*}{$\begin{array}{l}\text { Versura et al., } 2010 \\
\text { [126] }\end{array}$} & \multirow[t]{3}{*}{$\begin{array}{l}\text { Electrical } \\
\text { impedance }\end{array}$} & \multirow[t]{3}{*}{ Worst eye } & \multirow[t]{3}{*}{$295.5 \pm 9.8$} & $298.1 \pm 10.6$ & $0.9^{\mathrm{b}}$ & $\begin{array}{l}\text { Mild; OSDI } 13-21, \text { meibomian gland dysfunction } \\
\text { variably present }\end{array}$ \\
\hline & & & & $306.7 \pm 9.5$ & 3.7 & $\begin{array}{l}\text { Moderate; OSDI } 23-32 \text {, MGD variably present, } \\
\text { TBUT } \leq 10 \text { s, Schirmer } \leq 10 \mathrm{~mm}\end{array}$ \\
\hline & & & & $314.4 \pm 10.1$ & 6.0 & $\begin{array}{l}\text { Severe; OSDI } 33-100, \bar{M} G D \text { frequent, TBUT } \leq 5 \mathrm{~s} \text {, } \\
\text { Schirmer } \leq 5 \mathrm{~mm} \text {, moderate to marked corneal and } \\
\text { conjunctival staining }\end{array}$ \\
\hline $\begin{array}{l}\text { Jacobi et al., } 2011 \\
\qquad[127]^{\mathrm{a}}\end{array}$ & $\begin{array}{l}\text { Electrical } \\
\text { impedance }\end{array}$ & One eye & $301(298-304)$ & $320(301-324)$ & 5.9 & TFOS DEWS Grade 3 \\
\hline \multirow[t]{2}{*}{ 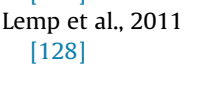 } & \multirow[t]{2}{*}{$\begin{array}{l}\text { Electrical } \\
\text { impedance }\end{array}$} & \multirow[t]{2}{*}{ Worst eye } & \multirow[t]{2}{*}{$300.8 \pm 7.8$} & $315 \pm 10.4$ & 4.5 & $\begin{array}{l}\text { Mild/Moderate; modified TFOS DEWS classification } \\
\text { system }\end{array}$ \\
\hline & & & & $336.7 \pm 22.2$ & 10.7 & Severe; modified TFOS DEWS classification system \\
\hline $\begin{array}{l}\text { Utine et al., } 2011 \\
\text { [164] }\end{array}$ & $\begin{array}{l}\text { Electrical } \\
\text { impedance }\end{array}$ & Both eyes & $294.9 \pm 8.3$ & $301.9 \pm 11.4$ & 2.3 & Primary Sjögren syndrome \\
\hline Li et al., 2012 [130] & $\begin{array}{l}\text { Electrical } \\
\text { impedance }\end{array}$ & Both eyes & $298 \pm 14.2$ & $304 \pm 10.8$ & $2.0^{\mathrm{b}}$ & $\begin{array}{l}\text { OSDI }>12 \text { and a TBUT of }<10 \text { s or Schirmer test score of } \\
<5 \mathrm{~mm}\end{array}$ \\
\hline $\begin{array}{l}\text { Sullivan et al., } 2012 \\
\text { [161] }\end{array}$ & $\begin{array}{l}\text { Electrical } \\
\text { impedance }\end{array}$ & Both eyes & - & $307.1 \pm 9.9$ & & $\begin{array}{l}\text { Mild/Moderate; modified TFOS DEWS classification } \\
\text { system }\end{array}$ \\
\hline \multirow[t]{2}{*}{$\begin{array}{l}\text { Szalai et al., } 2012 \\
\text { [129] }^{\text {a }}\end{array}$} & \multirow[t]{2}{*}{$\begin{array}{l}\text { Electrical } \\
\text { impedance }\end{array}$} & \multirow[t]{2}{*}{ Both eyes } & \multirow[t]{2}{*}{$303.5 \pm 12.9$} & $\begin{array}{l}324.3 \pm 19.8 \\
296.8 \pm 16.5\end{array}$ & $-2.3^{\mathrm{b}}$ & $\begin{array}{l}\text { Severe; modified TFOS DEWS classification system } \\
\text { Non-Sjögren syndrome; at least } 2 \text { of the following } 3 \\
\text { objective dry eye tests: Schirmer I value }<10 \mathrm{~mm} \text { per } \\
5 \text { min, TBUT }<10 \mathrm{~s} \text {, fluorescein corneal staining }>4 \\
\text { bright spots }\end{array}$ \\
\hline & & & & $303.4 \pm 17.2$ & $0^{\mathrm{b}}$ & Sjögren syndrome \\
\hline 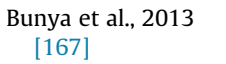 & $\begin{array}{l}\text { Electrical } \\
\text { impedance }\end{array}$ & Both eyes & & $314.5 \pm 18.0$ & & Severe Sjögren syndrome \\
\hline $\begin{array}{l}\text { Chen et al., } 2013 \\
\text { [131] }\end{array}$ & $\begin{array}{l}\text { Electrical } \\
\text { impedance }\end{array}$ & Both eyes & $301.6 \pm 14.2$ & - & & \\
\hline $\begin{array}{l}\text { Hassan et al., } 2013 \\
\quad[132]\end{array}$ & $\begin{array}{l}\text { Electrical } \\
\text { impedance }\end{array}$ & Both eyes & $303.62 \pm 12.29$ & - & & \\
\hline $\begin{array}{l}\text { Keech et al., } 2013 \\
\text { [133] }\end{array}$ & $\begin{array}{l}\text { Electrical } \\
\text { impedance }\end{array}$ & Both eyes & $304.0 \pm 8.4$ & $334.0 \pm 25.6$ & 9.0 & Symptomatic participants; OSDI $\geq 20$ \\
\hline $\begin{array}{l}\text { Amparo et al., } 2014 \\
{[168]^{\text {a }}}\end{array}$ & $\begin{array}{l}\text { Electrical } \\
\text { impedance }\end{array}$ & Worst eye & - & $312.8 \pm 20.3$ & & A previous diagnosis of dry-eye disease \\
\hline $\begin{array}{l}\text { Berchicci et al., } \\
\quad 2014 \text { [169] }\end{array}$ & $\begin{array}{l}\text { Electrical } \\
\text { impedance }\end{array}$ & Both eyes & - & $314 \pm 22.1$ & & Graft-Versus-Host Disease \\
\hline $\begin{array}{l}\text { Garcia et al., } 2014 \\
\quad[134]\end{array}$ & $\begin{array}{l}\text { Freezing point } \\
\text { depression }\end{array}$ & Both eyes & $270 \pm 4.4$ & - & & \\
\hline 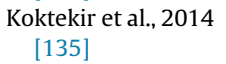 & $\begin{array}{l}\text { Electrical } \\
\text { impedance }\end{array}$ & Both eyes & $285.6 \pm 8.2$ & - & & \\
\hline $\begin{array}{l}\text { Bunya et al., } 2015 \\
\text { [137] }\end{array}$ & $\begin{array}{l}\text { Electrical } \\
\text { impedance }\end{array}$ & Both eyes & $312(299-326)$ & $\begin{array}{l}307(296-325) \\
314(306-321)\end{array}$ & $\begin{array}{l}-1.6^{\mathrm{b}} \\
0.6\end{array}$ & $\begin{array}{l}\text { Blepharitis } \\
\text { Sjögren syndrome }\end{array}$ \\
\hline Downie 2015 [92] & $\begin{array}{l}\text { Freezing point } \\
\text { depression }\end{array}$ & Both eyes & $296.2 \pm 9.9$ & $325.0 \pm 17.8$ & 8.9 & $\begin{array}{l}\text { OSDI score of } \geq 18 \text {, tear osmolarity } \geq 316 \\
\text { mOsm/L and at least one (of three) consecutive } \\
\text { fluorescein TBUT of }<10 \mathrm{~s} \text {, in at least one eye }\end{array}$ \\
\hline $\begin{array}{l}\text { Na et al., } 2015 \\
\text { [170] }\end{array}$ & $\begin{array}{l}\text { Electrical } \\
\text { impedance }\end{array}$ & Both eyes & 296 & 300 & 1.0 & Graft-Versus-Host Disease \\
\hline $\begin{array}{l}\text { Schargus et al., } \\
2015 \text { [171] }\end{array}$ & $\begin{array}{l}\text { Electrical } \\
\text { impedance }\end{array}$ & Worst eye & $300 \pm 16.5$ & $337 \pm 36$ & 11.0 & Ocular Graft-Versus-Host Disease \\
\hline $\begin{array}{l}\text { Tukenmez-Dikmen } \\
\text { et al., } 2015 \text { [163] } \\
\text { a }\end{array}$ & $\begin{array}{l}\text { Electrical } \\
\text { impedance }\end{array}$ & Both eyes & - & $\begin{array}{l}308.1 \pm 8.5 \\
318.9 \pm 12.8\end{array}$ & & $\begin{array}{l}\text { TFOS DEWS Grade } 1 \& 2 \\
\text { TFOS DEWS Grade } 3 \& 4\end{array}$ \\
\hline
\end{tabular}

${ }^{a}$ Do not provide information on the use of artificial tears prior to measurements. All other studies stipulated that no artificial tears were to be used, with washout periods ranging from no use at the visit to 1 month.

b Results were not statistically different between control and dry-eye groups. 
selection bias of subjects included, please refer to the TFOS DEWS II Diagnostic Methodology report [99]. Future studies are required to establish consistent cut-off values for dry eye, which are ideally derived from a study population where osmolarity was not a diagnostic criterion and where the sensitivity and specificity are tested in an independent cohort.

\subsection{Tear ferning}

Assessment of ferning patterns has been proposed as a simple and economical test of dry eye [172-178]. Normal individuals commonly display dense, uniform, closely branching ferns (Fig. 1) that change with altered tear functionality and chemical composition.

Collection of tears from the lower temporal tear meniscus with a capillary tube is most commonly used [124,126,178-190], with a low coefficient of variance [191]. It should be borne in mind that the composition of tears collected from the meniscus may not be reflective of that over the entire ocular surface, and thus the ferning pattern obtained may differ with differing collection sites. A tear sample of $1-4 \mu \mathrm{L}$ is expelled onto a clean glass slide, allowed to dry at stable room temperature $\left(20-26^{\circ} \mathrm{C}\right)$ and humidity $(\leq 50 \%)$, observed using white light microscopy and photographed within 10-15 min. Factors shown to influence the ferning pattern are tear volume [173], room temperature and humidity during drying [190], covering the tear sample during drying [174], time between collection and assessment [174], and oil on glass slides [191].

Many authors [124,126,177,179,181-183,186,188,190,192-198] grade tear fern patterns using the 1 (complete, uninterrupted ferning pattern with no spaces between ferns) to 4 (complete absence of ferning) scale of Rolando (Fig. 1) [172]. The scale displays good intra- and inter-observer agreements, particularly when collapsing grades for normal (grade 1 or 2 ) and abnormal ( 3 and 4 ) patterns $[185,199]$. However, representation of only a portion of the entire ferning pattern [185], and usage of full grades [199] may have increased the repeatability of the scale.

Tear ferning patterns are independent of sex [175,181], hormonal fluctuations in women with a regular menstrual cycle [182,197], races on the Asian continent [181] and time of day during waking [180]. Degradation of tear fern patterns, indicating abnormal tear functionality, occur upon eye opening after wakening [179], with contact lens wear [186] and with increasing age, independent of dry eye status [124,181,198,200]. The effect of reflex tearing on ferning patterns remains equivocal, with Norn [191] demonstrating no effect on ferning patterns when reflex tearing was provoked by inhalation of ammonium chloride, but an improvement in ferning patterns after exposure to draught, which was hypothesized to result from reflex tearing [201].

Ferning in dry eye tears is less regular, with increasing space between ferns and shortening of ferns, culminating in an absence of ferning. Over $90 \%$ of keratoconjunctivitis sicca patients fell into ferning classes 3 and 4 [172,202] Sjögren syndrome patients exhibited $87.8 \%$ and $83.3 \%$ respectively with grades of $3-5$ [176]. However, another study with Sjögren syndrome patients found only $59 \%$ and $48 \%$ showed class 3 and 4 ferning patterns [177]. 50\% of post-menopausal women with dry eye symptoms fell into class 2 [124]. Using average grades, mean and median values range between 2.0 and 2.9 for participants with dry eye [126,176,182,195]. Using the 5-point Masmali scale, the authors reported a median value of 2.3 , with $72.5 \%$ of samples graded between 2.0 and 3.0 [178]. Classifying ferning into normal and abnormal patterns or comparison of mean values between dry eye and non-dry eye participants can be analytically effective with this scale. Overall good sensitivity (80-90\%) and specificity (75-89\%) has been demonstrated for Sjögren syndrome [186], but more studies are needed to establish sensitivity and specificity and cut-off values in other forms of dry eye before this relatively simple approach is translated into private practice.

\section{6. $\mathrm{pH}$}

Mean tear $\mathrm{pH}$ values range between 6.8 and 8.2, with individual values ranging between 5.2 and 8.6 [203-216]. Yamada et al. [215] compared the $\mathrm{pH}$ values of collected tears to those measured on the
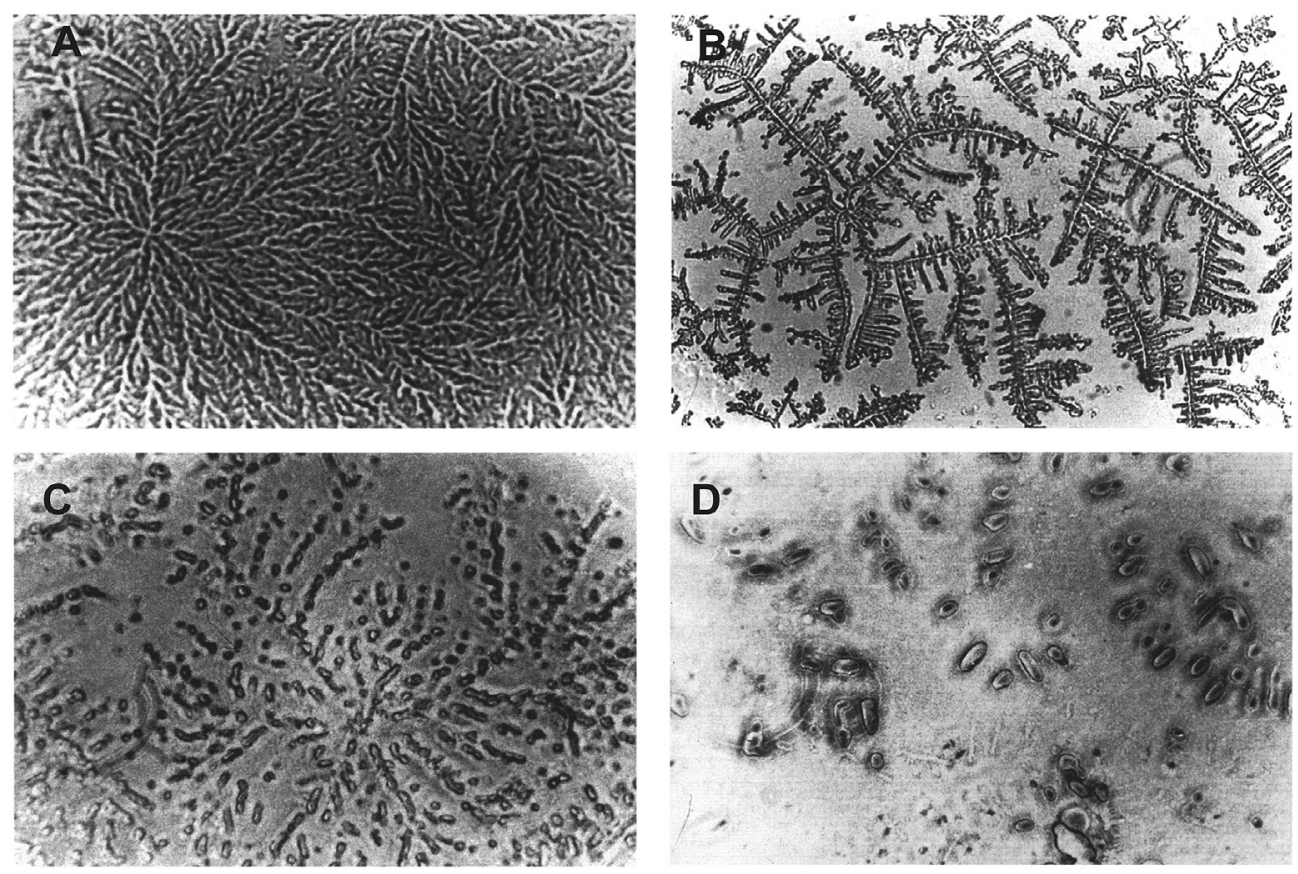

Fig. 1. Examples of tear ferning patterns for Rolando's grade 1 (A), 2 (B), 3 (C), 4 (D). From Maragou et al., 1996. Clin Rheumatol. 15: 125-32 [177]. 
eye and found an alkaline shift of $0.1 \mathrm{pH}$ units in collected tears, which was thought to be caused by interaction of the tear fluid with air. As with all physical measures of the tear film, the collection site may influence the result obtained. Tears collected for $\mathrm{pH}$ assessment are typically those from the lower meniscus and may not be reflective of the $\mathrm{pH}$ over the ocular surface.

There seems to be no effect of sex [205,212], but age [210,212], time of day [204,210], eye closure [204,210], prolonged eye opening [208,210,213], blinking [208] and reflex tearing [208] have been shown to affect $\mathrm{pH}$ values. An alkaline shift of approximately $0.2 \mathrm{pH}$ units can be observed between 10 and 50 year olds or between groups of under and over 40 year olds [210,212]. Slight acidification of the tear film by approximately $0.2 \mathrm{pH}$ units can be observed after eye closure overnight or for $1 \mathrm{~h}$ [204,210]. Blinking causes a slight acidic shift, but overall the tear film shifts from acidic to alkaline throughout the day, with a difference of usually no more than 0.6 pH units $[204,208,210]$. An alkaline shift of $2.5 \pm 0.6 \mathrm{pH}$ units/min has also been observed with prolonged eye opening, with a maximum value of 9.3, however, the tear film reaches equilibrium after 30-60 s [208]. It is important to remember that $\mathrm{pH}$ is measured on a logarithmic scale such that for every one unit change in $\mathrm{pH}$ there is a 10 -fold change in the concentration of hydrogen ions.

Investigations in dry eye using $\mathrm{pH}$ indicator paper showed no significant difference in $\mathrm{pH}$ mean values between a dry eye and control group ( $7.46 \pm 0.24$ and $7.45 \pm 0.23$ respectively), although $12 \%$ of participants with dry eye displayed a pH value over 7.7 , compared with only $4 \%$ in the control group [214]. Norn [205], using a micro-electrode inserted into the inferior conjunctival fornix, found tears in participants with keratoconjunctivitis sicca to be significantly more alkaline compared to non-dry eye participants when both eyes were measured $(0.2 \mathrm{pH}$ unit shift), but not when only one was assessed $(0.05 \mathrm{pH}$ unit shift). Reporting a systemic error, with the second eye measured showing an alkaline trend, the authors judged their observation in dry eye to be unreliable [205]. Using a similar method, Khurana et al. reported a small alkaline shift of $0.1 \mathrm{pH}$ units in participants with dry eye compared to non-dry eye ones [214]. Various methods have been used to measure tear film $\mathrm{pH}$, each having their own limitations. To date, there is limited evidence for a change in $\mathrm{pH}$ values with DED.

\subsection{Tear evaporation}

Inter-blink tear evaporation may contribute to dry eye. Tear evaporation rate has been considered an indicator of tear lipid layer stability [217-220], with higher tear evaporation rates associated with increased tear thinning, ocular dryness and discomfort [220-222]. An early study on humans measured the evaporation rate using an instrument adapted from dermatology [223], but this technique involved touching the corneal surface, which is a stimulus for reflex tearing and likely resulted in an overestimation of evaporation rates. Non-invasive analysis in an environment with relative humidity between 30 and $40 \%$ revealed a tear film evaporation rate of $0.4-50 \times 10^{-7} \mathrm{~g} / \mathrm{cm}^{2} / \mathrm{sec}$ (Table 3) [25-27,67,123,224-242]. This very large range of evaporation rates may derive from use of different assays. Measurements undertaken with ventilated chambers may better mimic natural air flow on the ocular surface than closed preocular chambers [243], although fast measurement $(<10 \mathrm{~s}$ ) closed chamber devices may be appropriate. Currently there is no commercially available instrument dedicated to detection of tear film evaporation. Thus, researchers have either used in-house designed systems or modifications of closed chamber dermatological units $[25,158,239]$.

The effect of age and sex on tear evaporation rates is equivocal. Some studies have shown that older age groups ( $>45$ years) have
1.5 times higher evaporation rates than younger adults and women have evaporation rates approximately 1.4 times higher than men [244-246], but other studies have failed to show any impact of age or sex [240,247]. Subjects who blink more than normal (likely being a consequence of evaporation) or have a larger exposed ocular surface have increased tear evaporation rates [246,248]. Low humidity increases evaporation [249-251], with tear evaporation rates of healthy individuals increasing by $>40 \%$ with a $10 \%$ reduction in relative humidity [249]. Increased tear evaporation rates in low humidity (5\%) environments has been associated with reduced lipid layer thickness and tear film stability [251]. Meta analyses point to a $2-3$ fold increase in tear evaporation rate as a diagnostic cut-off for DED, with a sensitivity of $45.5-61.2 \%$ and a specificity of 79.8-90.6\% [252].

\section{Biophysical studies of tears}

\subsection{Tear film evaporation and the lipid layer}

Goggle-based chambers detect very low but dispersed tear evaporation rates of $0.14 \pm 0.07 \mu \mathrm{L} / \mathrm{min}$ in the healthy eye, but $0.26 \pm 0.16 \mu \mathrm{L} / \mathrm{min}$ for patients with meibomian gland dysfunction (MGD) [252]. Tear film thinning kinetics measured by interferometry suggests a higher tear evaporation rate of $1.137 \mu \mathrm{L} / \mathrm{min}$ in the healthy eye, which is a value similar to that of water [25,252]. The thickness of the lipid layer may not affect the evaporation rate unless it is very thin (less than $24 \mathrm{~nm}$ ) or completely absent [24-27,67]. Nonetheless, increased expression of meibum in normal eyes correlates with reduced evaporation in both healthy individuals and patients with DED $[233,253]$. An abnormal tear film lipid layer is associated with increased evaporation [24-27,67]. Evaporation rates differ substantially between different studies, likely due to challenges in controlling environmental factors such as air flow and humidity [254]. Whether only evaporation from the ocular surface is being measured is also not always clear.

Such in vivo variability makes in vitro studies attractive [255]. Meibum films with physiological thickness do not retard evaporation in in vitro studies [255]. Evaporation found in studies using meibum films is in the range of $6-8 \%[225,256,257]$, or less in studies using artificial tear film lipid layers of up to $100 \mathrm{~nm}$ thick $[253,254,257,258]$. Only non-physiologically thick, $4 \mu \mathrm{m}$ or $\geq 17 \mu \mathrm{m}$, meibum films can reduce the evaporation of water in laboratory experiments, but then by only 7 or $23 \%$ respectively $[225,254]$. Straight chain alcohols and acids and pure wax esters used alone can retard evaporation [259-261]. Monolayers of tear film-like wax esters can retard evaporation when used at temperatures $3{ }^{\circ} \mathrm{C}$ lower than their bulk melting temperature $[258,260,261]$. However, meibum has a much more complex composition, structure and thermotropic behavior compared to the model films, and the melting temperature of meibum $\left(\sim 30^{\circ} \mathrm{C}\right)$ [262-264] is lower than the ocular surface temperature $\left(35^{\circ} \mathrm{C}\right)$. Recently in vitro studies with the Interfacial Dewetting and Drainage Optical Platform (i-DDrOP) on silicone hydrogel (SiHy) contact lenses have shown that the mucoaqueous subphase beneath thinner parts of meibomian films thins and dewets faster compared to that seen below thicker "islands" in the meibomian layer [265]. Therefore, it might be possible that meibum may locally be an effective barrier to evaporation. Suppression of tear evaporation by the lipid layer is thus poorly understood.

Three evaporation suppression hypotheses have been proposed: (1) the effect is based on a certain organization of the lipid layer, as proposed previously [266]; (2) the lipid layer is not solely the structure that is responsible for the retardation of evaporation, but specific protein or mucin (or a combination) interactions are also needed [267]. However, whole tears collected by capillary tube, 
Table 3

Evaporation of tears from normal eyes.

\begin{tabular}{|c|c|c|c|}
\hline Technique used & $\begin{array}{l}\text { Evaporation rate }(\text { mean } \pm \mathrm{SD}) \\
\left(\times 10^{-7} \mathrm{~g} / \mathrm{cm}^{2} / \mathrm{sec}\right)\end{array}$ & $\begin{array}{l}\text { Relative } \\
\text { humidity (\%) }\end{array}$ & Reference \\
\hline Open chamber with no temperature and humidity control & $26.9( \pm N R)$ & NR & Hamano et al., 1981 [226] \\
\hline Closed ventilated chamber using resistance hygrometry & $50 \pm 16.6$ & $50 \%$ & $\begin{array}{l}\text { Cedarstaff \& Tomlinson } \\
1983[227]\end{array}$ \\
\hline Temperature and humidity sensors interconnected with constant humidity & $4.1 \pm 0.4$ & $30 \%$ & $\begin{array}{l}\text { Rolando \& Refojo } 1983 \\
\text { [228] }\end{array}$ \\
\hline $\begin{array}{l}\text { Closed chamber modified dermatologic evaporimeter with two sensors placed at a } \\
\text { known distance from ocular surface }\end{array}$ & $12.5 \pm 1.8$ & NR & $\begin{array}{l}\text { Trees \& Tomlinson } 1990 \\
\text { [229] }\end{array}$ \\
\hline Closed chamber, temperature and humidity sensor & $15.6 \pm 3.8$ & $40 \%$ & $\begin{array}{l}\text { Tsubota \& Yamada } 1992 \\
\text { [230] }\end{array}$ \\
\hline Closed chamber humidity sensor & $14.7 \pm 6.7$ & $30 \%$ & Mathers 1993 [217] \\
\hline Closed chamber humidity sensor & $0.4( \pm \mathrm{NR})$ & $50 \%$ & $\begin{array}{l}\text { Craig \& Tomlinson } 1997 \\
\text { [67] }\end{array}$ \\
\hline Ventilated chamber with constant airflow of known water content & $4.1 \pm 1.4$ & NR & Goto et al. 2003 [232] \\
\hline Closed chamber humidity sensor & $10.8 \pm 5.3$ & NR & Thai et al. 2004 [236] \\
\hline Closed chamber humidity sensor & $15.1 \pm 7.3$ & $30 \%$ & $\begin{array}{l}\text { Guillon \& Maissa } 2008 \\
\text { [237] }\end{array}$ \\
\hline Closed chamber humidity sensor & $5.8 \pm 2.8$ & NR & Khanal et al., 2009 [123] \\
\hline Quartz crystal humidity sensor & $5.0 \pm 2.8$ & $18 \%$ & Kojima et al., 2011 [234] \\
\hline Closed chamber humidity sensor & $0.04 \pm 0.01\left(\mu \mathrm{l} / \mathrm{min} / \mathrm{cm}^{2}\right)$ & $30 \%$ & $\begin{array}{l}\text { Arciniega et al., } 2011 \\
\text { [233] }\end{array}$ \\
\hline Infrared thermography in a controlled adverse environmental chamber & $26 \pm 11.1$ & $45 \%$ & Petznick et al., 2013 [235] \\
\hline Ventilated chamber with constant airflow of known water content & $7.7 \pm 6.0$ & $\begin{array}{l}30-50 \% \text { (in } \\
\text { room) }\end{array}$ & $\begin{array}{l}\text { Hirayama et al., } 2013 \\
{[238]}\end{array}$ \\
\hline Closed chamber humidity sensor & 55.6 (95\% CI: 40.8-75.8) (g/m²/h) & $56 \%$ & Rohit et al., 2014 [239] \\
\hline Flow Evaporimeter & $26( \pm N R)$ & $40 \%$ & Peng et al., 2014 [25] \\
\hline Ocular thermography & $66.1 \pm 21.1(\mathrm{~W} / \mathrm{min})$ & NR & Yeo et al., 2016 [240] \\
\hline Closed chamber humidity sensor & $79 \pm 33\left(\mathrm{~g} / \mathrm{m}^{2} / \mathrm{h}\right)$ & $45 \%$ & $\begin{array}{l}\text { Alghamdi et al., } 2016 \\
\text { [241] }\end{array}$ \\
\hline
\end{tabular}

$\mathrm{NR}=$ Not Reported

apparently with all tear lipid and protein species and at least some mucins [17,19,21,268-272], evaporate in vitro with water-like rates; (3) water evaporation from the ocular surface is not at all controlled by lipids and the lipid layer has other functions [257]. A thick duplex film enriched with unsaturated and branched chain lipids, as found in meibum, is a much less effective barrier to evaporation than tightly packed lipid monolayers [273].

If tears do evaporate at the same rate as water, eventually the concentration of secretory mucins and proteins in the lipid layer would increase, and approximate mucin near the surface of the cornea [274]. A dense polymer network of mucin has a high hydration "water holding" property and might suppress further tear evaporation [275]. It is also possible that mucins, together with proteins and polar lipids from tears, enhance spreading and structure of the tear film lipid layer. Thus all tear film key constituents may contribute to increased evaporative resistance.

\subsection{Clinical observation and harvesting of tear film lipids}

The tear film lipid layer is derived predominantly from meibum from the meibomian glands and spreads upward over the mucoaqueous layer [8] with blinking. Thinning of the lipid layer superiorly may create a rise in surface tension as a driving force for spreading [8]. Spreading may initially involve interaction between polar lipids and the mucoaqueous layer [276]. Polar lipids then carry nonpolar lipids [277]. In the normal eye, spreading of the lipid layer can be observed clinically by interference video microscopy as an upwardly moving front of horizontally disposed, colored fringes (Fig. 2). Fringes reflect topographic variations in thickness of the lipid layer and are thereby reflective of its intermolecular organization. The lipid layer is compressed during the down stroke of the blink and restored in the upstroke, with only a moderate disturbance of its organization between consecutive blinks [4,26].
Spreading is rapid at first (about $10 \mathrm{~mm} \mathrm{~s}^{-1}$ ), although lagging behind the upper lid [278]. Spreading slows and stabilizes after one second or more, with the interference pattern showing remarkable stability over the remainder of the blink [34,278]. Spreading is slower and less laterally arranged in dry eye patients [34,278], with reduced stability of the lipid layer fringes [279], suggesting that intermolecular stability is lost.

The dynamic nature of the lipid layer allows it to respond to the shear stress induced by the changing area of the air-tear interface during blinking. The lipid layer must be compressible during the down-sweep [280,281], but must spread rapidly after the upsweep of the lid [26]. Polar lipids decrease the surface tension of the air-tear interface and increase the spreading rate of the lipid layer. Non-polar lipids increase the compressibility and stability of the lipid layer [281]. Imbalances in composition show as impaired viscoelastic properties.

Human meibum comprises $\sim 90 \%$ of the tear film lipid layer, and is often investigated as the archetype for the tear film lipid layer. Commercially available clinical devices (such as Yoshitomi's meibomian gland pressure forceps, or Arita's meibum collector) $[120,282]$ ensure collection of $\leq 0.5 \mathrm{mg}$ meibum per donor, thus allowing for multiple repetitions of experiments. The different meibum collection procedures (by glass microcapillary tube, Dacron swab, cytology micro brush, or spatula) and inherent intra- and inter-individual variability may contribute to variations in the amount and composition of the meibum samples [283-285].

The most representative tear film lipid layer mimic might be the lipid extract of whole human tears. However, to-date only one study has used it for in vitro analysis of surface tension [286], which is not surprising considering the difficulties in collecting a sufficient sample for reproducible experiments. Lipids extracted from deposits adsorbed on worn contact lenses have been used [287], 
although they contain higher amounts of phospholipids than meibum. Schirmer strips can be used to collect lipids [288]. The tear film contains $\sim 8 \%$ of amphiphilic (polar) lipids [289-291] that may be released from the lipid-binding protein lipocalin [292] from the mucoaqueous layer upon organic solvent extraction. These phospholipids are at very low levels in meibum [21,272], but as surfactants, if they are not bound to lipocalin, may have a significant role at the tear interface $[255,285,293]$.

\subsection{Surface tension of tears}

The tear film lipid layer lowers the tear surface tension, thus sustaining the tear film's high area-to-volume aspect ratio. Tear surface tension of healthy individuals is $43.6 \pm 2.7 \mathrm{mN} / \mathrm{m}$ [294], rising to $53.0-55.5 \mathrm{mN} / \mathrm{m}$ after delipidation, which is remarkably close to the upper boundary of values observed in samples collected from patients with dry eye, of $49.6 \pm 2.2 \mathrm{mN} / \mathrm{m}$ [286].

Supplementing delipidated tears with meibum lipids does not restore the surface tension [286,295]. Normal surface tension may thus rely on lipids and perhaps some proteins and glycoproteins from the mucoaqueous layer, such as lipocalin, lysozyme, and mucin, that are thought to intercalate with the lipid layer $[272,276,296]$. Increased surface tension in dry eye implicates abnormally enhanced protein content at the air/tear interface as a consequence of a compromised lipid layer. Proteins appear to take hours to penetrate a normal meibum lipid layer [297-300].

Data on the thermotropic phase transitions (via spectroscopy, differential scanning calorimetry and X-ray diffraction studies) [262,264,301-303] and interfacial and bulk rheology [29,301,302] of tear lipids in vitro and in vivo, suggest a thick viscoelastic duplex structure composed of a monomolecular layer of amphiphilic polar lipids at the mucoaqueous surface and a generally unstructured shear thinning lipophilic suspension at the lipid-air interface. The lipophilic suspension consists of lipid lamellarcrystallite particulates immersed in a continuous liquid phase with no long-range order. An alternative hypothesis rebrands the old folded trilayer model of McCulley and Shine and views the tear film lipid layer as a lamellar sandwich [304]. Lamellar models demand an ordered, almost rigid solid [302], which conflicts with the need for rapid reorganization during blinking.

Due to the abundance $(\geq 90 \%)$ of non-polar lipids, both meibum and contact lens extracts do not spread as monolayers at the air/ water surface, but instead form thick (10 nm to $>100 \mathrm{~nm}$ ) duplex films. They are thick enough to display bulk properties with two separate interfaces, but thin enough to neglect the effects of gravity) $[257,285,288,301,302,305]$. Uniform spreading of meibum is enhanced by polymers that contain polyanionic polysaccharide moieties, such as hyaluronic acid and secretory mucin glycoproteins [296,305], that form polymer interfacial gel-like networks due to hydrogen bonding of the polymer moieties with each other and with the phospholipid head groups. As a consequence, film viscosity is enhanced, and a more uniform 2-dimensional (2D) distribution of lipids and water is achieved [257,296,305].

Films of meibum and contact lens lipid extracts are noncollapsible, which helps them to withstand the dramatic area changes during the blink. In some studies, meibum layers show almost full surface pressure $(\pi)$ /area reversibility (i.e. very low $\pi$ /area hysteresis), which point to meibum's capacity to rapidly reorganize during area cycling (as a model for the interblink period) [29,296,305-307]. Interestingly, meibum films expand and thin at lower temperatures $\left(23-25^{\circ} \mathrm{C}\right)$, but shrink and thicken at physiological $\left(\approx 35^{\circ} \mathrm{C}\right)$ temperatures $[29,263,301,305,308]$. Such behavior agrees with the liquid suspension model of the non-polar lipids of the lipid layer. The non-polar lipid oily cap might act as a lipophilic solvent $[29,301,309-311]$ to accommodate polar lipids, which may form inverse micelles within it, during temperature-induced interface/bulk redistribution of the polar layer and during film compression. In other words, it may prevent expulsion of polar lipids into the aqueous phase such that polar lipids can promptly return to the mucoaqueous interface at film expansion.

Meibum interfacial properties and structure are largely insensitive to changes in osmolarity [312,313]. However, both meibum and contact lens lipid extracts are sensitive to the presence of (glyco)proteins (lactoferrin, lysozyme, mucin, lipocalin, serum albumins, lactoglobulin, lactoferrin, secretory IgA, keratin, lung surfactant proteins) [297-300,307,314] and pharmaceutical agents (hyaluronic acid, benzalkonium chloride, SofZia, Polyquad, whole eye drops and lens care solutions) [305,315-317] in the film
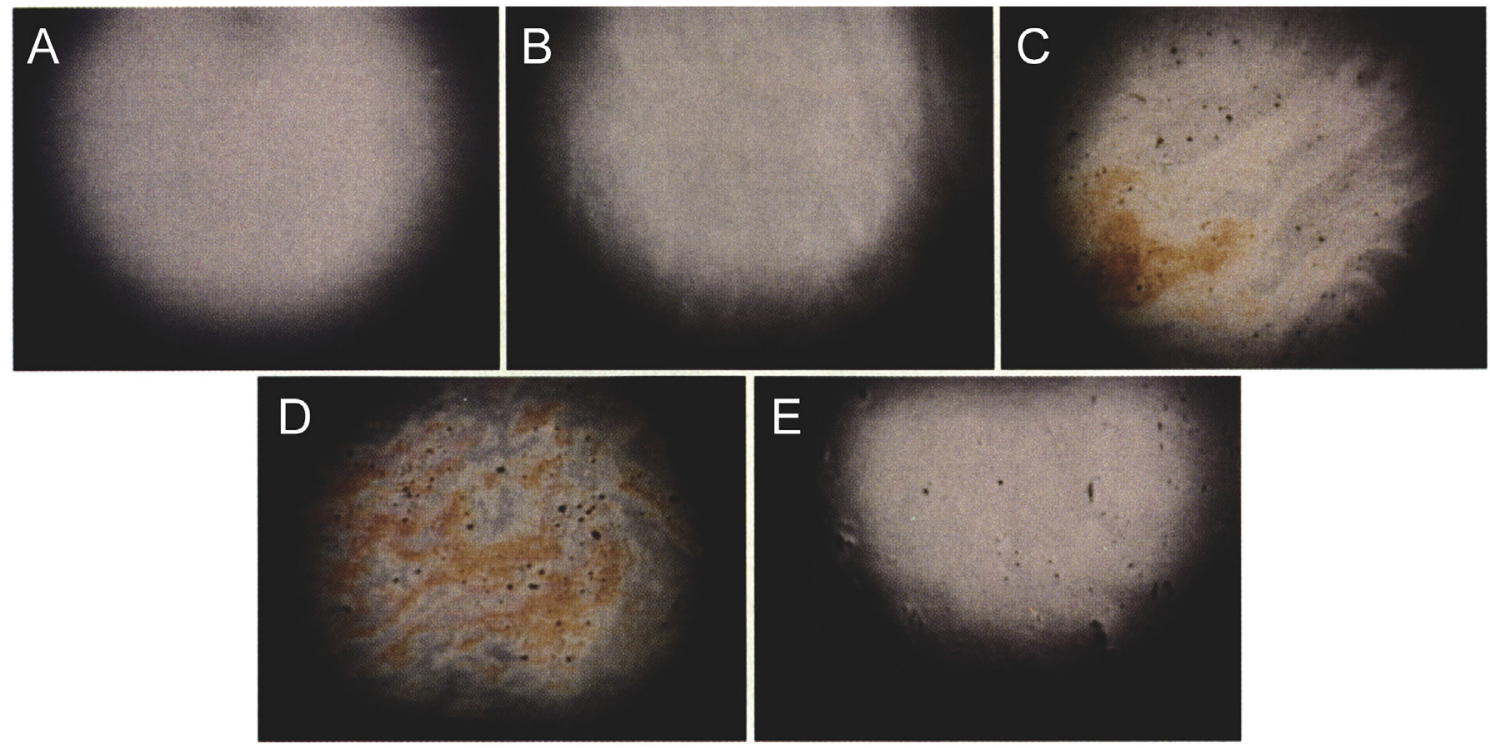

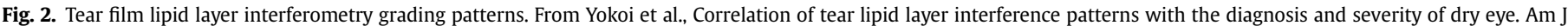

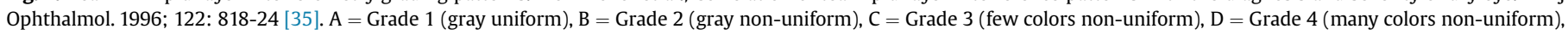
$\mathrm{E}=$ Grade 5 (partly exposed corneal surface). 
subphase. However, even in sub-physiologically "diluted" $(5-10 \mathrm{mN} / \mathrm{m}$ vs. $\sim 30 \mathrm{mN} / \mathrm{m})$ meibum films, the kinetics of the penetration of such substances is much slower $(>1 \mathrm{~h})$ than the physiological time scale [297-300].

An alternative mechanism has been proposed, whereby the proteins or pharmaceuticals dissolved in the mucoaqueous subphase do not have to insert into the meibum or contact lens lipid extracts films. Instead, they need only to interact with polar lipid head groups aligned at the mucoaqueous interface. This is a rapid interaction that immediately alters the structure and dynamic interfacial properties of the layers [287,305,311]. These data, along with studies evaluating the impact of lipid (or lipophilic) inclusions directly into meibum layers, demonstrate that non-surface active or lipophilic substances are well tolerated by tear lipid films [318-322], while polar surface active ingredients can disrupt the film's structural integrity and surface properties [314-317]. Interactions between the tear film lipid layer and pharmaceutical agents are of particular pharmacokinetic importance as they may impart long term effects at the ocular surface, in light of the much slower in vivo turnover rate of the tear film lipid layer compared to the mucoaqueous layer $(0.93 \pm 0.36 \% / \mathrm{min}$ vs. $10.3 \pm 3.7 \% / \mathrm{min}$ respectively) [323].

Shear rheology experiments have demonstrated the viscoelastic nature of meibum films, which were able to stabilize tear filmmimicking films and to reduce the critical film thickness for dewetting [28]. The protective effect of meibum layers was stronger than that of Newtonian arachidonic acid and primarily viscous dipalmitoylphosphatidylcholine films, in line with the classic paradigm that viscoelastic surfactants are particularly effective at stabilizing thin films [324].

Meibum and contact lens lipid extract films also display viscoelastic behavior in dilatational rheology studies [29-31], with predominantly elastic properties, thereby enabling resistance to deformation during tear film breakup. Whereas films of meibum collected from healthy donors are continuous, thick and predominantly elastic, films from patients with meibomian gland dysfunction are discontinuous, patchy and show viscoelasticity compromised at time scales (ie at low frequencies) encompassing the durations of blink and interblink intervals found in vivo [29]. The in vitro data correlate well with the impaired spreading and heterogeneous structure of the tear film lipid layer of patients with MGD seen in vivo [29]. Similar characteristic differences in the viscoelastic properties are reported between films of contact lens lipid extracts from Caucasians versus dry eye-susceptible Asians $[30,325]$. More attention should be paid to the capacity of the lipid layer to elastically stabilize the air/tear interface.

\subsection{Tear film lipid layer bulk properties}

Differential scanning calorimetry reveals that the phase transitions in meibum start at $10-15{ }^{\circ} \mathrm{C}$ and end at $35-36{ }^{\circ} \mathrm{C}$, with a melting temperature $(\mathrm{Tm})$ of $\sim 30{ }^{\circ} \mathrm{C}[264,302]$. Thus, it is reasonable to assume that in the meibomian gland orifices meibum is both disorganized and liquid to facilitate excretion. When exposed to the cooler $\left(33-35{ }^{\circ} \mathrm{C}\right)$ ocular surface, meibum solidifies to a partially melted liquid crystalline state, thereby enhancing lipid layer inplane elasticity, and via denser 2D molecular packing, ensuring a barrier to water evaporation.

Combining differential scanning calorimetry with small- and wide-angle X-ray diffraction points to meibum as a liquid suspension consisting of lipid lamellar-crystallite particulates immersed in a continuous liquid phase, with no long-range order at physiological temperature [262,264,301-303]. Hot stage cross-polarized light microscopy confirms such a view and reveals that in meibum from patients with MGD there is an increased presence of non-lipid, non-melting, chloroform-insoluble inclusions of protein, including cytokeratin [262]. Spectroscopy studies also confirmed that MGD meibum contains more protein and relatively less methyl groups $\left(\mathrm{CH}_{3}\right)$ and cis double bonds $(\mathrm{cis}=\mathrm{CH})$ compared to normal meibum [303]. The increased content of non-melting proteinaceous particles that are poorly miscible with lipid can account for the impaired spreading and discontinuous structure of meibum films in vitro and for their worsened viscoelasticity and evaporation suppression capability in vitro and in vivo [29-31].

Bulk shear rheology evaluation suggests that meibum is a shear thinning liquid of extremely high viscosity [302]. At $35^{\circ} \mathrm{C}$, the shear viscosity of bovine and human meibum is approximately $10^{5}$ greater than that of water and 3-4 orders of magnitude more viscous than mineral oil. However, such high bulk viscosity is inconsistent with the high mobility of fluorescent probes reported in meibum layers [296] and with the rapid reorganization of meibum films during area cycling [29,296,305-307]. More research needs to be performed to resolve this issue.

Research on the bulk rheology of non-stimulated (or mildly stimulated) tears is relatively old, but in light of the new findings on the tear lipidome, there is a need for reappraisal. Human reflex tears collected after cold air stimulation are non-Newtonian and shear thinning [326]. Their viscosity at rest is $\sim 9 \mathrm{cP}$ and when shear is applied it rapidly drops to $1 \mathrm{cP}$ (at shear rates $\geq 100 \mathrm{~s}^{-1}$ ) $[327,328]$. This indicates that the tear constituents, and particularly the compounds dissolved in the mucoaqueous layer, when at rest form a "transient" intermolecular network via weak non-covalent interactions (hydrogen-bonding, hydrophobic and/or electrostatic interactions etc.). Thus, they increase the mucoaqueous layer viscosity in the open eye, which raises its resistance to thinning and enhances tear film stability. At blink, the high shear applied by the eyelid breaks these weak interactions, the intermolecular network disintegrates and the aqueous can flow like water, thus preventing any damage that high viscosity may cause to the underlying corneal epithelium. The exact nature of the compounds involved in the transient intermolecular network remains unclear. Pure monocomponent solutions of mucin or tear proteins in physiological concentrations are low viscosity and/or Newtonian fluids. Also, if the lipocalin-bound lipids are extracted, then tears become a low viscosity Newtonian fluid. This suggests that lipid/protein interactions, lipocalin and possibly lysozyme and lactoferrin play important roles in the shear thinning property of tears.

An interesting study found that when whole human tears are subjected to shear (at rates of $2-160 \mathrm{sec}^{-1}$ ), dry eye tears need $>10$ times longer relaxation times compared to normal tears $(2.8 \pm 0.14 \mathrm{~s}$ vs. $0.26 \pm 0.12 \mathrm{~s})$ in order to equilibrate after the shear is ceased [328]. This suggests that a longer period should be needed for dry eye tear film, compared to a healthy one, to stabilize at the ocular surface after a blink. This demonstrates the potential importance of elasticity for tear film stability.

\section{Biochemical properties of tears}

\subsection{The tear lipidome}

In the normal eye, clear oil can be expressed from the meibomian orifices, which are located anteriorly to the mucocutaneous junction of the lid rim [329], by pressing on the glands through the lids. Expressibility is greatest nasally and least temporally [330]. An average amount of meibum stored in the meibomian glands is in the range of several hundred micrograms per eyelid [26]. The lid reservoir contains at least 30 times the amount of lipid present on the surface of the tear film (approximately $300 \mu \mathrm{g}$ vs. $10 \mu \mathrm{g}$, respectively) [331,332]. Comparison of the lipids from meibum and whole tears $[21,255,333]$ showed that the classes and ratios of lipids 
in whole tear samples were very similar to the classes and ratios of lipids and ratios in meibum. The only exception was phospholipids, the majority of which may be from another source.

Tears from the meniscus and meibum have been extensively studied to determine if changes in one or more components can be correlated with dry eye. Overcoming the technical difficulties involved with collection and processing small volumes without contamination has formed a major part of this journey, and therefore these studies have included developing techniques for collecting, identifying and quantifying both specific families of lipids and individual lipids. Techniques for analyzing meibum and tear lipid components have been extensively reviewed in previous publications [159,276,284,309,334]. Techniques employed to measure lipid composition each have limitations. Mass spectrometry (MS) is excellent for identifying lipid species, but until recently, has been weak in quantification. Nuclear magnetic resonance (NMR) is quantitative, however, single signals may derive from many different species of lipids. Only by a process of elimination can individual lipids be attributed to particular spectra.

Meibum is composed of approximately 95\% non-polar lipids and 5\% amphipathic lipids. Collection methods can alter the composition of the amphipathic lipids [282]. In humans, the non-polar component is composed of $30-50 \mathrm{~mol} \%$ (ie the fraction of the wax esters compared to the total amount of lipid expressed as moles) of wax esters [284,309,334], 30-45 $\mathrm{mol} \%$ of cholesterol esters $[21,335,336]$ and a small percentage of triglycerides $(\sim 2 \%)$ [309]. The wax esters generally have an oleic acid component (C18:1) and the alcohol components vary from C18-C30. A feature of the cholesteryl esters is that they have very long acyl chains, predominantly C22:1-C34:1 [21,272]. In both cases, the acid groups can have odd numbers of carbons (such as C25) and this is unusual because fatty acids are normally synthesized using acetic acid (2C) as the building block. Other lipids found in meibum include free cholesterol, which makes up $<0.5 \mathrm{~mol} \%$ and phospholipids, which make up $<0.01 \mathrm{~mol} \%$ of meibum [21]. The predominant amphipathic lipid family found in meibum is the (O-acyl)- $\omega$-hydroxy fatty acids (OAHFAs), which comprise about $4 \mathrm{~mol} \%$ of total meibum $[21,336,337]$. The amount of OAHFAs and the low level of phospholipids imply that OAHFAs are the major surfactants in the tear film lipid layer, and although this has not been shown, it gathers support from in vitro experiments where OAHFAs have been shown to readily spread over large surface areas of an mucoaqueous subphase [320].

The range of mol\% of total lipids for each major lipid class means that to correlate one of these main classes of non-polar lipids with dry eye requires a very large change relative to normal. In this regard, it should be noted that an earlier finding that normal, but not dry eye subjects, did not have cholesteryl esters [338] has not been confirmed in more recent studies [333,336].

Particular genetic profiles that correlate with particular ratios of lipids in tears or meibum have not been studied, but if there were such correlations, ethnicity does not appear to be a factor, because a population study of Asians found similar lipid ratios [336] to those found in other studies [21,272]. The ratios of lipids in meibum do not vary with age [339], but there are changes in certain polar lipids (not identified) in meibum with sex and age [340]. Whether or not the ratio changes for an individual as they develop dry eye has not been studied, although there is a relatively large variation in mol\% lipid types among individuals [341]. Recently, using NMR spectroscopy, squalene was detected in meibum [318,342]. Squalene is of interest because it illustrates an example of a lipid that might play a protective role rather than a role in the formation of the tear film lipid layer. Squalene is anti-inflammatory and antibacterial and could have antioxidant properties by scavenging free radicals produced by UV rays [343].
A recent development in the field has been to compare meibum and the lipids of whole tears from the meniscus [21,341]. This centers on the concept that the lipid layer of the tear film might contain not only lipids derived from meibomian glands, but also lipids that have migrated from the mucoaqueous layer. To put this in perspective, the upper limits of total lipid concentration reported in whole tears collected from the meniscus are $380-580 \mathrm{pmol} / \mu \mathrm{L}$ $(\sim 0.5 \mathrm{mmol} / \mathrm{L})$ [291,344], of which non-polar lipids comprise $\sim 85 \mathrm{~mol} \%$, OAHFAs $\sim 4 \mathrm{~mol} \%$ and phospholipids $\sim 10 \mathrm{~mol} \%$. For individual subjects, main lipid classes in whole tears were in the same ratios as those found in meibum, except for phospholipids that derive from the meniscus, irrespective of the analytical technique used. The relative amount of phospholipid varies markedly between individuals from 1 to $30 \mathrm{~mol} \%$ of total lipids; lysophosphatidylcholine is the most abundant species [341]. However, over a 3day period, the ratios for an individual were the same [341].

Whether phospholipids contribute to lipid layer performance is an area of debate. Some argue for insufficient available phospholipid [309], with most of the intact phosphatidylcholine (but not lysophosphatidylcholine) bound to lipocalin. Others suggest that there is sufficient phospholipid in stimulated tears to form a monolayer [292]. Assuming $0.5 \mathrm{mmol} / \mathrm{L}\left(5 \times 10^{-4} \mathrm{~mol} / \mathrm{L}\right)$ total lipid and $10 \mathrm{~mol} \%$ phospholipid $\left(5 \times 10^{-5} \mathrm{~mol} / \mathrm{L}\right)$ in whole tears and a total tear volume of $10 \mu \mathrm{L}\left(10^{-5} \mathrm{~L}\right)$, then the total number of phospholipid molecules [345] available for lipid layer adsorption would be $3 \times 10^{14}\left(5 \times 10^{-5} \times 10^{-5} \times 6 \times 10^{23}\right)$. If one assumes a lipid layer surface area of $2 \mathrm{~cm}^{2}$ ( or $\left.2 \times 10^{16} \AA^{2}\right), \sim 70 \AA^{2}\left(2 \times 10^{16} \AA^{2}\right.$ / $3 \times 10^{14}$ ) should be available per surface phospholipid, which is identical to the area occupied by a single phosphatidylcholine molecule [345]. This calculation is based on the understanding that all phospholipids in $10 \mu \mathrm{L}$ of tears have adsorbed to the tear film lipid layer and none is bound to lipocalin in the mucoaqueous layer. There is a strong case for a 'perched tear film', and if this were the case then the true ocular surface tear volume would be about $0.06 \mu \mathrm{L}$. Overall, it appears that phospholipids are insufficient to form a layer. The countering argument is that phospholipids collected from tears of the meniscus were already part of the lipid layer at higher concentration and so there are more than ample phospholipids to form a layer at the ocular surface.

Several studies have investigated whether the collection technique of whole tears from the meniscus affected the lipid profiles obtained [288,290,291]. Rohit and co-workers compared flushed \& reflex tears with basal tears and found a relative mol\% increase of phospholipids and free cholesterol [291], pointing to a preference for basal tears, and suggested care to avoid reflex tearing during collection. Moreover, reflex or flush tears contain very low levels of several lipids. Others found lipid profiles from capillary-collected basal tears and flushed tears to be almost identical [290], and that tears collected by Schirmer strips had similar profiles to these but with a greater amount of total lipid ( 7.5 times). Two studies examined the lipid profile on different regions of the Schirmer strips that were used to collect tear samples. Using an IR method, Borchman and colleagues estimated that in the first $5 \mathrm{~mm}$ of the Schirmer strip, only $5 \%$ of the lipids were from the meibomian glands and also noticed that the lipid profile did not change over the first $15 \mathrm{~mm}$ [288]. Contrary to these findings, Lam and coworkers using a MS method, showed that the first $5 \mathrm{~mm}$ was composed of $15 \%$ phospholipids and approximately $80 \%$ was made up of meibomian lipids [290]. They also noticed that in the next $5 \mathrm{~mm}$ of the strip, the quantity of meibomian lipids halved, with few other lipids being detected and no signal for phospholipids. These results suggest that the use of Schirmer strips to collect tears may be not reliable.

In another study of mixed purpose, the main lipid classes found in meibum of wearers of contact lenses with and without dry eye 
were compared. The opportunity was also taken to compare the effect of different collection techniques (microcapillary tube, Dacron swab, cytology micro-brush, spatulas) and extraction techniques (immediate and following storage) [283] on the lipid profiles obtained. A cytology micro-brush was the most efficient at recovering phospholipids (50\%), followed by the spatula $(40 \%)$, microcapillary tube (38\%), and Dacron swab (23\%), and the authors concluded that the choice of collection device and extraction method plays a significant role in the detection of meibum lipids, particularly phospholipids [283]. This study also showed that contact lens wearers not suffering from dry eye were more likely to have inorganic phosphates present in their meibum samples compared with samples from contact lens wearers who had dry eye [283]. Another study that compared lipid composition of meibum collected using cotton buds, the meibomian gland evaluator and meibomian gland forceps demonstrated that the use of the evaluator resulted in smaller polar lipid quantities than the cotton bud approach [282]. There were no significant differences between techniques for nonpolar lipids [282].

Several studies have evaluated the impact of age on the composition of meibum and lipids from whole tears from the meniscus and compared these with subjects suffering from MGD [288,303,339,346-350]. Interestingly, Lam et al. found OAHFAs to increase with age [333], which is unexpected because they also found that OAHFAs decreased with dry eye [336]. There was no difference in meibum phospholipid between males and females [351], but another study has shown a difference in polar (not identified) between the sexes [340]. Studies using NMR have shown that there was an increase in order of the molecules in MGD relative to age-matched controls and a corresponding decrease in lipid order with age [303]. An investigation of the meibum from Asians with different severities of dry eye showed that there was no overall difference in the ratios of the different classes of lipids between dry eye patients and normal subjects [336]. The proportion of total lipids that were triacyl glycerols was higher in the mildest category of dry eye compared with more severe categories, and the relative percentage of OAHFAs to total lipids progressively fell with increasing severity of dry eye. This was the only class of lipids to do so [336]. Some changes in the relative percentage of individual species of lipids to total lipid detected were found, but the trends were not consistent in direction across the dry eye categories.

Recently, several studies have profiled lipids in whole tears from the meniscus of patients with different severities of DED [21,289-292,333,344,351,352]. Beyond the relative ease of tear collection versus meibum, marked levels of phospholipids are detectable in tears, ratios of lipids in whole tears from the meniscus reflect lipid-species ratios in meibum, and all meibum lipids have been identified in the tears. Table 4 summarizes recent studies (adapted from Millar and Schuett) [255]. Lam et al. observed a decrease in low molecular weight wax esters and a tendency of medium molecular weight wax esters to be more unsaturated although total tear lipids were unchanged in dry eye patients versus control subjects [290]. Another study by the same group used HPLC/MS/MS to determine correlations between structure-specific human amphipathic tear lipids and dry eye [333]. They found that several amphipathic lipids, cholesteryl sulfates, glucosylceramides, ganglioside mannoside 3 , and lysophosphatidylcholines, were positively correlated with increased Schirmer I results, and that phosphatidic acids and phosphatidylglycerols showed a negative correlation. Small amounts of cholesteryl sulfate in meibum and tears from patients suffering with dry eye syndrome have been detected $[290,333]$. However, its role in meibum or the tear film needs further investigation. These components are commonly associated with epithelia, where they are believed to have a secondary messenger role [353]. It is possible that the cholesteryl sulfate detected in Lam et al.'s samples [290] may have originated from meibomian ductal cells.

In summary, tear lipid profiles from studies to date are variable, warranting investigation of the source $(s)$ of variation (collection methods, analysis techniques or a combination of both) and close collaboration among different tear and meibum lipid laboratories worldwide. An initial step would be comparative analysis of a common shared sample towards comprehensive procedural standardization of all analytical and collection steps.

\subsection{Mucins}

Mucins are large high molecular weight glycoproteins that contain one or more protein domains, rich in serines and threonines, which are extensively glycosylated via O-glycan attachments. These important glycan chains constitute a significant part (50-80\%) of the weight of the mucin [354,355]. Mucins, the building blocks of mucus, in general are present at apical epithelial surfaces of the respiratory, gastrointestinal, and reproductive tracts, as well as the ocular surface. Mucins provide a variety of protective functions, including but not limited to, lubrication, barrier formation and hydration. Fig. 3 demonstrates the role of mucins in the tear film structure.

At least 20 mucin genes (MUC) have been identified in humans [356], the products of which are classified into two types: secretory mucins and transmembrane mucins. The secretory mucins are further subdivided into large gel-forming mucins and small soluble (or non-gel forming) mucins [356]. The gel forming mucins are MUC2, MUC5AC, MUC5B, MUC6 and MUC19, the small soluble mucins are MUC7, MUC8 and MUC9, and 10 others have been characterized as transmembrane [356]. Ocular surface mucins are synthesized by corneal and conjunctival epithelia and lacrimal glands, where they contribute to the epithelial barrier and prevent binding of pathogens to the ocular surface, and are present in the tears where they maintain hydration [17,18,271,357-359]. The role of mucins in ocular surface health and DED is a subject of great interest, that has been reviewed a number of times in recent years [15,359-362].

Gel-forming mucins can be incredibly large, up to $40 \mathrm{MDa}$, thanks to their ability to multimerize through disulfide bonding of cysteine rich domains that flank the large central tandem repeat region [355]. The source of gel-forming mucins on the ocular surface are goblet cells of the conjunctiva, with MUC5AC being the most abundantly expressed [271,359] (though mRNA for others have also been found $[363,364])$. The abundance of MUC5AC present on the ocular surface is determined by the number of conjunctival goblet cells and the stimulation of its secretion by these cells. Gel-forming mucins are important for hydration of the ocular surface, and have also been suggested to play an important role in not only tear structure, but also in preventing debris and pathogens from binding to the ocular surface and damaging cells [18] by clearing them from the ocular surface through entrapment in the mucus layer and blinking [17,359].

Several studies have demonstrated decreased levels of MUC5AC in dry eye, yet it is important to note that altered levels of MUC5AC (and gel forming mucins in general), both decreased and increased, can negatively impact ocular surface health. As such, mucin production must be tightly regulated for ocular surface homeostasis. In patients with moderate DED a decrease in the total number of goblet cells, as well as empty goblet cells, has been observed by impression cytology [365]. MUC5AC has also been shown by impression cytology to be lower in dry eye patients with severe symptoms compared to mild and moderate symptoms [366], which was associated with increased inflammation, and (along with decreased levels of MUC16) in patients with an unstable tear film or 
Table 4

Concentration of lipids in tears (adapted from Millar and Schuett) [255].

\begin{tabular}{|c|c|c|c|c|c|c|c|c|c|c|c|}
\hline \multirow[t]{2}{*}{ Lipid } & \multirow[t]{2}{*}{$\begin{array}{l}\text { Saville et al., } \\
2010 \text { [289] }\end{array}$} & \multirow[t]{2}{*}{$\begin{array}{l}\text { Saville et al., } \\
2011 \text { [351] }\end{array}$} & \multirow[t]{2}{*}{$\begin{array}{l}\text { Rantamaki et al., } \\
2011 \text { [352] }\end{array}$} & \multirow[t]{2}{*}{$\begin{array}{l}\text { Dean and Glasgow } \\
2012[292]\end{array}$} & \multirow[t]{2}{*}{$\begin{array}{l}\text { Brown et al., } \\
2013 \text { [21] }\end{array}$} & \multicolumn{3}{|c|}{$\begin{array}{l}\text { Rohit et al., } 2014 \\
{[291]}\end{array}$} & \multirow[t]{2}{*}{$\begin{array}{l}\text { Lam et al., } \\
2014 \text { [290] }\end{array}$} & \multirow[t]{2}{*}{$\begin{array}{l}\text { Lam et al., } \\
2014 \text { [333] }\end{array}$} & \multirow[t]{2}{*}{$\begin{array}{l}\text { Lam et al., } \\
2014[344]\end{array}$} \\
\hline & & & & & & Basal & Reflex & Flush & & & \\
\hline Collection method & Cap $^{a}$ & Cap & Cap & Cap (reflex) & Cap & Cap & Cap & Cap & Sch & Sch & Sch \\
\hline \multicolumn{12}{|l|}{ Mol \% } \\
\hline Cholesterol-Ester & & & & & 39 & 54.8 & 35.7 & 33 & 44.8 & 43 & 33 \\
\hline Wax Ester & & & & & 43 & 29.1 & 18.6 & 30 & 35.2 & 30 & 46 \\
\hline Cholesterol & & & & & & 8.2 & 17.2 & $\sim 20$ & 5.9 & 8 & 8 \\
\hline OAHFA & & & & & 4.4 & $\sim 2.5$ & $<1$ & $<1$ & 2.5 & 2 & 1.1 \\
\hline Trigylceride & & & & & 2.1 & & & & 2.8 & 1 & 2 \\
\hline \multicolumn{12}{|l|}{ Phospholipids: } \\
\hline Phospholipid total & & & & & 12 & & & & & & \\
\hline Phosphatidylcholine & & & & & 1.6 & & & & 2.5 & 2 & 3 \\
\hline $\begin{array}{l}\text { Lysophosphatidyl- } \\
\text { choline }\end{array}$ & & & & & 8 & & & & 0.5 & 0.8 & 1.7 \\
\hline $\begin{array}{l}\text { Phosphatidyl- } \\
\text { ethanolamine }\end{array}$ & & & & & 0.8 & & & & 0.7 & 1 & 1.2 \\
\hline $\begin{array}{l}\text { Lysophosphatidyl- } \\
\text { ethanolamine }\end{array}$ & & & & & & & & & 1.3 & 1.6 & 2 \\
\hline Phosphatidylserine & & & & & 0.5 & & & & 0.1 & 0.5 & 0.3 \\
\hline Sphingomyelin & & & & & 1.1 & & & & 1.5 & 3 & \\
\hline Ceramide & & & & & & & & & & & \\
\hline
\end{tabular}

\begin{tabular}{|c|c|c|c|c|c|c|c|c|}
\hline \multirow[b]{3}{*}{ Cholesterol-Ester } & \multicolumn{8}{|c|}{ Concentration } \\
\hline & \multirow[t]{2}{*}{$\mathrm{pmol} / \mu \mathrm{l}$} & \multirow[t]{2}{*}{ ng/ng tear } & \multirow[t]{2}{*}{$\mu \mathrm{M}$} & \multirow[t]{2}{*}{$\mathrm{ng} / \mathrm{ml}$} & \multicolumn{3}{|c|}{$\mathrm{pmol} / \mu \mathrm{l}$} & \multirow[t]{2}{*}{$\mu \mathrm{mol} / \mathrm{ml}$} \\
\hline & & & & & 178.1 & 27.9 & 13.5 & \\
\hline Wax Ester & & & & & 81.8 & 15.5 & 8.3 & \\
\hline Cholesterol & & & & & 16.6 & 9.8 & 5.9 & \\
\hline OAHFA & & & & & 4.3 & 0.4 & 0.1 & \\
\hline Trigylceride & & & 1.5 & & 1.6 & 0.1 & 0.2 & \\
\hline \multicolumn{9}{|l|}{ Phospholipids: } \\
\hline Phospholipid total & & 11 & 29.6 & & & & & \\
\hline Phosphatidylcholine & 6 & & 20.9 & 194 & 1.6 & 1.1 & 0.5 & \\
\hline $\begin{array}{l}\text { Lysophosphatidyl- } \\
\text { choline }\end{array}$ & & & & & 3.5 & 9.5 & 3.2 & \\
\hline $\begin{array}{l}\text { Phosphatidyl- } \\
\text { ethanolamine }\end{array}$ & & & 5.2 & & 0.1 & 0.1 & 0 & \\
\hline $\begin{array}{l}\text { Lysophosphatidyl- } \\
\text { ethanolamine }\end{array}$ & & & & & 1.5 & 1.2 & 0 & \\
\hline Phosphatidylserine & & & 0.1 & & & & & \\
\hline Sphingomyelin & 5 & & 0.9 & & 1.9 & 1.6 & 0.6 & \\
\hline Ceramide & & & 0.9 & & & & & \\
\hline Total lipid $(\mathrm{pmol} / \mu \mathrm{L})$ & & & & & $\sim 380$ & $\sim 100$ & $\sim 40$ & 0.58 \\
\hline
\end{tabular}

${ }^{\mathrm{a}}$ Cap $=$ collected by capillary tubes; $\mathrm{Sch}=$ collected by Schirmer strips.

aqueous deficiency compared to control eyes [367]. Consistent with these findings, very recently, goblet cell deficiency, and thus decreased MUC5AC expression, was observed in subjects (office workers using visual display terminals) with DED, particularly so in moderate to severe cases [368]. In patients with atopic keratoconjunctivitis, the number of goblet cells and MUC5AC mRNA levels were significantly diminished [369]; a concomitant increase in MUC16 was also observed and the authors speculated that MUC16 compensates for lack of MUC5AC. In Sjögren syndrome patients, decreased MUC5AC mRNA and protein in tears and decreased MUC19 mRNA and protein has also been reported [270,364]. In summary, there is an abundance of data demonstrating DED is associated with decreased levels of MUC5AC.

MUC7 is currently the only small soluble mucin to be detected in ocular tissue, but it has not been detected in tears [271,363,370,371]. MUC7 is small ( $180 \mathrm{kDa})$ [372] compared to gelforming mucins, and exists as a monomer with a typical rigid structure 'bottle-brush' shape provided by water-binding O-glycans [361,373]. While MUC7 is expressed in the acinar cells of the lacrimal gland and in human conjunctiva, it is not known which cell type is responsible for synthesis and secretion in the conjunctiva, nor is it known what stimulates MUC7 secretion in ocular tissues $[271,363,370,371]$. As MUC7 has not been detected in the tears, its putative role in the tear film is not well understood. It is reasonable to speculate, based on MUC7 having the expected O-linked glycans of a mucin, that it would contribute to hydration of the ocular surface. However, no studies to date clearly demonstrate the function of MUC7 on the ocular surface. MUC7 expression, as assessed by mRNA levels in conjunctival impression cytology, has been reported to not be different between normal and patients with dry eye [374].

Transmembrane mucins expressed in the most superficial cell layer of the corneal and conjunctival stratified epithelia include MUC1, MUC4, and MUC16 [15,17,375]. MUC20 is one of the more highly expressed mucins in the human conjunctiva and is predominant along the plasma membranes of intermediate cell layers [376,377]. Transmembrane mucins have large extracellular domains, a hydrophobic membrane-spanning domain, and a short cytoplasmic domain. The extracellular domain comprises the tandem repeats rich in serine and threonine, which are subject to $O$ linked glycosylation [354], and can extend up to 200-500 nm above the ocular surface [362]. Soluble forms of MUC1, MUC4, and MUC16 have been detected in tears [271]. MUC16 has recently been localized to mucin granules of goblet cells as well, though its function remains to be determined [16]. In general, the transmembrane mucins play important protective roles on the ocular 


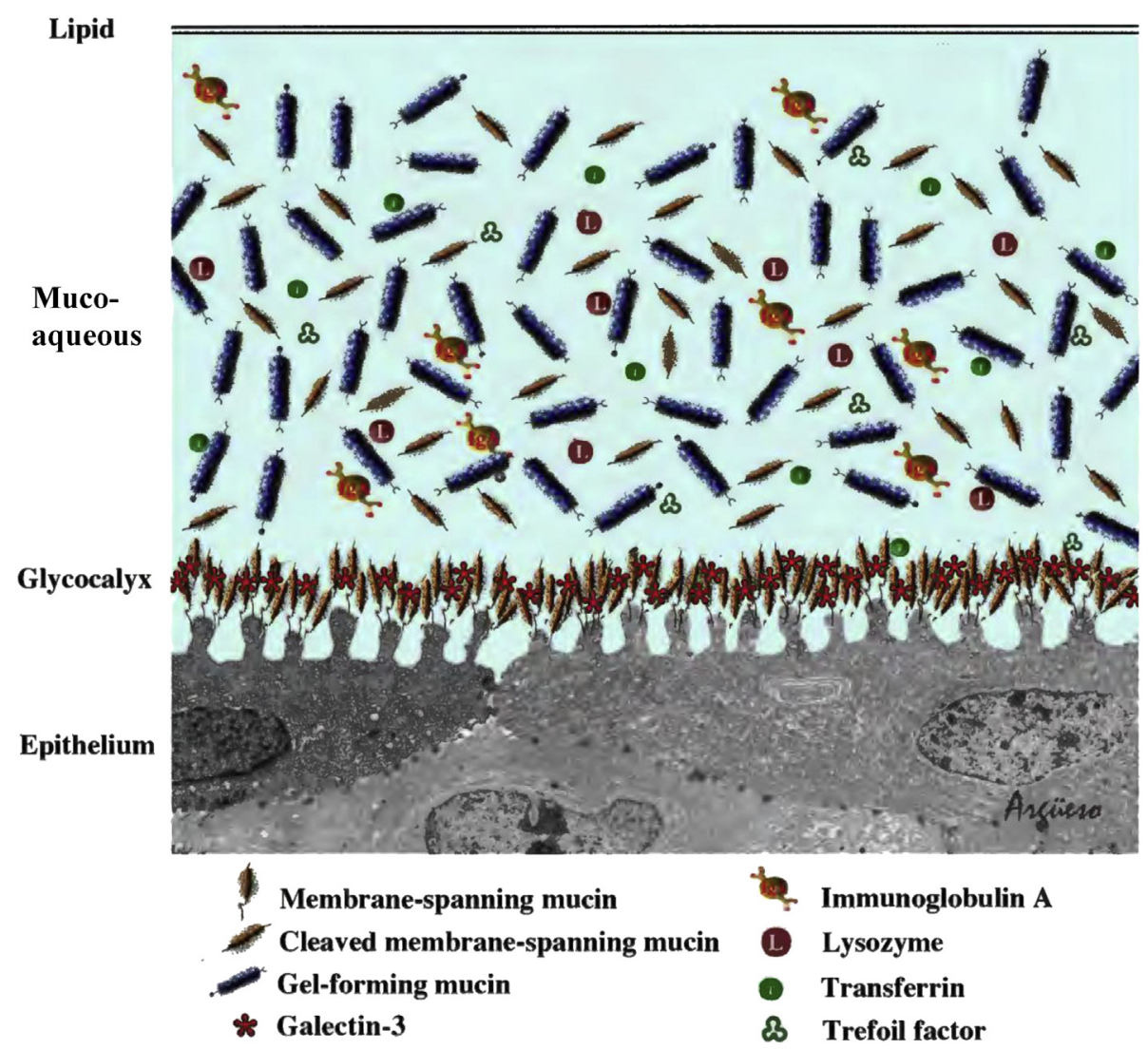

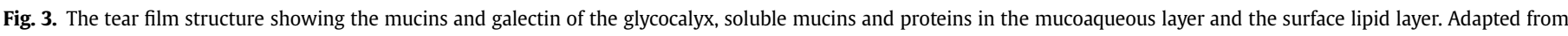
Craig et al., 2013 [54].

surface. These include, consistent with those mentioned above, hydration of the ocular surface, and anti-adhesive properties between the cells of the conjunctiva and ocular surface [361], as well as contributing to tear film stabilization [15]. The cytoplasmic domain can associate with cytoskeletal components and also have numerous phosphorylation sites that suggest it may function in cell signaling [378,379]. A direct comparison between MUC 1 and MUC16 barrier function in the same epithelium suggested that transmembrane mucin barriers vary in the context of other transmembrane mucins, and that MUC16 provides a major barrier when present [380]. Messenger RNA transcripts of the transmembrane mucins MUC13, MUC15, MUC17 have been identified in human conjunctiva [381], but neither their presence in tears nor their functions have yet been elucidated.

Transmembrane mucins also contribute to the highly organized protective epithelial barrier on the apical glycocalyx of the ocular surface epithelia cells though binding to galectin-3 (a multivalent $\beta$-galactoside-binding lectin) [382]. Indeed, galectin-3 co-localizes with MUC1 and MUC16 on the apical surface of epithelial cells, in a carbohydrate-dependent manner, and plays a key role in maintaining mucosal barrier function. The concentration of galectin-3 protein in tears (but not conjunctival epithelium expression) was found to be significantly higher in patients with dry eye and associated with epithelial dysfunction in dry eye, and the data demonstrate proteolytic cleavage of galectin-3 that may contribute to impaired ocular surface barrier function [383].

Changes in transmembrane mucin have been observed in patients with DED, but remain controversial. In post-menopausal women with non-Sjögren syndrome dry eye, increased MUC1 and MUC16 mRNA and protein levels have been reported relative to controls [384]. Similarly, increased MUC1 and MUC16 mRNA and soluble protein levels have been observed in Sjögren syndrome [385,386]. Conversely, decreased levels of MUC1 and MUC4 mRNA levels were reported in conjunctival epithelia of dry eye patients, and those authors suggested MUC1 mRNA levels could be used as a diagnostic biomarker for dry eye [374]. Such alterations could be the result of dry eye-related inflammatory mediators (eg IL-1, IL-6, IFN- $\gamma$, TNF- $\alpha$ ) regulating the expression of transmembrane mucin, although, to date, studies examining this hypothesis have been in vitro only [387-389]. In patients with complete androgen insensitivity syndrome who have DED [390], MUC1 mRNA and protein as well as the gel forming MUC5AC levels were decreased compared to those in control patients [376].

Altered glycosylation of ocular mucins has been observed in dry eye. Differential regulation of genes involved in glycosylation, as well as altered distribution of the responsible enzymes, has been observed in the conjunctiva of patients with DED [376,391]. Alteration of MUC16 sialylation, as shown by using the monoclonal antibody $\mathrm{H} 185$, has been detected in patients with dry eye symptoms [392,393]. Upregulated sialylation of MUC1 in mild-tomoderate dry eye and a decrease in severe dry eye has also been observed [394]. Indeed, altered sialylation of mucins in DED appears to depend on disease severity; whereas increased sialylation has been noted in the earlier stages of disease development, it is eventually lost with disease progression [395,396]. Increased sialylation on the cell surface would increase negative charge and enhance cell repulsion, as well as hydration through attraction of water. Additional work is required on the glycosylation of mucins and mucin-like molecules in DED.

A mucin-like glycoprotein called lubricin, or proteoglycan 4 , is 
present on the ocular surface, where it provides lubrication and plays a protective role [397]. Lubricin was originally discovered in synovial fluid and on the surface of cartilage, and was found to also be present at the epithelial surface of human cornea and conjunctiva, though it is yet to be detected in tears [397]. Lack of lubricin on a mouse eye is associated with increased ocular surface damage, as demonstrated by an increase in corneal fluorescein staining [397], though to date no studies exist demonstrating alterations in lubricin expression with dry eye. In vitro, lubricin reduces friction at a human cornea-eyelid biointerface, as well as tissue-contact lens biomaterial interfaces [398-400]. Recently, recombinant human lubricin was found to demonstrate improvement in both the signs and symptoms of DED compared to a control drop based on hyaluronate) [401]. Another heavily O-linked glycoprotein found in tears is Deleted in Malignant Brain Tumors-1 (also known as gp-340) and this has two isoforms [402]. The role of this protein in the tear film is unknown, although gp340 has been shown to be identical with the salivary agglutinin that strongly binds to bacteria and can activate the complement system $[403,404]$ so may be involved in host defense.

In conclusion, mucins are critical to ocular surface health and deregulation of their synthesis is an important factor in ocular surface disease. Decreased MUC5AC expression and alteration in mucin glycosylation in dry eye is a consistent finding among most studies, while changes in transmembrane mucin expression is more variable (see Stephens \& McNamara [360] for summary tables). Additional work is required to elucidate the role of individual mucins in disease, with the potential confounding factor of compensatory and/or complementary responses. Such work will likely benefit from the use of new, sophisticated genomic, glycomic and proteomic methods.

\subsection{The tear proteome}

The mucoaqueous layer contains salts and numerous proteins derived from the lacrimal gland and conjunctiva. A much expanded understanding of the tear proteome $[405,406]$ has been achieved over the past decade and this section will concentrate on research conducted within this time frame. Techniques that have been used for proteomic analysis include unbiased tandem mass spectrometric (MS/MS) sequencing [19,268,269,407-414], candidate immunocapture [368,415-421] and other approaches (Table 5), from which a select group of putative disease biomarkers have emerged (Tables 6 and 7).

MS/MS runs are fed by trypsinized tear protein fragments that are first subjected to reverse-phase C-18 (without or with cation exchange $[269,407])$ separation. In some cases, tear proteins were first partitioned by 1 - or 2-D sodium dodecyl sulfate polyacrylamide gel electrophoresis [269,408,409,414], which offers the advantage of separating monomers from polymers, or were collected into normal or dry eye pools for differential labeling by mass [407] or by fluorescence [408]. In other cases, tear proteins were first adsorbed onto protein chips, disks or tips bearing C-8, C-18 or cation ion exchange chemistry $[410,422]$, or abundant albumin was first immunodepleted from tears [409], the latter an acknowledgement of the limited dynamic range of MS/MS, by which changes in less abundant tear proteins are overlooked.

Although well-suited for discovery, MS/MS coupled with chromatography is currently not practical as a quantitative, high throughput tear diagnostic, despite some success in a few academic studies. For this reason, candidate immunological approaches have been explored (Table 6) $[270,368,415,417,420,421,423-436]$. These include antibody array (16 inflammatory cytokines [437]), sandwich ELISA (for MMP-9 [415,418,421], MUC5AC [368], IL-1 $\beta$ and IL-6 [415]), direct ELISA (lacritin [416,438]), and bead adsorption [439] (13 inflammatory cytokines, EGF, vascular endothelial growth factor (VEGF) [417,419], TGF $\beta 1$ and 2 [420]). An expanded selection of quantitative immunoassays built on validated biomarkers (Tables 6 and 7) should be the way of the future. Investigators should be careful to control for non-specific tear matrix effects $[437,440]$, and independently validate commercial immunoassays where possible (one commercial lacritin ELISA displayed no reactivity for purified recombinant lacritin [405]).

Currently, almost 1800 proteins are known to constitute the human tear proteome. Before the original TFOS DEWS report in 2007, 491 proteins had been identified [268]. In 2012, Zhou et al. [19] reported 1543 proteins, of which 1304 were new. Over half are indicated to be 'intracellular' or associated with the 'plasma membrane' by Gene Ontology, but those that selectively decrease or increase in ocular surface diseases and thus are potential biomarkers are to date largely 'extracellular' according to Gene Ontology [270,368,407,408,410,411,425,428,430,431,434,441-448].

Other technical considerations include the method of tear collection, whether topical anesthesia is employed to reduce reflex tearing [442], sampling from open versus closed eyes [268,437] and the optimal collection point on the eye. Capture of tears by microcapillary tubes is most common in proteomic studies [268,269,408,409,418-421,432,437,450], although others collect tears onto Schirmer strips [269,407,410-412,442], using sponges $[409,415,429]$ or via micropipette tip $[368,417,450]$. Posa et al. [456] and Grus et al. [442] note that microcapillary tubes and Schirmer strips are equally effective, whereas Green-Church et al. [269] suggest that the tear film collection method impacts proteins present in the sample. However, Schirmer strips are preferred by patients for comfort and perceived safety. Schirmer strips also appear to retain proteins $<40 \mathrm{kDa}$ [442]. Most studies fail to mention the use of anesthesia, whether tears are from open or closed eyes, and the site of collection by tubes and sponges (sampling is slightly more common from the lateral [417-419,450] versus medial [420] canthus). Noting whether anesthesia has been used is important, with relative levels of 15 tear proteins, possibly more, differing between basal and reflex tears [457]. Previous studies have shown that certain tear proteins such as lysozyme, lactoferrin, and lipocalin-1 are regulated, in that their concentration remains approximately the same during changes to the amount of tears being produced (for example during reflex tearing) [457]. Other proteins, such as sIgA, are constitutive or have a constant level of production, such that their concentration decreases during increases in tear fluid production [458]. Some proteins appear in the tear film via leakage from conjunctival blood vessels $[459,460]$. The concentration of sIgA could be used to normalize protein levels that might be affected by collection of reflex vs. non-reflex tears [461], and this is an area worthy of further study, although $\operatorname{sig} A$ is deregulated in some pathological conditions. Indeed, it is currently not known whether most of the proteins within the proteome are constitutive, regulated or derived from serum (or elsewhere). A correct normalization process usually involves a "normalizer protein" or "housekeeping protein" [462]. A strict definition of a housekeeping protein is a constitutive protein that should be expressed under normal and pathological conditions at relatively constant levels. Such a protein has yet to be described in tears. A publication of cerebral spinal fluid proteomics indicates that the preferable way to quantify proteins is to first match the samples on total protein amount and then normalize the data based on the median intensities [463]. This technique has yet to be used in tear film biochemistry studies.

Human tear biomarkers might predict, diagnose and even, in 
Table 5

Mass spectrometric approaches.

\begin{tabular}{|c|c|c|}
\hline Name & Abbreviation & Approach \\
\hline $\begin{array}{l}\text { Surface-Enhanced Laser Desorption/Ionization Time- } \\
\text { Of-Flight Mass Spectrometry }\end{array}$ & $\begin{array}{l}\text { SELDI-TOF- } \\
\text { MS }\end{array}$ & $\begin{array}{l}\text { Peptides are initially screened by differential binding chemistry (ie hydrophobic, anion, cation } \\
\text { exchange), then are ionized and masses determined. }\end{array}$ \\
\hline $\begin{array}{l}\text { Matrix-Assisted Laser Desorption/Ionization Time-Of- } \\
\text { Flight Mass Spectrometry }\end{array}$ & $\begin{array}{l}\text { MALDI-TOF } \\
\text { MS }\end{array}$ & $\begin{array}{l}\text { Peptides are separated by liquid chromatography, or 2D or 1D polyacrylamide gel electrophoresis, } \\
\text { then ionized and masses determined. }\end{array}$ \\
\hline Isobaric Tag for Relative and Absolute Quantitation & iTRAQ & Stable isotope tagging to differentiate peptides from different sources, ie. normal vs. dry eye. \\
\hline Tandem Mass Spectrometry & MS/MS & $\begin{array}{l}\text { Ionized peptides are separated by mass, selected ions are fragmented, further separated and } \\
\text { sequence derived. }\end{array}$ \\
\hline
\end{tabular}

some cases, be therapeutic for ocular surface disease. Nine early candidate biomarkers were identified primarily by immunoassay (see Tables 5 and 6 for expanded details):

a) epidermal growth factor (EGF): reduced in Sjögren syndrome and aqueous deficient dry eye (ADDE) [430,464], augmented in evaporative dry eye due to MGD [417].

b) interleukin $1 \alpha$ (IL-1 $\alpha)$ : increased in Sjögren syndrome dry eye and MGD [433].

c) interleukin 6 (IL-6): increased in Sjögren syndrome dry eye $[432,465]$.

d) lactoferrin (LTF): reduced in Sjögren syndrome and nonSjögren syndrome dry eye [466].

e) lipocalin 1 (LCN1): a putative auto-antigen for Sjögren syndrome [467] that is decreased in MGD [468].

f) matrix metalloproteinase 9 (MMP-9): increased in Sjögren syndrome dry eye, but unchanged from normal in MGD [433].

g) MUC5AC: reduced in Sjögren syndrome dry eye [270,469].

h) plasmin activity from plasminogen (PLG): increased in Sjögren syndrome dry eye [434].

i) group IIA phospholipase A2 (PLA2G2A): increased in dry eye $[470,471]$.

Seven more have been identified by unbiased MS/MS analysis of 2-D gel protein bands that differed in quantity between normal and blepharitis tears [443]. Selectively down-regulated biomarkers were albumin (ALB), immunoglobulin kappa variable 3-20 (IGKV320), serpin peptidase inhibitor clade A member 1 (SERPINA1), prolactin-induced protein (PIP), cystatin S (CST4), lacritin (LACRT) and lysozyme [443].

Topping the 'extracellular' list of deficient or augmented biomarkers in unbiased MS/MS screens (Table 6) in decreasing order of replications (respectively $\geq 6,5,4,3,2$ ) listed alphabetically are $(\geq 6)$ lacritin, lactoferrin, lipocalin 1 , prolactin-inducible protein, proline rich 4 (PRR4) and S100 calcium binding protein A8 (S100A8); next (5) are cystatin S (CST4), lysozyme (LYZ) and secretoglobin family member 2 A member 1 ; followed by (4) albumin (ALB) and S100 calcium binding protein A9 (S100A9); and (3) alpha-2-glycoprotein 1 (AZGP1), apolipoprotein A-II (APOA2), beta 2 microglobulin (B2M), haptoglobin (HP), orosomucoid 1 (ORM1), polymeric immunoglobulin receptor (PIGR), proline rich lacrimal 1 (PROL1), secretoglobin family member 1D member 1 , serpin peptidase inhibitor clade A member 1; and finally (2) actin beta (ACTB), complement component 3 (C3), deleted in malignant brain tumors 1 (DMBT1), enolase 1 (alpha; EN01), secretoglobin family member 2A member 2, transferrin (TF). Thirty-four other 'extracellular' proteins are deficient or augmented in single unbiased MS/ MS screens - many from Sjögren syndrome.

Among intracellular proteins (Table 7) [407,409,411,424,425, $429,430,433,444,446,464,470,472]$ in decreasing order of replications (respectively $4,3,2$ ) are annexin A1 (ANXA1), followed by annexin A11 (ANXA11), glutathione S-transferase pi 1 (GSTP1), peroxiredoxin (PRDX5), S100 calcium binding protein A4 (S100A4), S100 calcium binding protein A6 (S100A6) and S100 calcium binding protein A11 (S100A11). Seven others are deregulated in single unbiased MS/MS screens to date. The surprisingly large representation of intracellular proteins in tears is presumed to be due to normal shedding of ocular surface epithelial cells [268], but why so few are more abundant in diseased tears is unknown. The classification of proteins by gene ontology, whilst useful, is a fairly blunt technique as, for example, secretory phospholipase A2 group IIA is classified as an intracellular protein when it is known to be secreted onto mucosal surfaces $[470,473]$.

Not detected by MS/MS, but apparent by candidate immunoscreening or activity assays (Table 6 ) $[415,417,420,421,423,424,426$, $427,429,432,433,449,450]$ were several growth factors and cytokines. VEGF levels were increased in MGD [417]. Elevated in ADDE were soluble epidermal growth factor receptor, colony stimulating factor 3 (CSF3), transforming growth factor activity, and soluble tumor necrosis factor superfamily member 1B (TNFRSF1B) [429]. Levels of twelve chemokines were augmented in ADDE or MGD $[424,427,429]$. Fifteen interleukins or interleukin-associated molecules were for the most part increased in ADDE but two decreased and one increased in MGD [415,417,423,425,427,429]. There was disagreement over whether interferon gamma (IFNG) is increased or decreased in ADDE (although it is clearly increased in animal dry eye models) $[423,427,429,474,475]$. MMP-9 was increased in ADDE, post-LASIK dry eye, blepharitis, and conjunctivochalasis $[415,421,433]$. Five intracellular or plasma membrane tear proteins were detected only by candidate immuno-screening: transforming growth factor alpha (TGFA), phospholipase A2 group IIA (PLA2G2A), aquaporin 5 (AQP5), interleukin 1 alpha (IL1A) and interleukin 33 (IL33) - all increased in ADDE. AQP5 and IL1A were also increased in Sjögren syndrome, and the latter also in MGD $[410,417,423,425,427,429,430,432,433,464,476,477]$. It is noteworthy that of extracellular biomarkers most are immune-related (34 proteins), or fall under the category of protease/inhibitor/ antimicrobial (14 proteins), or carrier/binding/protein steroid associated (11 proteins), or cytoprotective/anti-apoptotic (6 proteins). Intracellular ones are most commonly associated with cell communication/signal transductions ( 6 proteins), metabolism/energy pathways (4 proteins) or regulation of transcription/nucleic acid metabolism ( 4 proteins).

To date, half of the candidate biomarkers (Tables 5 and 6) lack immunological validation. Once confirmed, dry eye versus normal protein concentrations are needed, for which there should be good agreement among different laboratories. Initial values have been documented for several members of the interleukin family (IL1A, IL1B, IL-2, IL-4, IL-5, IL-6, IL-10), CXCL8 [415,424,425,427], TNF- $\alpha$ and IFN- $\gamma$ [427,432], MMP-9 [415] and MMP-9 activity [421,433], LTF and EGF [425,430,433,450], ENO1, S100A4 [407], LYZ, TF, LCN1, ALB, AZGP1 [450], CALCA, NPY, NGF, CCL3, CCL4, and CCL5 $[424,426]$. Values for IL1B, IL-6, MMP-9 and TNF- $\alpha$ vary greatly. Most have not been subjected to replication by others. If the assumption that biomarkers repeatedly deficient or augmented in 
Table 6

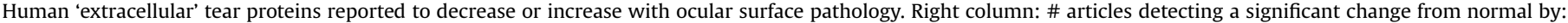

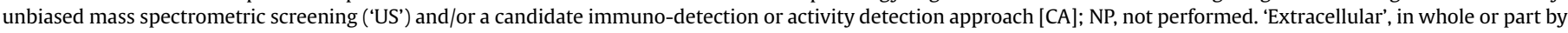
Gene Ontology.

\begin{tabular}{|c|c|c|c|c|}
\hline $\begin{array}{l}\text { Gene } \\
\text { Symbol }\end{array}$ & Protein & Change from Normal \& Pathology & Known Function(s) & $\begin{array}{l}\text { \# Articles } \\
\text { US/[CA] }\end{array}$ \\
\hline \multicolumn{5}{|c|}{ Angiogenesis } \\
\hline VEGF & $\begin{array}{l}\text { vascular endothelial growth } \\
\text { factor A }\end{array}$ & $\uparrow A D D E[449], \uparrow$ MGD [417] & angiogenesis, endothelial cell migration & $0 /[2]$ \\
\hline ZG16B & zymogen granule protein $16 \mathrm{~B}$ & \multicolumn{2}{|l|}{ Calcium } & $1 /[\mathrm{NP}]$ \\
\hline AHSG & alpha-2-HS-glycoprotein & $\uparrow \operatorname{SSDE}[411]$ & calcification inhibitor & $1 /[\mathrm{NP}]$ \\
\hline ANXA2 & annexin $\mathrm{A} 2$ & $\uparrow \operatorname{SSDE}[411]$ & osteoclast formation and bone resorption & $1 /[\mathrm{NP}]$ \\
\hline ANXA5 & annexin A5 & $\downarrow$ SSDE [411] & promotes $\mathrm{Ca}^{2+}$ channel activity & $1 /[\mathrm{NP}]$ \\
\hline CALCA & $\begin{array}{l}\text { calcitonin related polypeptide } \\
\text { alpha }\end{array}$ & $\downarrow$ ADDE $[426]$ & $\mathrm{Ca}^{2+}$ regulation & $0 /[1]$ \\
\hline CALR & calreticulin & $\uparrow \operatorname{SSDE}[411]$ & $\begin{array}{l}\mathrm{Ca}^{2+} \text { binding protein in ER and nucleus; SS } \\
\text { assoc. }\end{array}$ & $1 /[\mathrm{NP}]$ \\
\hline NPY & neuropeptide Y & $\downarrow$ SSDE [426] & promotes $\mathrm{Ca}^{2+}$ signaling & $0 /[1]$ \\
\hline \multicolumn{5}{|c|}{ Carbohydrate } \\
\hline ENO1 & enolase 1 , (alpha) & $\begin{array}{l}\uparrow \mathrm{ADDE}[407,414] \\
\uparrow \mathrm{ADDE} / \mathrm{MGD}[414]\end{array}$ & glycolytic enzyme & $2 /[1]$ \\
\hline \multicolumn{5}{|c|}{ Carrier/Binding Protein/Steroid Associated } \\
\hline ALB & albumin & $\begin{array}{l}\uparrow \mathrm{ADDE}[444,450], \downarrow \mathrm{BL}[443], \uparrow \mathrm{CLDE}[408], \\
\uparrow \mathrm{FK}[441], \uparrow \mathrm{MGD}[451]\end{array}$ & carrier protein & $4 /[2]$ \\
\hline AZGP1 & alpha-2-glycoprotein 1 & $\downarrow$ ADDE $[447,450], \downarrow$ MGD [409], $\uparrow$ FK $[441]$ & zinc-binding, lipid degradation, cell adhesion & $3 /[1]$ \\
\hline DMBT1 & $\begin{array}{l}\text { deleted in malignant brain } \\
\text { tumors } 1\end{array}$ & $\downarrow$ ADDE, $\downarrow$ ADDE/MGD [414], $\uparrow$ CLDE [408] & scavenger receptor, binds surfactant protein $\mathrm{D}$ & $2 /[\mathrm{NP}]$ \\
\hline HP & haptoglobin & $\uparrow \mathrm{ADDE}[447], \uparrow \mathrm{CDK}[445], \uparrow \mathrm{FK}[441]$ & $\begin{array}{l}\text { hemoglobin binding, turnover to diminish iron } \\
\text { loss }\end{array}$ & $3 /[\mathrm{NP}]$ \\
\hline LCN1 & lipocalin-1 & $\begin{array}{l}\downarrow \uparrow \operatorname{ADDE}[409,423,424,447,450], \downarrow \text { FK }[441], \\
\downarrow \text { MGD }[451], \downarrow \text { SSDE }[411,428]\end{array}$ & $\begin{array}{l}\text { hydrophobic protein binding, cysteine protease } \\
\text { inhibitor }\end{array}$ & $9 /[3]$ \\
\hline SCGB1D1 & secretoglobin family $1 \mathrm{D}$ member $1^{\mathrm{a}}$ & $\downarrow \uparrow \operatorname{ADDE}[410,447], \downarrow$ CLDE $[408], \downarrow$ MGD $[451]$ & $\begin{array}{l}\text { in complex that binds steroids, including } \\
\text { androgen }\end{array}$ & $3 /[1]$ \\
\hline SCGB1D2 & secretoglobin, family $1 \mathrm{D}$, member 2 & $\downarrow$ MGD [451] & $\begin{array}{l}\text { in complex that binds steroids, including } \\
\text { androgen }\end{array}$ & $0 /[1]$ \\
\hline SCGB2A1 & $\begin{array}{l}\text { secretoglobin, family } 2 \mathrm{~A} \text {, } \\
\text { member } 1^{\mathrm{b}}\end{array}$ & $\downarrow \uparrow$ ADDE $[409,410,414,424,447], \downarrow$ ADDE/MGD [414] & possibly binds steroids, including androgen & $5 /[N P]$ \\
\hline SCGB2A2 & secretoglobin, family $2 \mathrm{~A}$, member 2 & $\downarrow$ ADDE [447], $\uparrow$ CLDE [408] & cell migration? & $2 /[\mathrm{NP}]$ \\
\hline TCN1 & transcobalamin I & $\downarrow \mathrm{ADDE}[447]$ & binds and helps move vitamin B12 into cells & $1 /[\mathrm{NP}]$ \\
\hline $\mathrm{TF}$ & transferrin & $\begin{array}{r}\downarrow \mathrm{ADDE}[414,450], \uparrow \mathrm{ADDE} / \mathrm{MGD}[414], \uparrow \mathrm{SSDE}[411] \\
\text { Cell Adhesion/Motility/Structure }\end{array}$ & iron binding and transport to proliferating cells & $2 /[1]$ \\
\hline АСТВ & beta actin & $\uparrow \operatorname{MGD}[409], \uparrow \operatorname{SSDE}[411]$ & cell structure, motility & $2 /[N P]$ \\
\hline CFL1 & cofilin 1 & $\uparrow \operatorname{SSDE}[411]$ & cytoskeleton organization & $1 /[\mathrm{NP}]$ \\
\hline LGALS3 & $\begin{array}{l}\text { lectin, galactoside-binding, } \\
\text { soluble } 3\end{array}$ & $\uparrow \mathrm{ADDE}[446]$ & cell adhesion, T cell regulation, antimicrobial & $1 /[\mathrm{NP}]$ \\
\hline LGALS7B & galectin 7 & $\downarrow$ MGD [409] & cell - cell and cell matrix communication & $1 /[\mathrm{NP}]$ \\
\hline MIF & $\begin{array}{l}\text { macrophage migration inhibitory } \\
\text { factor }\end{array}$ & $\uparrow \operatorname{SSDE}[411]$ & chemo attractant and cell communication & $1 /[\mathrm{NP}]$ \\
\hline \multicolumn{5}{|c|}{ Cell Growth } \\
\hline EGF & epidermal growth factor & $\begin{array}{l}\downarrow \uparrow \operatorname{ADDE}[424], \uparrow \operatorname{MGD}[417,431], \uparrow \mathrm{NK}[431], \downarrow \uparrow \mathrm{SSDE} \\
{[430,431,451]}\end{array}$ & mitogen: growth \& differentiation & $1 /[6]$ \\
\hline EGFR & $\begin{array}{l}\text { soluble epidermal growth factor } \\
\text { receptor }\end{array}$ & $\uparrow A D D E[429]$ & transmembrane receptor kinase & $0 /[1]$ \\
\hline GCSF & $\begin{array}{l}\text { granulocyte colony stimulating } \\
\text { factor }\end{array}$ & $\uparrow A D D E[449]$ & colony-stimulating factor & $0 /[1]$ \\
\hline GMCSF & $\begin{array}{l}\text { granulocyte monocyte colony } \\
\text { stimulating factor }\end{array}$ & $\uparrow A D D E[449]$ & colony-stimulating factor & $0 /[1]$ \\
\hline LACRT & lacritin & $\begin{array}{l}\downarrow \text { ADDE }[447], \downarrow \text { ADDE/MGD [414], } \downarrow \text { BL }[443], \\
\downarrow \text { CDK }[445], \downarrow \text { CLDE }[408], \downarrow \text { FK }[441], \downarrow \text { SSDE } \\
{[411,428,452]}\end{array}$ & basal tearing, cell survival, wound healing & $8 /[1]$ \\
\hline NGF & $\begin{array}{l}\text { nerve growth factor (beta } \\
\text { polypeptide) }\end{array}$ & $\uparrow \mathrm{ADDE}[426]$ & neuronal differentiation and growth & $0 /[1]$ \\
\hline \multicolumn{5}{|c|}{ Cytoprotective/Anti-Apoptotic } \\
\hline CASP14 & caspase 14 & $\downarrow$ SSDE $[411]$ & apoptosis induction & $1 /[N P]$ \\
\hline CLU & clusterin & $\uparrow \operatorname{SSDE}[411]$ & inhibits apoptosis & $1 /[\mathrm{NP}]$ \\
\hline MUC5AC & mucin $5 \mathrm{AC}$ & $\downarrow$ ADDE $[368], \downarrow \uparrow \operatorname{SSDE}[270,411]$ & mucus/gel-forming, cytoprotective, hydrophilic & $1 /[2]$ \\
\hline PIP & prolactin-inducible protein & $\begin{array}{l}\downarrow \text { ADDE }[407,409,424,447], \downarrow \text { BL }[443], \uparrow \text { CLDE }[408,453], \\
\downarrow \text { SSDE }[411]\end{array}$ & inhibitor of T-cell apoptosis, aspartyl protease & $8 /[\mathrm{NP}]$ \\
\hline PROL1 & proline rich, lacrimal 1 & $\begin{array}{l}\downarrow \text { ADDE }[414,447], \downarrow \text { ADDE/MGD [414], } \downarrow \text { MGD [414], } \\
\downarrow \text { TAO }[446]\end{array}$ & possible ocular protective function & $3 /[\mathrm{NP}]$ \\
\hline PRR4 & proline rich 4 (lacrimal) & $\begin{array}{l}\downarrow \text { ADDE }[410,414,442,447], \downarrow \text { MGD }[414] \downarrow \text { CLDE }[408], \\
\downarrow \text { SSDE }[411,428], \downarrow \text { TAO }[446]\end{array}$ & possible ocular protective function & $8 /[N P]$ \\
\hline \multicolumn{5}{|c|}{ Immune } \\
\hline C3 & complement component 3 & $\uparrow A D D E[447], \uparrow S S D E[411]$ & complement activation & $2 /[\mathrm{NP}]$ \\
\hline $\mathrm{C} 4 \mathrm{~A}$ & complement component $4 \mathrm{~A}$ & $\uparrow \operatorname{SSDE}[411]$ & cleaved to a trimer for complement activation & $1 /[\mathrm{NP}]$ \\
\hline CCL2 & chemokine ( $\mathrm{C}-\mathrm{C}$ motif) ligand 2 & $\uparrow \operatorname{ADDE}[429,449]$ & monocyte, basophil specific chemotaxis & $0 /[2]$ \\
\hline
\end{tabular}


Table 6 (continued)

\begin{tabular}{|c|c|c|c|c|}
\hline $\begin{array}{l}\text { Gene } \\
\text { Symbol }\end{array}$ & Protein & Change from Normal \& Pathology & Known Function(s) & $\begin{array}{l}\text { \# Articles } \\
\text { US/[CA] }\end{array}$ \\
\hline CCL3 & chemokine ( $\mathrm{C}-\mathrm{C}$ motif) ligand 3 & $\uparrow \operatorname{ADDE}[424], \uparrow \operatorname{SSDE}[424]$ & inflammatory response & $0 /[1]$ \\
\hline CCL4 & chemokine ( $\mathrm{C}-\mathrm{C}$ motif) ligand 4 & $\uparrow \operatorname{ADDE}[424], \uparrow \operatorname{SSDE}[424]$ & inflammatory, chemokinetic & $0 /[1]$ \\
\hline CCL5 & chemokine (C-C motif) ligand 5 & $\uparrow \operatorname{ADDE}[424], \uparrow$ SSDE $[424]$ & chemoattractant, histamine release & $0 /[1]$ \\
\hline CCL11 & chemokine ( $\mathrm{C}-\mathrm{C}$ motif) 11 & $\uparrow \mathrm{ADDE}[449]$ & Eosinophil chemotaxis & $0 /[1]$ \\
\hline CCL15 & chemokine ( $\mathrm{C}-\mathrm{C}$ motif) ligand 15 & $\uparrow A D D E[429]$ & $\begin{array}{l}\text { neutrophil, monocyte, and lymphocyte } \\
\text { chemotaxis }\end{array}$ & $0 /[1]$ \\
\hline CSF3 & $\begin{array}{l}\text { colony stimulating factor } 3 \\
\text { (granulocyte) }\end{array}$ & $\uparrow A D D E[429]$ & $\begin{array}{l}\text { production, different, function of granulocytes, } \\
\text { macrophages }\end{array}$ & $0 /[1]$ \\
\hline CX3CL1 & chemokine ( $\mathrm{C}-\mathrm{X} 3-\mathrm{C}$ motif) ligand 1 & $\uparrow \mathrm{ADDE}[429], \uparrow \mathrm{MGD}[417]$ & neutrophil chemotaxis & $0 /[2]$ \\
\hline CXCL5 & chemokine ( $\mathrm{C}-\mathrm{X}-\mathrm{C}$ motif) ligand 5 & $\uparrow A D D E[429]$ & inflammatory cytokine, neutrophil activation & $0 /[1]$ \\
\hline CXCL8 & chemokine ( $\mathrm{C}-\mathrm{X}-\mathrm{C}$ motif) ligand 8 & $\uparrow \operatorname{ADDE}[427,449]$ & inflammatory mediator & $0 /[2]$ \\
\hline CXCL9 & chemokine ( $\mathrm{C}-\mathrm{X}-\mathrm{C}$ motif) ligand 9 & $\uparrow \operatorname{SSDE}[436]$ & $\mathrm{T}$ cell chemotaxis & $0 /[1]$ \\
\hline CXCL10 & chemokine ( $\mathrm{C}-\mathrm{X}-\mathrm{C}$ motif) ligand 10 & $\uparrow$ SSDE [436], $\uparrow$ MGD [417] & T cell, monocyte chemotaxis & $0 /[2]$ \\
\hline CXCL11 & chemokine ( $\mathrm{C}-\mathrm{X}-\mathrm{C}$ motif) ligand 11 & $\uparrow \operatorname{ADDE}[436], \uparrow \operatorname{SSDE}[436]$ & $\mathrm{T}$ cell chemotaxis & $0 /[1]$ \\
\hline ELANE & neutrophil elastase & $\uparrow$ SSDE $[411]$ & phagocytosis and leukocyte migration & $1 /[\mathrm{NP}]$ \\
\hline IL1B & interleukin 1 beta & $\uparrow \operatorname{ADDE}[423,427,429,449], \uparrow \mathrm{CCH}[415]$ & pro inflammatory response & $0 /[5]$ \\
\hline IL1RN & interleukin 1 receptor antagonist & $\uparrow \operatorname{ADDE}[435,449], \uparrow \operatorname{MGD}[417]$ & cytokine activity & $0 /[3]$ \\
\hline IL1R1 & $\begin{array}{l}\text { interleukin } 1 \text { receptor, type I } \\
\text { (soluble) }\end{array}$ & $\uparrow$ ADDE [429] & immune mediator & $0 /[1]$ \\
\hline IL2 & interleukin 2 & $\uparrow A D D E[427]$ & $\mathrm{T}, \mathrm{B}$ cell proliferation & $0 /[1]$ \\
\hline IL4 & interleukin 4 & $\downarrow$ ADDE $[427,429]$ & immune response, growth factor & $0 /[2]$ \\
\hline IL5 & interleukin 5 & $\uparrow \operatorname{ADDE}[423,427]$ & B cell, eosinophil growth \& differentiation & $0 /[2]$ \\
\hline IL6 & interleukin 6 & $\begin{array}{l}\uparrow \operatorname{ADDE}[423,425,427,429,432], \uparrow \mathrm{CCH}[415], \\
\uparrow \operatorname{MGD}[425], \uparrow \operatorname{SSDE}[411,425]\end{array}$ & B cell, nerve cell differentiation & $1 /[7]$ \\
\hline IL6R & interleukin 6 receptor alpha & $\uparrow \mathrm{ADDE}[429]$ & $\begin{array}{l}\text { regulation of immune response, hematopoiesis., } \\
\text { acute-phase reaction }\end{array}$ & $0 /[1]$ \\
\hline IL6ST & interleukin 6 signal transducer & $\uparrow A D D E[429]$ & shared interleukin transducing receptor subunit & $0 /[1]$ \\
\hline IL-9 & interleukin 9 & $\uparrow \mathrm{ADDE}[449]$ & Cell proliferation, anti-apoptosis & $0 /[1]$ \\
\hline IL10 & interleukin 10 & $\uparrow \mathrm{ADDE}[427]$ & inflammation, immunoregulation & $0 /[1]$ \\
\hline IL12 & interleukin 12 & $\uparrow \operatorname{ADDE}[449], \downarrow$ ADDE [429] & activated $\mathrm{T}$, NK cell mitogen & $0 /[2]$ \\
\hline IL15 & interleukin 15 & $\uparrow \mathrm{ADDE}[449]$ & cell proliferation of natural killer cells & $0 /[1]$ \\
\hline IL16 & $\begin{array}{l}\text { interleukin } 16 \text { (lymphocyte } \\
\text { chemoattractant factor) }\end{array}$ & $\uparrow A D D E[429]$ & $\begin{array}{l}\mathrm{CD}^{+} \text {lymphocyte, monocyte, eosinophil } \\
\text { migration }\end{array}$ & $0 /[1]$ \\
\hline IL17A & interleukin $17 \mathrm{~A}$ & $\downarrow$ ADDE [429] & proinflammatory response & $0 /[1]$ \\
\hline IFNG & interferon, gamma & $\downarrow \uparrow \operatorname{ADDE}[423,427,429]$ & immune-regulatory, antiviral & $0 /[3]$ \\
\hline JCHAIN & $\begin{array}{l}\text { joining chain of multimeric IgA } \\
\text { and IgM }\end{array}$ & $\uparrow \mathrm{CDK}[445]$ & linkage of IgA or IgM monomers & $1 /[\mathrm{NP}]$ \\
\hline IG & Immunoglobulin $\mathrm{G}$ & $\uparrow \mathrm{RA}+\mathrm{SS}[454]$ & Immunoglobulin & $0 /[1]$ \\
\hline ORM1 & orosomucoid 1 & $\uparrow \operatorname{ADDE}[407,414], \uparrow$ ADDE/MGD [414], $\uparrow$ SSDE [411] & modulator of acute-phase immune activity & $3 /[\mathrm{NP}]$ \\
\hline ORM2 & orosomucoid 2 & $\uparrow \operatorname{SSDE}[411]$ & modulator of acute-phase immune activity & $1 /[\mathrm{NP}]$ \\
\hline PEBP1 & $\begin{array}{l}\text { Phosphatidyl-ethanolamine } \\
\text { binding protein } 1\end{array}$ & $\uparrow$ ADDE [414], $\uparrow$ ADDE/MGD [414] & modulates NF-kB in Sjögren syndrome & $1 /[\mathrm{NP}]$ \\
\hline SERPING1 & $\begin{array}{l}\text { serpin peptidase inhibitor clade } A \\
\text { member } 1\end{array}$ & $\uparrow \operatorname{SSDE}[411]$ & complement activation regulator & $1 /[\mathrm{NP}]$ \\
\hline $\begin{array}{l}\text { TGFB } \\
\text { activator }\end{array}$ & $\begin{array}{l}\text { transforming growth factor beta } 1 \\
\& 2 \text { activation }\end{array}$ & $\uparrow \operatorname{SSDE}[420]$ & suppress IL-2 T cell growth & $0 /[1]$ \\
\hline TNF & tumor necrosis factor & $\uparrow \operatorname{ADDE}[423,427,432], \uparrow \operatorname{SSDE}[432]$ & autoimmune, pyrogen, mitogen, differentiation & $0 /[3]$ \\
\hline TNFRSF1B & $\begin{array}{l}\text { soluble TNF receptor superfamily } \\
\text { member } 1 \mathrm{~B}\end{array}$ & $\uparrow A D D E[429]$ & part of TNF receptor heterocomplex & $0 /[1]$ \\
\hline \multicolumn{5}{|c|}{ Lipid/Cholesterol } \\
\hline APOA2 & apolipoprotein A-II & $\uparrow \mathrm{FK}[441], \uparrow \operatorname{SSDE}[411]$ & in high density lipoprotein particles & $2 /[\mathrm{NP}]$ \\
\hline \multicolumn{5}{|c|}{ Other/Unknown } \\
\hline B2M & beta-2-microglobulin & $\uparrow \operatorname{ADDE}[410], \downarrow$ CLDE $[408]$ & $\begin{array}{l}\text { loss associated with hypercatabolic } \\
\text { hypoproteinemia }\end{array}$ & $2 /[\mathrm{NP}]$ \\
\hline POTEI & $\begin{array}{l}\text { POTE ankyrin domain family } \\
\text { member I }\end{array}$ & $\uparrow \mathrm{TAO}[446]$ & $?$ & $1 /[\mathrm{NP}]$ \\
\hline SMR3B & $\begin{array}{l}\text { submaxillary gland androgen } \\
\text { regulator protein } 3 \mathrm{~B}\end{array}$ & $\downarrow$ ADDE [442] & $?$ & $1 /[\mathrm{NP}]$ \\
\hline SOD1 & superoxide dismutase 1 & $\uparrow \operatorname{SSDE}[411]$ & Antioxidant & $1 /[\mathrm{NP}]$ \\
\hline \multicolumn{5}{|c|}{ Phosphatase/Kinase/GTPase/Other Enzyme Phosphatase } \\
\hline F2 & coagulation factor II (thrombin) & $\uparrow \operatorname{SSDE}[428]$ & fibrinogen to fibrin conversion & $1 /[\mathrm{NP}]$ \\
\hline MMP9 & matrix metallopeptidase 9 & $\begin{array}{l}\uparrow \mathrm{ADDE}[415], \uparrow \mathrm{BL}[415], \uparrow \mathrm{CCH}[415], \uparrow \mathrm{MGD}[433], \\
\uparrow \operatorname{PLDE}[421], \uparrow \operatorname{SSDE}[433]\end{array}$ & matrix collagen IV and V degradation & $0 /[3]$ \\
\hline S100A8 & $\begin{array}{l}\text { S100 calcium binding protein A8 } \\
\text { (calgranulin } \mathrm{A} \text { ) }\end{array}$ & $\begin{array}{l}\uparrow \operatorname{ADDE}[407,409,410,414,424,442,446], \uparrow \operatorname{SSDE}[411], \\
\uparrow \operatorname{MGD}[414,448], \downarrow \text { TAO }[446]\end{array}$ & $\begin{array}{l}\text { cytokine \& inhibitor of casein kinase/ } \\
\text { Inflammation }\end{array}$ & $9 /[N P]$ \\
\hline S100A9 & $\begin{array}{l}\text { S100 calcium binding protein A9 } \\
\text { (calgranulin B) }\end{array}$ & $\begin{array}{l}\uparrow \mathrm{ADDE}[407,409,414,424], \uparrow \mathrm{ADDE} / \mathrm{MGD}[414] \uparrow \mathrm{SSDE} \\
{[423], \uparrow \mathrm{MGD}[414,448]}\end{array}$ & possible inhibitor of casein kinase & $6 /[N P]$ \\
\hline \multicolumn{5}{|c|}{ Protease inhibitor/Antimicrobial } \\
\hline AZU1 & $\begin{array}{l}\text { azurocidin } 1 \text { (cationic antimicrobial } \\
\text { protein } 37 \text { ) }\end{array}$ & $\uparrow \operatorname{SSDE}[411]$ & antibacterial and monocyte chemoattractant & $1 /[\mathrm{NP}]$ \\
\hline CST1 & cystatin SN & $\uparrow \mathrm{ADDE}[423], \downarrow$ MGD $[409]$ & cysteine protease inhibitor & $1 /[1]$ \\
\hline CST4 & cystatin $\mathrm{S}$ & $\begin{array}{l}\downarrow \text { ADDE [447], } \downarrow \text { BL [443], } \downarrow \text { FK [441], } \downarrow \text { MGD [409], } \\
\downarrow \text { SSDE [428] }\end{array}$ & cysteine protease inhibitor/antimicrobial & $5 /[\mathrm{NP}]$ \\
\hline CTSB & cathepsin B & $\downarrow$ SSDE $[428]$ & lysosomal cysteine protease & $1 /[\mathrm{NP}]$ \\
\hline CTSS & cathepsin S & $\uparrow \operatorname{SSDE}[455]$ & lysosomal cysteine protease & $0 /[1]$ \\
\hline
\end{tabular}


Table 6 (continued)

\begin{tabular}{|c|c|c|c|c|}
\hline $\begin{array}{l}\text { Gene } \\
\text { Symbol }\end{array}$ & Protein & Change from Normal \& Pathology & Known Function(s) & $\begin{array}{l}\text { \# Articles } \\
\text { US/[CA] }\end{array}$ \\
\hline DCD & dermcidin & $\uparrow \operatorname{SSDE}[411]$ & C-terminal antibacterial, N-terminal prosurvival & $1 /[\mathrm{NP}]$ \\
\hline IGHA1 & $\begin{array}{l}\text { immunoglobulin heavy constant } \\
\text { alpha } 1\end{array}$ & $\downarrow$ SSDE [411] & microbial and foreign antigen defense & $1 /[\mathrm{NP}]$ \\
\hline IGKV3-20 & $\begin{array}{l}\text { immunoglobulin kappa variable 3- } \\
20\end{array}$ & $\downarrow \mathrm{BL}[443]$ & microbial and foreign antigen defense & $1 /[\mathrm{NP}]$ \\
\hline IGLC2 & immunoglobulin lambda constant 2 & $\downarrow \mathrm{ADDE}[447]$ & microbial and foreign antigen defense & $1 /[\mathrm{NP}]$ \\
\hline LTF & lactoferrin & $\begin{array}{l}\downarrow \text { ADDE }[409,424,444,450], \uparrow \text { FK }[441], \downarrow \text { MGD }[451], \\
\downarrow \text { SSDE }[411,430,433]\end{array}$ & iron metabolism, antibacterial & $6 /[4]$ \\
\hline LYZ & lysozyme & $\downarrow$ ADDE $[407,447,450], \downarrow$ BL $[443], \downarrow$ SSDE $[411]$ & hydrolase, antibacterial & $5 /[\mathrm{NP}]$ \\
\hline PIGR & $\begin{array}{l}\text { polymeric immunoglobulin } \\
\text { receptor }\end{array}$ & $\downarrow$ ADDE [447], $\downarrow$ CDK [445], $\downarrow$ SSDE $[411]$ & $\begin{array}{l}\text { antibacterial, polymeric Ig transcellular } \\
\text { transport }\end{array}$ & $3 /[\mathrm{NP}]$ \\
\hline PLG & plasminogen & $\uparrow S S D E[434]$ & $\begin{array}{l}\text { activates urokinase-type plasminogen activator, } \\
\text { collagenase }\end{array}$ & $1 /[\mathrm{NP}]$ \\
\hline S100A7 & $\begin{array}{l}\text { s100 calcium binding protein A7 } \\
\text { (psoriasin) }\end{array}$ & $\uparrow \operatorname{SSDE}[411]$ & chemotactic, antibacterial & $1 /[\mathrm{NP}]$ \\
\hline SERPINA1 & $\begin{array}{l}\text { serpin peptidase inhibitor clade A } \\
\text { member } 1\end{array}$ & $\uparrow$ ADDE $[423,442], \downarrow$ BL $[443], \uparrow$ FK $[441]$ & serine protease inhibitor, anti-inflammatory & $3 /[1]$ \\
\hline
\end{tabular}

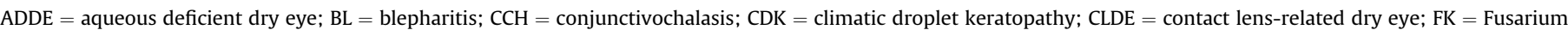

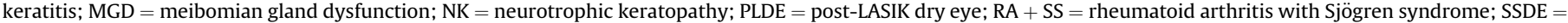
Sjögren syndrome-associated dry eye; TAO = thyroid-associated orbit pathology.

a Also known as lipophilin A.

b Also known as mammaglobin B, mammaglobin 2 \& lipophilin C.

unbiased MS/MS screens may indeed be the most promising, then future priority could be given to the extracellular biomarkers that have been commonly found by MS/MS screening and, with the exception of LTF and LYZ, have not been subjected to this kind of analysis.

Poor efficacy of anti-inflammatory agents for dry eye highlights the need for new therapeutic strategies [478]. Some biomarkers all extracellular ones deficient in dry eye - have shown benefits for ocular surface homeostasis and/or tearing in preclinical and, in some cases, clinical situations. Albumin [479], lactoferrin [480] and lacritin [481] each have prosurvival and wound healing activities $[479,482]$. When applied topically, albumin was reported to provide symptom relief in most dry eye patients with graft versus host disease [483]. Lactoferrin can promote healing of damaged human corneal epithelial cells in culture [484]. In a mouse corneal alkali injury model, topical lactoferrin protected corneal epithelial cells from hydrogen peroxide oxidative damage [485], and when fed to one year old mice, reportedly reduced inflammation of both lacrimal glands and the conjunctiva, and reduced oxidative stress [486]. A lactoferrin supplement was recently reported to increase tearing in a randomized double blind placebo controlled dry eye study in humans [487], and to restore tearing and TBUT in a randomized controlled study of cataract surgery-induced dry eye [488]. Topical lacritin reduced corneal staining in the Aire ${ }^{-/-}$mouse model of dry eye [489] and promoted the health of cultured human corneal epithelial cells exposed to interferon gamma and tumor necrosis factor [481] or to benzalkonium chloride [490]. Normal human tears immunodepleted of lacritin lacked cell survival activity. Spiking lacritin, but not the truncation mutant C-25, into ADDE tears restored cell survival activity [481]. Topical lacritin, but not C-25, promoted basal tearing when applied topically to eyes of normal rabbits [491]. Topical lacritin (discovered out of an unbiased screen for factors that promote basal tearing) [438] also restored tearing in Aire ${ }^{-/-}$dry eye mice [489]. Tear film stability is enhanced by interaction of lysozyme with the tear protein vitelline membrane outer layer protein 1 homolog (VMO1) [492].

A successful biomarker(s) should facilitate the prognosis, diagnosis and monitoring of ocular surface disease in patients. It should also aid in the development of new therapeutics. Several individual biomarkers have been proposed, including lysozyme and lactoferrin [159], and MMP-9 [421]. Grouping biomarkers into an optimized panel may offer superior sensitivity and sensitivity (Table 8) $[407,409,410,421,442,450,493]$, as revealed by Receiver Operating Characteristic (ROC) curve analysis which plots true positive (sensitivity) and false positive (specificity) rates respectively on yand $\mathrm{x}$-axes. The Area Under the upward rising Curve (AUC) is a measure of test accuracy, with a perfect test having an AUC value of 1 , but is surprisingly lacking for several assayed biomarkers (Table 8). However, all these markers require further validation in independent studies and cohorts of participants from different geographic populations, age and etiology of DED. Panels in their present form require mass spectrometry, an approach currently not appropriate for day-to-day patient analysis. Evolution of panels into an integrated immunological assay holds considerable promise.

Biomarkers should help identify and screen out individuals at risk of developing DED prior to refractive eye surgery, that itself can promote extended dryness. To date, biomarker analysis has been carried out after LASIK $[421,494]$ but not before. Prophylactic treatment for at risk individuals might also be possible, for example treatments that promote natural basal tearing, ocular surface homeostasis and corneal sensory innervation. Similarly, diagnosis of the type [409] and severity $[407,410,430,432,444,450]$ of dry eye, or other ocular surface pathology [446], should become much more precise. One can also imagine a precision medicine approach to dry eye, whereby deficiency of one or several functionally-relevant tear proteins is topically corrected. Follow up of patients may also be more accurate, such as monitoring of tear MMP-9 after surgery for conjunctivochalasis [418], or for monitoring the increase of tear lacritin, lysozyme and prolactin-inducible protein, and decrease of enolase 1 (alpha), S100A6 and S100A11 coincident with reduced ocular surface inflammation one year after switching patients from preserved latanoprost to preservative-free tafluprost for glaucoma [495].

Currently, the only commercial options to investigate tear film biomarkers are Inflammadry ${ }^{\mathbb{B}}$ (MMP-9) and TearScan ${ }^{\mathrm{TM}}$ Lactoferrin Diagnostic Test Kit. Inflammadry detects $\sim 40 \mathrm{ng} / \mathrm{ml}$ or more MMP9 , with indicated sensitivity and specificity values respectively of 85 and $94 \%$, and negative and positive predictive values respectively of 
Table 7

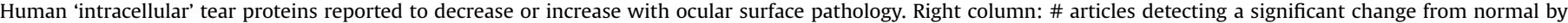

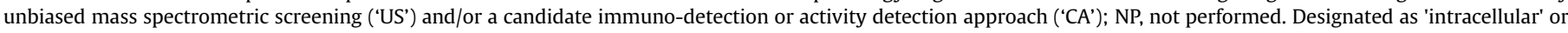
associated with the 'plasma membrane' by Gene Ontology.

\begin{tabular}{|c|c|c|c|c|}
\hline $\begin{array}{l}\text { Gene } \\
\text { Symbol }\end{array}$ & Protein & Change from Normal \& Pathology & Known Function(s) & $\begin{array}{l}\text { \# Articles with } \\
\text { Change } \\
\text { from Normal: US/ } \\
\text { [CA] }\end{array}$ \\
\hline \multicolumn{5}{|c|}{ Regulation of transcription/Nucleic acid metabolism } \\
\hline BAZ2B & $\begin{array}{l}\text { bromodomain adjacent to zinc finger } \\
\text { domain } 2 \mathrm{~B}\end{array}$ & $\uparrow \mathrm{ADDE}[444]$ & likely transcription regulator activity & $1 /[\mathrm{NP}]$ \\
\hline MDN1 & midasin AAA ATPase 1 & $\uparrow \mathrm{TAO}[446]$ & ribosome maturation & $1 /[\mathrm{NP}]$ \\
\hline RREB1 & $\begin{array}{l}\text { ras responsive element binding protein } \\
1^{\text {a }}\end{array}$ & $\uparrow \mathrm{ADDE}[444]$ & zinc finger transcription factor & $1 /[\mathrm{NP}]$ \\
\hline SMARCA4 & Transcription activator BRG1 & $\uparrow \mathrm{ADDE}[446], \downarrow$ TAO $[446]$ & transcription regulation & $1 /[\mathrm{NP}]$ \\
\hline \multicolumn{5}{|c|}{ Cell communication/Signal transduction } \\
\hline ANXA11 & annexin A11 & $\uparrow \operatorname{ADDE}[409], \uparrow S S D E[411]$ & calcium-dependent phospholipid binding protein & $2 /[\mathrm{NP}]$ \\
\hline PLAA & phospholipase A2-activating protein & $\uparrow \mathrm{ADDE}[409]$ & secosteroid $1 \alpha, 25$-dihydroxy vitamin D3 signaling & $1 /[\mathrm{NP}]$ \\
\hline S100A6 & S100 calcium binding protein $\mathrm{A}^{\mathrm{b}}$ & $\uparrow \operatorname{ADDE}[409], \uparrow \operatorname{SSDE}[411]$ & calcium binding/epithelial integrity, growth & $2 /[1]$ \\
\hline S100A11 & S100 calcium binding protein $\mathrm{A} 11^{\mathrm{C}}$ & $\uparrow \operatorname{ADDE}[407], \uparrow \operatorname{SSDE}[411]$ & calcium ion binding & $2 /[\mathrm{NP}]$ \\
\hline S100A12 & S100 calcium-binding protein $\mathrm{A} 12^{\mathrm{d}}$ & $\uparrow \operatorname{SSDE}[411]$ & proinflammatory, calcium binding & $1 /[\mathrm{NP}]$ \\
\hline TGFA & transforming growth factor alpha & $\uparrow \mathrm{ADDE}[429]$ & $\begin{array}{l}\text { targets EGFR to stimulate cell differentiation and } \\
\text { proliferation }\end{array}$ & $0 /[1]$ \\
\hline \multicolumn{5}{|c|}{ Cell growth and/or maintenance } \\
\hline S100A4 & S100 calcium binding protein A4 & $\uparrow \mathrm{ADDE}[407,409]$ & calcium binding possibly in cell motility, invasion & $2 /[1]$ \\
\hline \multicolumn{5}{|c|}{ Cytoprotective/Anti-Apoptotic } \\
\hline ALDH3A1 & aldehyde hydrogenase 3A1 & $\uparrow \mathrm{ADDE} / \mathrm{MGD}[414]$ & promotes survival of corneal epithelial cells & $1 /[\mathrm{NP}]$ \\
\hline HSPB1 & $\begin{array}{l}\text { heat shock protein family } \mathrm{B} \text { (small) } \\
\text { member } 1\end{array}$ & $\uparrow \operatorname{ADDE}[446]$ & stress resistance, organization of actin & $1 /[\mathrm{NP}]$ \\
\hline \multicolumn{5}{|c|}{ Metabolism/Energy pathways } \\
\hline ANXA1 & annexin A1 & $\uparrow \operatorname{ADDE}[409,424,446], \uparrow \operatorname{SSDE}[411]$ & inhibits phospholipase a2, anti-inflammatory & $4 /[\mathrm{NP}]$ \\
\hline GSTP1 & glutathione S-transferase pi 1 & $\uparrow \mathrm{ADDE}[409], \uparrow \mathrm{CCH}[472]$ & $\begin{array}{l}\text { links reduced glutathione to electrophilic \& } \\
\text { hydrophobic molecules }\end{array}$ & $2 /[\mathrm{NP}]$ \\
\hline PRDX5 & peroxiredoxin 5 & $\uparrow \mathrm{ADDE}[409], \uparrow \mathrm{CCH}[472]$ & $\begin{array}{l}\text { antioxidant, reduces hydrogen peroxide and alkyl } \\
\text { hydroperoxide }\end{array}$ & $2 /[\mathrm{NP}]$ \\
\hline PLA2G2A & phospholipase A2 group IIA & $\uparrow \operatorname{ADDE}[470]$ & hydrolysis of phosphoglycerides & $0 /[1]$ \\
\hline \multicolumn{5}{|c|}{ Transport } \\
\hline AQP5 & aquaporin 5 & $\uparrow \operatorname{ADDE}[430], \uparrow \operatorname{SSDE}[430]$ & $\begin{array}{l}\text { tear, saliva, pulmonary secretion; water } \\
\text { channel protein }\end{array}$ & $0 /[1]$ \\
\hline \multicolumn{5}{|c|}{ Immune response } \\
\hline IL1A & interleukin 1 alpha & $\begin{array}{l}\uparrow \mathrm{ADDE}[425,433], \uparrow \mathrm{MGD}[433], \uparrow \mathrm{S} \\
{[433,464]}\end{array}$ & hematopoiesis, immune response, inflammation & $0 /[3]$ \\
\hline IL33 & interleukin 33 & $\uparrow \operatorname{ADDE}[429]$ & $\begin{array}{l}\text { Th2 cell mat; mast/natural killer cell, basophil, } \\
\text { eosinophil activator }\end{array}$ & $0 /[1]$ \\
\hline
\end{tabular}

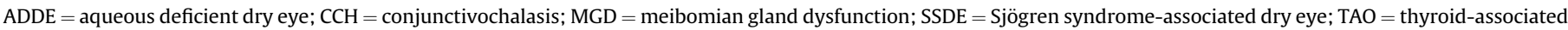
orbitopathy.

a Also known as zinc finger motif enhancer-binding protein 1.

b Also known as calcyclin.

c Also known as calgizzarin.

d Also known as calgranulin C.

73\% and 97\% [493]. Clinical studies suggest specificity and sensitivity of $80 \%$ in patients with pseudoexfoliation syndrome [496], positive agreement of $81 \%$ and a negative agreement of $98 \%$ in dry eye patients [497], and 57\% detection of MMP-9 in post-LASIK dry eye patients [421]. However, in a population with no previous diagnosis of DED and who were classified as having mild dry eye in the study, the Inflammadry assay was positive for only $11 \%$ of subjects with symptoms of dry eye [498], and in a study of symptomatic (DEQ-5 $\geq 6$ ) subjects, only $39 \%$ tested positive with the Inflammadry test [499]. These data suggest that the Inflammadry test is better at detecting moderate to severe dry eye subjects. The lactoferrin assay has indicated sensitivity and specificity values, respectively, of 83 and $98 \%$, and precision of $<9 \%$ coefficient of variation. Both are semi-quantitative assays.

Proteomics and biomarker cell biology are progressively transforming ocular surface clinical research. From proteomics, new immunoassays will enhance prognosis and diagnosis. From cell biology, new therapeutics should emerge. Proteomic discovery will continue to be challenged by the nine orders of magnitude between the most $(\mathrm{mg} / \mathrm{mL})$ and least $(\mathrm{pg} / \mathrm{mL})$ abundant proteins [500]. Development of multiplexed systems that allow simultaneous quantification of several biomarkers in a single tear sample (commercially available only thus far for cytokines, interleukins and metalloproteinases - although development work is underway) [446,501-503], and coordinated clinical validation studies are needed. More information is needed on biomarker dynamic range, cut-off definition, specificity, sensitivity, positive predictive value and negative predictive value, and linkage of biomarker detection to treatment.

Lagging behind immunoassay and discovery is an appreciation for the biology of biomarkers. Are there disease modifications, such as glycosylation, methylation, acetylation or covalent cross-linking, and disease-upregulated slice variants? N-glycosylation in climatic droplet keratopathy was the subject of one MS/MS study [445] and Perumal et al. [504] discovered different methylated isoforms of proline-rich protein 4 in tears for which disease or functional implications are unknown. Cross-linking by tissue transglutaminase (TGM2) in tears may play an important disease role, as conjunctival expression of TGM2 is elevated both in Sjögren syndrome and MGD [505], and substrates include S100A7, annexin A1, alpha-2-HSglycoprotein, enolase 1 , actin, beta-2-microglobulin, plasminogen [506], and lacritin [507]. Notably, TGM2 constitutively inactivates 
Table 8

Diagnostic power of individual and panels of biomarkers for dry eye discrimination relative to normal controls.

\begin{tabular}{|c|c|c|c|c|c|c|c|c|c|c|}
\hline $\begin{array}{l}\text { Biomarker } \\
\text { (reference) }\end{array}$ & Dry Eye & $\begin{array}{l}\text { Number of } \\
\text { subjects } \\
\text { (dry-eye/ } \\
\text { normal) }\end{array}$ & AUC & $\mathrm{CA}(\%)$ & $\begin{array}{l}\text { Sensitivity } \\
(\%)\end{array}$ & $\begin{array}{l}\text { Specificity } \\
(\%)\end{array}$ & PPV & NPV & Technique & Reference \\
\hline \multicolumn{11}{|c|}{ Individual } \\
\hline ALB & ADDE & $160 / 45$ & 0.729 & - & 42.5 & 90.9 & 97.1 & - & $\begin{array}{l}\text { Protein LabChip } \\
\text { Bionalyzer }\end{array}$ & Versura et al., 2013 [450] \\
\hline ANXA1 & ADDE & $63 / 43$ & - & 89.7 & 92.0 & 85.6 & - & - & $\begin{array}{l}\text { 2D-PAGE/ } \\
\text { MALDI-TOF MS }\end{array}$ & Soria et al., 2013 [409] \\
\hline ANXA11 & ADDE & $63 / 43$ & - & 76.0 & 84.0 & 61.6 & - & - & $\begin{array}{l}\text { 2D-PAGE/ } \\
\text { MALDI-TOF MS }\end{array}$ & Soria et al., 2013 [409] \\
\hline AZGP1 & ADDE & $160 / 45$ & 0.759 & - & 56.9 & 87.5 & 81.8 & - & $\begin{array}{l}\text { Protein LabChip } \\
\text { Bionalyzer }\end{array}$ & Versura et al., 2013 [450] \\
\hline CST4 & ADDE & $63 / 43$ & - & 67.7 & 90.2 & 27.2 & - & - & $\begin{array}{l}\text { 2D-PAGE/ } \\
\text { MALDI-TOF MS }\end{array}$ & Soria et al., 2013 [409] \\
\hline ENO1 & ADDE & $56 / 40$ & 0.850 & - & 77.0 & 88.5 & - & - & ITRAQ & Zhou et al., 2009 [407] \\
\hline LCN1 & ADDE & $160 / 45$ & 0.843 & - & 65.5 & 94.9 & 97.1 & - & $\begin{array}{l}\text { Protein LabChip } \\
\text { Bionalyzer }\end{array}$ & Versura et al., 2013 [450] \\
\hline LTF & ADDE & $160 / 45$ & 0.812 & - & 44.2 & 93.2 & 94.5 & - & $\begin{array}{l}\text { Protein LabChip } \\
\text { Bionalyzer }\end{array}$ & Versura et al., 2013 [450] \\
\hline LYZ & ADDE & $160 / 45$ & 0.826 & - & 57.8 & 96.6 & 97.9 & - & $\begin{array}{l}\text { Protein LabChip } \\
\text { Bionalyzer }\end{array}$ & Versura et al., 2013 [450] \\
\hline \multirow[t]{3}{*}{ MMP9 } & ADDE & $143 / 63$ & - & - & 85.0 & 94.0 & 97.0 & 73.0 & Immunocapture & $\begin{array}{l}\text { Sambursky et al., } \\
2013 \text { [493] }\end{array}$ \\
\hline & ADDE & $146 / 91$ & - & - & 81.0 & 98.0 & - & - & Immunocapture & $\begin{array}{l}\text { Sambursky et al., } \\
2014 \text { [497] }\end{array}$ \\
\hline & PLDE & $14 / 34$ & - & - & 57.1 & - & - & - & Immunocapture & Chan et al., 2015 [421] \\
\hline PIP & ADDE & $56 / 40$ & 0.810 & - & 71.7 & 87.1 & - & - & ITRAQ & Zhou et al., 2009 [407] \\
\hline PLAA & ADDE & $63 / 43$ & - & 92.3 & 94.2 & 88.0 & - & - & $\begin{array}{l}\text { 2D-PAGE/ } \\
\text { MALDI-TOF MS }\end{array}$ & Soria et al., 2013 [409] \\
\hline PRDX5 & ADDE & $63 / 43$ & - & 75.1 & 91.6 & 45.6 & - & - & $\begin{array}{l}\text { 2D-PAGE/ } \\
\text { MALDI-TOF MS }\end{array}$ & Soria et al., 2013 [409] \\
\hline S100A6 & ADDE & $63 / 43$ & - & 90.6 & 93.8 & 84.8 & - & - & $\begin{array}{l}\text { 2D-PAGE/ } \\
\text { MALDI-TOF MS }\end{array}$ & Soria et al., 2013 [409] \\
\hline $\mathrm{TF}$ & ADDE & $160 / 45$ & 0.885 & - & 70.8 & 96.7 & 98.1 & - & $\begin{array}{l}\text { Protein LabChip } \\
\text { Bionalyzer }\end{array}$ & Versura et al., 2013 [450] \\
\hline \multicolumn{11}{|c|}{ Panel } \\
\hline $\begin{array}{l}\text { PRR4, S100A8, } \\
\text { SERPINA1, } \\
\text { SMR3B plus } \\
\text { two unknowns } \\
(3700 \text { and } 3916 \mathrm{Da})\end{array}$ & ADDE & $88 / 71$ & 0.93 & - & 90.0 & 90.0 & - & - & SELDI-TOF-MS & Grus et al., 2005 [442] \\
\hline $\begin{array}{l}\text { ENO1, PIP, } \\
\text { LCN1, S100A9 }\end{array}$ & ADDE & $56 / 40$ & 0.96 & - & 91.0 & 90.0 & - & - & ITRAQ & Zhou et al., 2009 [407] \\
\hline $\begin{array}{l}\text { ANXA1, ANXA11, } \\
\text { CST4, PLAA, } \\
\text { S100A6 }\end{array}$ & ADDE & $63 / 43$ & 1.00 & 94.6 & 96.0 & 92.0 & - & - & $\begin{array}{l}\text { 2D-PAGE/MALDI-TOF } \\
\text { MS }\end{array}$ & Soria et al., 2013 [409] \\
\hline $\begin{array}{l}\text { B2M, PRR4 } \\
\text { (4043 \& } 4078 \text { Da) } \\
\text { S100A8, SCGB1D1, } \\
\text { SCGB2A1 }\end{array}$ & $\begin{array}{l}\text { ADDE } \\
\text { MGD }\end{array}$ & $\begin{array}{l}40 / 39 \\
40 / 39\end{array}$ & $\begin{array}{l}1.00 \\
1.00\end{array}$ & - & $\begin{array}{l}100.0 \\
100.0\end{array}$ & $\begin{array}{l}100.0 \\
100.0\end{array}$ & - & - & SELDI-TOF-MS & Boehm et al., 2013 [410] \\
\hline
\end{tabular}

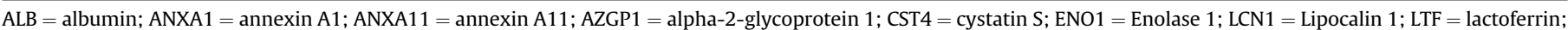

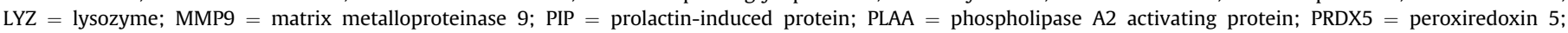

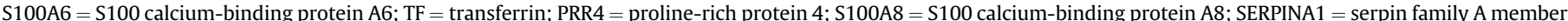

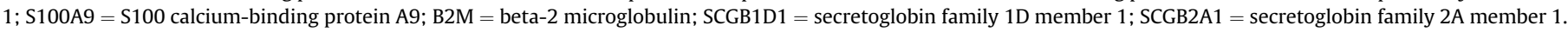
$\mathrm{ADDE}=$ aqueous deficient dry eye; MGD - meibomian gland dysfunction

lacritin's C-terminal 'business end' necessary for cell targeting [507], and more higher order protein complexes have been noted in dry eye [508], the latter also perhaps from mis-folding as a potential new direction in dry eye research.

\subsection{Lipid-protein-mucin interactions}

Secreted mucins may have an active role in lipid organization at the surface of the tear film [296,509] and phospholipid transfer protein functions to scavenge lipophilic substances from ocular mucins [510], but data supporting a direct interaction between mucins and lipids are lacking. In the epithelial glycocalyx, the transmembrane mucins MUC1 and MUC16 bind galectin-3 to promote ocular surface barrier function [382]. This interaction is dependent on the surface recognition carbohydrate residues and the capacity of galectin-3 to form surface lattices [511]. The altered mucin glycosylation observed in DED could lead to loss of galectin3 binding affinity and release of cellular galectin-3 into the tear film. This hypothesis is supported by increased shed galectin-3 levels in dry eye tears concomitant with a galectin-3 proteolytic cleavage product with the potential to impair proper barrier function [383]. Clusterin, a cytoprotective chaperone, inhibits MMP-9 [512] and interacts with galectin-3 to ameliorate ocular surface barrier disruption by a sealing mechanism on the ocular surface [513]. Elevated levels of MMP-9 have been linked to epithelial barrier disruption.

The dominant lipid binding protein in tears is lipocalin-1 [255,514,515]. Lipocalin-1 (previously known as tear prealbumin) can bind a broad range of lipid ligands such as fatty acids, cholesterol and phosphatidyl lipids, but has a low affinity for 
lysophospholipids $[515,516]$. Lipocalin stabilizes the tear film by both scavenging lipids from the hydrophobic ocular surface into the mucoaqueous layer [517], and by interacting with tear polar lipids to reduce surface tension [286]. Whether lipocalin-1 is altered in ADDE is uncertain (Table 6). It is increased in tears of intolerant contact lens wearers [518], but decreased in tears of patients with MGD [468] and Sjögren syndrome [519] (Table 6).

Other proteins known to interact with lipids in the tear film include the tear surfactant proteins B and C [520], apolipoprotein D [521], lysozyme [299], keratins [300], secretoglobins (also known as lipophilins, mammaglobins, lacryglobin and uteroglobins) [522-524] and phospholipid transfer protein [525]. Of these, only levels of lysozyme are altered in dry eye (down in ADDE and Sjögren syndrome dry eye, and in blepharitis - see Table 6).

Some soluble tear proteins interact with the epithelial cell surface to help promote ocular surface health. Lacritin is a multifunctional tear protein that in its monomeric form [507] binds cell surface heparan sulfate proteoglycan syndecan-1 [526] to promote basal tear secretion [438]. Binding of lacritin to syndecan-1 is dependent on heparanase modification of heparan sulfate to expose both a 3-O-sulfate site in cleaved heparan sulfate and the core protein sequence GAGAL [527]. Tear levels of active lacritin monomer are reduced in all forms of dry eye (Table 6) and in blepharitis [443]. Further, the levels of heparan sulfotransferases are downregulated in conjunctival cells from dry eye patients [376], which could influence heparanase cleavage and/or lacritin binding of syndecan-1 [527]. Vitelline membrane outer layer 1 homolog has been shown to interact with lysozyme and stabilize the tear film [492], but the relevance of this interaction to DED has not been yet established.

\subsection{The tear metabolome}

The aim of metabolomics is to identify, determine, interpret, and quantify the complex time-related concentration, activity, and flux of endogenous metabolites in cells, tissues, and other biosamples [528]. The mucoaqueous layer of the tear film contains electrolytes (such as sodium, potassium, calcium, magnesium, chlorine, phosphate, bicarbonate), protein fragments as peptides, and metabolites (such as amino acids, urea, glucose, lactate). Because the levels of the latter are low (confounded by low volumes of sample), the tear metabolome is poorly characterized [529].

The main analytical techniques implemented in metabolomics analysis are proton nuclear magnetic resonance spectroscopy $\left({ }^{1} \mathrm{H}\right.$ NMR) [530,531], MS, gas chromatography, and liquid chromatography-MS (LC-MS) [532,533]. Following informationdependent acquisition, directed liquid chromatography/tandem mass spectrometry (LC-MS/MS) coupled to peak mining can be performed, using isotope pattern matching [534]. NMR and GC-MS (gas chromatography mass spectrometry) offer high reproducibility and straightforward identification of metabolites. NMR is nondestructive, requires minimal sample preparation and offers the benefit of obtaining quantitative data simultaneously. However, it is the least sensitive of the above techniques and may be biased toward the detection of high-abundance metabolites.

The analysis includes extraction of metabolites, chromatographic separation and acquisition of data. Post-acquisition data processing typically comprises peak detection and alignment, followed by chemometric analysis to identify the marker ions. Metabolites are then identified through database searches, and their identities are confirmed by comparison of retention time and tandem mass spectra with pure standards [535]. However, no analytical platform can resolve and detect all the metabolites in a sample [534].

The study of tear metabolite profiling is of particular interest, as metabolomics provides an insight into the dynamic biochemical processes occurring in biological systems [536]. The most comprehensive description of human tear metabolome has been published by Chen et al., [534] who identified 60 metabolites representing diverse compound classes, of which 16 had been previously reported. To date, 85 metabolites have been identified in the tears of normal human subjects, 41 previously reported [537-546] and 44 newly reported by Chen et al. [534].

Healthy and dry eye tears display differences. Reduced levels of carnitine in dry eye patients appear to associate with low retention of water in the mucoaqueous layer. This may contribute to hyperevaporation associated with hyperosmolarity [542]. Nakatsukasa et al. [537] have identified 23 amino acids in healthy subjects and found reduced levels of taurine, methionine, and arginine in the severe dry eye patients, in comparison with those in healthy individuals, relative to a change to total amino acid concentration. The concentration of diadenosine polyphosphates increases in tears from dry eye subjects and those with Sjögren syndrome [547,548].

Most recently, differences between the metabolomic profiles of reflex tears in patients with mild-to-moderate and moderate DED and healthy subjects have been analyzed using ${ }^{1} \mathrm{H}$ NMR spectroscopy [530]. Differences between tear metabolite levels were found for cholesterol, $\mathrm{N}$-acetylglucosamine, glutamate, creatine, aminon-butyrate, choline, acetylcholine, arginine, phosphoethanolamine, glucose, and phenylalanine (Table 9). The healthy subjects had elevated concentration of glycoproteins, lipids, cholesterol, leucine, glycerol, and glutamate in comparison with dry eye patients. In the dry eye samples, an increase in glucose and lactate and a decrease in formic acid and $\mathrm{N}$-acetylglucosamine levels were found. Increased levels of serotonin have been correlated with dry eye signs and symptoms and higher concentrations of this neurotransmitter have been found in symptomatic ADDE tears compared to tears of symptomatic dry eye patients with normal tear production [549].

Finally, the effect of antioxidants and polyunsaturated fatty acid oral treatments on the profile of reflex tear metabolites has been demonstrated [531]. The metabolomics methods have some limitations for the study of human tears and further studies are required to broaden our knowledge of the tear metabolome. However, it is clear that the metabolome reflects the status of local and systemic biological processes, opening new routes of identification of potential biomarkers for disease diagnosis and treatment monitoring.

\section{Translational dry eye animal models of tear film}

There are several genetic, surgically or dry chamber/druginduced models of DED in different species [489,550-554]. The most characterized model is the desiccating stress murine model without or with prior injection of scopolamine to block parasympathetic stimulation of tear secreting machinery [555-574]. In this dry eye mouse desiccating stress model, the levels of several tear cytokines and chemokines and some others molecules increase as a result of dry eye induction (Table 10). These changes are similar to those found in human tears (although not always evaluated with the same techniques; see Table 6) [407,409-411,415,424,425,427,429,432,442,444,446,447,450]. Some, such as IL-17, do not always behave similarly [429]. The regulatory effects of cytokines and chemokines in tears have been observed after depletion of antigen presenting cells in mice [566]. It should be noted that the most commonly expressed mRNAs in mouse and human lacrimal gland differ substantially [575].

Zhou et al. [576] have reported on similarities to human dry eye tear protein expression in a rabbit model of Sjögren syndromeassociated dry eye induced autoimmune dacryoadenitis 
(Table 10). The expression of S100A6, S100A9, and serum albumin was upregulated in this model, whereas TF, PIP, polymeric immunoglobulin receptor (pIgR) and Ig gamma chain $C$ region were downregulated. In this animal model, the changes in the expression of S100A6, TF, PIP, and pIgR were verified. The protein pIgR may be unique to Sjögren syndrome, while the remaining proteins were also found in the tears of non-Sjögren syndrome dry eye patients $[407,409,448]$.

The Harderian gland, that releases secretions onto the ocular surface and fills the orbit of all animals with the exception of primates, is a potential complicating factor that is largely often overlooked. Butovich et al. [577] have compared the mouse, canine, rabbit, and human meibum lipidomes using HPLC and GLC. This study demonstrated that mouse and human meibomian lipidomes are most closely matched, and the canine lipidome is the second closest. Thus, the rabbit is not the best model of the human tear film for studying the lipidome biochemistry and biophysics [577].

Some progress has also been made in the search for appropriate dry eye models with respect to severity. Three rabbit dry eye models for mild (lacrimal gland and nictitating membrane removal), moderate (conjunctival burn with 50\% trichloroacetic acid), and severe manifestations of dry eye (combination of both methods), have been developed [578]. However, there is a lack of studies analyzing tear instability in these models [579].

\section{Non-pathophysiological factors impacting the tear film}

\subsection{Contact lenses}

Contact lens wear increases the risk of developing dry eye from between 2.01 and 2.96 times [580-582]. Contact lenses compartmentalize the tear film into two layers; the outer pre-lens tear film layer in front of the lens, and the inner post-lens tear film layer, which lies between the lens and the cornea [583,584]. With lens wear, the tear film undergoes extensive biophysical and biochemical changes, which have the potential to influence tear function and/or contact lens tolerance.

In 2013 TFOS published the outcomes of a workshop on Contact Lens Discomfort, including a subcommittee report of Contact Lens Interactions With the Tear Film [54]. The following were associated with worsening of comfort during lens wear: increases in the rapidity of tear film breakup time on the cornea or over the surface of a contact lens; higher contact lens water content; the grade of tear ferning (grade 0 vs. grades 1 or 2 ); increased tear evaporation rate during contact lens wear; reduced tear flow rate and tear volume; impaired tear film lipid layer; mucin degradation on contact lenses; increases in the concentrations of lipocalin-1, secretory phospholipase A2 (and activity), and lipid aldehyde products. The following section will concentrate on references published since that report.

In cross-sectional studies there are no statistically significant differences in tear film osmolarity between contact lens wearers and non-lens wearers [131,585]. The concentration of phospholipase A2 levels in tears has been associated with an increased concentration of malondialdehyde, which is also a by-product of phospholipid degradation and shorter TBUT over a contact lens [586].

The limited thickness of the post-lens tear film $(1-2 \mu \mathrm{m})$ has clinical implications, as the stagnation of tears beneath a contact lens is believed to be one of the major causes of complications seen with contact lens wear, including mucin ball formation and ocular surface staining [587]. Technological limitations have not allowed for the accurate and non-invasive determination of fluid circulation between the pre- and post-lens tear film, a phenomenon commonly referred to as tear exchange or tear turnover. Fluorophotometry studies on tear exchange have demonstrated that tear exchange occurs in 30 min with soft lenses [588,589], which is longer than that with rigid lenses or no lens wear [590]. This large difference probably relates to lens size and material stiffness, and therefore lens movement with the blink. Silicone hydrogel materials were reported to improve tear exchange by $5 \%$ compared to hydrogels [589] due to the slightly higher modulus, which improves lens movement. Good tear exchange may minimize the risk of adverse sequelae via timely flushing of debris and metabolic byproducts from the ocular surface. Innovations in soft lens designs, in an attempt to increase tear exchange, have not proven clinically effective thus far [587].

A thicker lipid layer during contact lens wear is associated with increased stability of the tear film, increased interblink period and decreased tear evaporation rate [586]. Using interferometry, the lipid layer thickness over soft contact lenses was estimated to be around $15 \mathrm{~nm}$ [586]. Reduced pre-lens TBUT values have been associated with increased symptoms of discomfort in hydrogel contact lens wearers [586]. A prospective, randomized, crossover study, showed that a daily disposable silicone hydrogel contact lens manufactured from delefilcon A permitted significantly longer NIBUT compared to lenses made from narafilcon A and filcon II-3, in addition to inducing significantly less corneal staining after $16 \mathrm{~h}$ of wear [595]. However, the study found no improvement in comfort with any particular contact lens [595]. Use of a liposomal eye spray has been reported to improve pre-lens TBUT [586]. Recently, a prospective, randomized, double blind study reported a favorable

Table 9

Metabolite differences in the tears of dry eye tears in comparison to control subjects.

\begin{tabular}{|c|c|c|}
\hline Metabolites & Change in dry eye tears & Reference \\
\hline Cholesterol/lipids & $\downarrow$ & Galbis-Estrada et al., 2014 [530] \\
\hline N-Acetylglucosamine & $\downarrow$ & Galbis-Estrada et al., 2014 [530] \\
\hline Glutamate & $\downarrow$ & Galbis-Estrada et al., 2014 [530] \\
\hline Carnitine & $\downarrow$ & Galbis-Estrada et al., 2014 [542] \\
\hline Taurine & $\downarrow$ & Nakatsukasa et al., 2011 [537] \\
\hline Methionine & $\downarrow$ & Nakatsukasa et al., 2011 [537] \\
\hline Arginine & $\downarrow$ & Nakatsukasa et al., 2011 [537] \\
\hline Serotonin & $\uparrow$ & Chhadva et al., 2015 [549] \\
\hline Total creatine & $\uparrow$ & Galbis-Estrada et al., 2014 [530] \\
\hline Arginine + phosphoetanolamine & $\uparrow$ & Galbis-Estrada et al., 2014 [530] \\
\hline Phenylalanine & $\uparrow$ & Galbis-Estrada et al., 2014 [530] \\
\hline Choline/acetylcholine & $\uparrow$ & Galbis-Estrada et al., 2014 [530] \\
\hline Choline & $\uparrow$ & Galbis-Estrada et al., 2014 [530] \\
\hline Glucose & $\uparrow$ & Galbis-Estrada et al., 2014 [530] \\
\hline Amino-n-butyrate & $\uparrow$ & Galbis-Estrada et al., 2014 [530] \\
\hline Diadenosine polyphosphates (Ap4A and Ap5A) & $\uparrow$ & Carracedo et al., 2010 [547] Peral et al., 2006 [548] \\
\hline
\end{tabular}


Table 10

Animal tear proteins that appear to decrease or increase in induced dry eye.

\begin{tabular}{|c|c|c|c|c|c|}
\hline Dry Eye & Animal & Model & $\begin{array}{l}\text { Tear Change from Normal \& Induced } \\
\text { DE }\end{array}$ & $\begin{array}{l}\text { Technology for } \\
\text { Tear Analysis }\end{array}$ & Reference \\
\hline $\begin{array}{l}\text { Aqueous deficient dry eye } \\
\text { (lacrimal insufficiency) }\end{array}$ & Rabbit & $\begin{array}{l}\text { Induced autoimmune dacryoadenitis } \\
\text { (IAD) }\end{array}$ & $\begin{array}{c}\uparrow S 100 \mathrm{~A} 6, \uparrow \mathrm{S} 100 \mathrm{~A} 9, \uparrow \mathrm{ALB}, \downarrow \mathrm{TF}, \downarrow \mathrm{PIP}, \\
\downarrow \text { pIgR, } \downarrow \text { Ig y chain } \mathrm{C} \text { region }\end{array}$ & $\begin{array}{l}\text { iTRAQ + nanoLC- } \\
\text { nanoESI-MS/MS }\end{array}$ & Zhou et al., 2013 [576] \\
\hline \multirow{6}{*}{$\begin{array}{l}\text { Combined lacrimal insufficiency } \\
\text { and evaporative dry eye } \\
\text { models }\end{array}$} & Mice & $\begin{array}{l}\text { Desiccating stress (DS) model and } \\
\text { scopolamine }\end{array}$ & $\uparrow \mathrm{IL}-17$ & $\begin{array}{l}\text { Immunobead } \\
\text { assay }\end{array}$ & $\begin{array}{l}\text { De Paiva et al., } 2009 \text { [555], } \\
\text { Dursun et al., } 2002 \text { [568] }\end{array}$ \\
\hline & & & $\begin{array}{c}\uparrow \text { IL-1 } \beta, \text { TNF- } \alpha, \text { IL-2, IL-6, CCL5, CXCL10, } \\
\text { IFN-y, IL-17, IL-10 }\end{array}$ & Luminex & $\begin{array}{l}\text { Schaumburg et al., } 2011 \\
\text { [566] }\end{array}$ \\
\hline & & & $\begin{array}{l}\uparrow \text { IL- } 1 \alpha, \text { TNF- } \alpha \text {, IL- } 2, \text { IL- } 12, \text { IFN- } \gamma, \text { IL-4 } \\
\text { and IL-10 (mouse strain dependent) }\end{array}$ & $\begin{array}{l}\text { Immunobead } \\
\text { assay }\end{array}$ & Corrales et al., 2007 [574] \\
\hline & & & $\uparrow \mathrm{IL}-1 \beta, \mathrm{MMP9}$ & $\begin{array}{l}\text { ELISA, } \\
\text { Zymography }\end{array}$ & Luo et al., 2004 [591] \\
\hline & & & $\uparrow \mathrm{SP}-\mathrm{D}$ & $\begin{array}{l}\text { Western } \\
\text { immunoblot }\end{array}$ & Heimer et al., 2013 [592] \\
\hline & & & $\uparrow$ MMP1, MMP3, MMP9 & Activity assay & Corrales et al., 2006 [573] \\
\hline Aqueous deficient & Mice & $\begin{array}{l}\text { IL-2r alpha (CD25) knockout mice } \\
\text { (develop Sjögren syndrome-like } \\
\text { disease) }\end{array}$ & $\uparrow$ IL- $1 \alpha$ and IFN- $\gamma$ & Luminex & De Paiva et al., 2010 [554] \\
\hline $\begin{array}{l}\text { Preganglionic parasympathetic } \\
\text { denervation }\end{array}$ & Rabbit & Parasympathetic denervation & $\uparrow$ CGRP after cyclosporine treatment & ELISA & $\begin{array}{l}\text { Toshida et al., } 2009 \text { [593], } \\
\text { Toshida et al., } 2007 \text { [594] }\end{array}$ \\
\hline
\end{tabular}

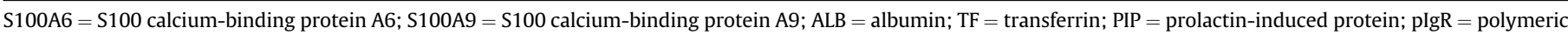

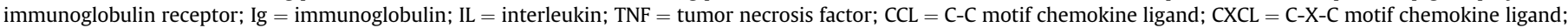
IFN = interferon; MMP-9 = matrix metallopeptidase 9; SP-D = surfactant protein-D; CGRP = calcitonin gene-related peptide

effect of Omega 3 fatty acid supplements in improving tear film stability, tear film breakup time and wear comfort in contact lens wearers [596].

The hypothesis that inflammation may be involved in contact lens discomfort has not been supported by two studies examining levels of cytokines in tears of contact lens wearers. One study examining tear cytokine concentrations of symptomatic and asymptomatic lens wearers found no difference in the concentration of 11 cytokines in tears, including IL-1 $\beta$, IL-6 and IL-8 [597]. The other study found no change in the concentration of 14 cytokines in tears over the course of a day wearing contact lenses, even though comfort was significantly reduced [440]. The latter study did find the concentration of VEGF was correlated with ocular comfort, but the change in VEGF concentration was more pronounced when contact lenses were not worn rather than during lens wear.

Although previous studies evaluating transmembrane mucins during contact lens wear reported conflicting results, using fluorescein-labeled wheat germ agglutinin (F-WGA) as a marker, Fukui et al. [598] reported less fluorescence intensity in soft contact lens wearers. Observing a positive correlation between tear film breakup time and F-WGA fluorescence, the authors suggested that a decrease or compositional alteration of ocular surface glycocalyx could be a factor in contact lens-induced dryness. Disturbance of the glycocalyx during contact lens wear may be due to slower epithelial turnover and consequently decreased quality of surface mucin, contact lens-induced friction and resultant inflammation, or restricted tear exchange resulting in restricted delivery of secreted mucins on the corneal surface [598].

What is still unclear is the natural history of contact lens discomfort. Are people who experience contact lens discomfort normal before lens wear and at risk of developing symptoms of dry eye even on contact lens removal entirely as a result of wearing lenses? Or are those people predisposed to dry eye (perhaps having subclinical signs or symptoms) and contact lens wear tips them towards dry eye?

\subsection{Hormonal factors}

Low androgen levels have been reported to be consistently associated with dry eye [599]. Biophysical and biochemical changes in the tear film in postmenopausal women have been investigated in a few studies. Tear osmolarity in postmenopausal women with dry eye symptoms were shown to be significantly higher than those without symptoms [124], and sex hormone levels correlated with tear osmolarity $[600,601]$. Tear ferning tests were also reported to have higher grades in postmenopausal women with dryness complaints than asymptomatic postmenopausal women [124]. As for the biochemical changes, although tear film levels of lipocalin and lysozyme do not seem to change in postmenopausal women with dry eye [602], in one study lactoferrin levels were reported to significantly decrease [603]. The effect of hormone replacement therapy is controversial; some studies suggested it improves tear function tests and increases goblet cell density [604,605], whereas, others reported hormone replacement therapy (particularly estrogen alone) to be associated with a higher risk of dry eye [606]. A further, more exhaustive discussion on this topic is provided in the TFOS DEWS II Sex, Gender, and Hormones report [607].

Thyroid eye disease may be associated with tear function abnormalities. Increased dryness symptoms, decreased tear film breakup time, decreased corneal sensitivity, and increased ocular surface staining have been reported both during the active and inactive phases of Graves' ophthalmopathy [608,609]. Increased tear osmolarity $[610,611]$ and increased levels of inflammatory mediators such as IL-1 $\beta$, IL-6, IL-8 and plasminogen activator inhibitor- 1 have also been found in the tear film of patients with active Graves' ophthalmopathy [609,612].

\subsection{Environmental factors}

The use of visual display units (VDU) is also a factor that is associated with dryness symptoms, even in young subjects. Up to $27.4 \%$ of VDU users reportedly have high tear osmolarity levels [613]. Kojima et al. [614] reported that long-term VDU users (using digital devices more than $4 \mathrm{~h}$ per day) exhibited a significantly reduced TMH and increased symptom scores compared to shortterm VDU users and controls. VDU-related dryness has been attributed to reduction in spontaneous blink rate [615-618], predominance of incomplete blinks [615], the presence of MGD [619], lipid layer instability and decreased TBUT [614,615]. In normal subjects, NIBUT has been shown to decrease significantly after 30 min of playing a computer game [93]. The resultant tear film hyperosmolarity was suggested to be reliable in diagnosing dry eye 
in VDU users, and osmolarity levels were shown to correlate with tear function tests and tear film breakup levels [620]. Frequent breaks from VDU use, blinking awareness training and moist cool air devices were reported to provide relief of ocular dryness and improvement of tear stability for these subjects [238,621].

In vitro and in vivo studies have shown that increasing the ambient temperature increases the tear evaporation rate, TBUT, lipid layer thickness, and ocular surface temperature [254,622]. High altitude exposure, with cold and dry air, leads to a decrease in TBUT and an increase in tear film osmolarity [148]. Controlled environmental chamber studies provide a way of controlling the environmental temperature and humidity independently or together. One controlled environmental chamber study showed that, after $2 \mathrm{~h}$ exposure in the chamber, TBUT decreased, corneal staining and tear MMP-9 levels increased in both symptomatic (mild to moderate dry eye) and asymptomatic control subjects exposed to 5\% (low) humidity in a desiccating environment [419]. The authors concluded that acute adverse changes in environmental conditions could lead to significant functional deterioration in subjects with or without dry eye symptoms [419]. In another study, changing the humidity from $40 \%$ (normal) to 5\% (low) significantly increased tear evaporation rate, decreased lipid layer thickness, increased tear instability, and reduced tear production [251]. Exposing non-adapted contact lens wearers to a controlled environmental chamber for 20 min increased tear osmolarity, evaporation rates, visual symptoms and tear instability significantly for hydrogel wearers compared to silicone hydrogel wearers [234]. Another factor that may impact the tear film, leading to signs and symptoms of dry-eye, is air pollution [623]. Exposure to trafficderived air pollution reduces the goblet cell numbers in the conjunctiva [624]. Further details can be found in the TFOS DEWS II Iatrogenic Dry Eye report [625].

In conclusion, several factors, including contact lens wear and environmental conditions (such as VDU use, ambient temperature and humidity) significantly affect tear film stability and function. However, it is yet to be established if any of these changes can lead to the development of chronic DED.

\section{Conclusions and new frontiers}

A two layered tear film model of the tear film's structure is preferred over the traditional three layered model, with a mucoaqueous gel layer lying beneath, but at least partly integrated with, an overlying lipid layer. The mucoaqueous layer makes up the bulk of the thin $(2-6 \mu \mathrm{m})$ tear film, but most data on thickness is from the precorneal tear film and there is virtually no data on the preconjunctival and other compartment tear films. The lipid layer is very thin, at approximately $42 \mathrm{~nm}$.

Tears are distributed over the ocular surface by the combined actions of the lids, capillary movement and upward drift of the lipid layer. Tear film thinning and breakup occurs mainly as a result of evaporation of water from the tear film, and breakup times are usually twice as rapid as normal, for people with DED. The development of lateral shearing interferometry or double pass methods may improve discrimination of TBUT between normal and dry eye subjects.

It is important that future studies be clear about how, and from which compartment, tears are collected, and the type of tears (reflex, basal, or after sleep). Most studies that have measured tear film osmolarity have used tears from the lower tear film meniscus and have shown increases in tear osmolarity with dry eye. However, it is likely that the osmolarity of the lower meniscus does not accurately reflect the osmolarity over the rest of the ocular surface. Development of techniques to measure tear film osmolarity over the cornea, ideally before and after the tear film ruptures, may provide important insight into diagnosis, improve discrimination of the type of DED present, assist with development of new treatments, and provide more accurate tests for monitoring treatments for DED. Tear evaporation rates increase with dry eye by approximately twofold. However, the lack of commercially available, reliable evaporimeters to measure this in the clinic limits its use to specialized facilities. The development of evaporimeters that can be used in clinical settings and take into account variations in ambient humidity and temperature would be extremely valuable.

Mucins help to stabilize and spread tears by binding, via their high levels of glycosylation, to water. The lipid layer reduces the surface tension of tears, allowing the thin film to avoid collapse. The lipid layer is probably responsible for reducing evaporation of tears, but how this occurs and the role of proteins and mucins in this process requires further investigation. Also, further investigation is needed to understand how proteins and mucins form the mucoaqueous gel.

The traditional belief that the tear film lipid layer can reduce water evaporation from the mucoaqueous layer has been recently questioned, by experiments in vitro that have shown that meibum or artificial lipid mixtures can only reduce evaporation of underlying water by $\leq 8 \%$. It may be that intercalating proteins and mucins in the tear film lipid layer are needed to reduce evaporation. However, if this is the case, then results showing the importance of the ability of the tear film lipid layer to reduce the surface tension of tears and that the presence of proteins in this layer disrupts this system are difficult to reconcile. Also, proteins in meibum impair its spreading and worsen its viscoelasticity. Clearly, more studies in these areas are needed.

The tear lipidome has been explored in great detail since the publication of the first TFOS DEWS report in 2007. At least five, probably more, lipid classes are present, with each class having many different types due to the large number of possible fatty acids than can be esterified within each class. The majority of lipids in meibum and the tear film lipidome are wax and cholesterol esters. Debates regarding the presence of phospholipids in meibum have largely been settled and experiments show very low levels of this lipid class in meibum. However, the presence of relatively high levels of phospholipids in the tear film lipidome then begs the questions of where these originate from, and indeed if they are really in the tear film lipid layer or are extracted from lipid-binding proteins in tears such as lipocalin (and thereby sequestered away from the tear film lipid layer). Studies have shown that dry eye may be related to changes in the tear film lipidome, especially to changes in the concentration of OAHFAs, but more work is required to confirm these findings. Multi-laboratory and multi-national testing of common pooled meibum and tear lipid extracts is required to provide baseline lipidome data that can then be used as a gold standard to examine the effects of dry eye and its treatments.

There are various mucins found in tears, with the major soluble mucin being MUC5AC and the transmembrane mucins being MUC1, MUC4 and MUC16. However, mRNA for other mucins has been found in ocular surface epithelial cells, and so may be present in tears, although perhaps in low concentrations. There are changes to the concentration of MUC5AC, MUC1, MUC4 and MUC16 in tears of dry eye subjects, but not all studies agree on the magnitude or direction of the changes. However, decreased MUC5AC expression and alteration in mucin glycosylation in dry eye is a consistent finding among most studies. Further studies using the latest glycomic, proteomic and genomic techniques will be beneficial in helping to determine the role of changes to mucin in DED.

There has been an explosion in the number of proteins known to be present in the tear film proteome, with approximately 1800 proteins being present. The use of non-biased MS methods to evaluate changes to proteins, along with more traditional immuno- 
assays, has helped to show that several proteins change from normal levels in dry eye tears. These proteins can be used as biomarkers, which might help to predict, diagnose and even, in some cases, be therapeutic for dry eye. However, MS is not appropriate for converting into point-of-care analysis, whereas immunological techniques may be. To date, many candidate biomarkers found by MS have yet to be validated by immunological techniques. Furthermore, validating the biomarkers in separate populations is often lacking, resulting in a lack of data on sensitivity and specificity. Data that have been generated on specificity and sensitivity of protein biomarkers show that panels of at least four proteins are superior to individual proteins. More information is needed on biomarker dynamic range, cut-off definition, specificity, sensitivity, positive predictive value and negative predictive value, and linkage of biomarker detection to treatment. Also, testing application of biomarkers in animal models to demonstrate whether they can alleviate dry eye signs is lacking for many.

Investigations into the tear film metabolome have been small and sporadic, but much could be learned from more research in this area. The metabolome is a measure of endogenous metabolites in tears. Due to the fact that these metabolites can be many and varied, sophisticated laboratory techniques are needed during the discovery phase, and so development of assays appropriate for point-of-care use will need to be made for any metabolites that can be used as biomarkers. Changes to amino acids or their derivatives in the tear film of dry eye subjects have been found to be possible markers of the disease.

This subcommittee also examined the effect of nonpathophysiological factors impacting the tear film. Epidemiological evidence pointing to the high risk of having dry eye if the person has been a contact lens wearer has focused attention in this area, as had the publication of the TFOS report of Contact Lens Discomfort in 2013 [54]. Recent data does not support an underlying inflammatory response being associated with contact lens discomfort, but there are clearly changes to the tear lipid layer and mucins during contact lens wear. Whether these changes are transient or more permanent has not been investigated. Furthermore, it is unclear whether those people who have increased discomfort or dryness symptoms during contact lens wear were predisposed to becoming dry eye patients even if they did not wear lenses, or whether lens wear accelerated their path toward DED. With our increasing use of electronic means to communicate, the associated dry eye symptoms that can occur and how to manage or treat these is an area worthy of research in the future.

The tear film is clearly required for a healthy ocular surface. There are several changes to the tear film that occur in dry eye. How biochemical changes relate to biophysical changes, and how these relate to clinical manifestations of tear film stability and volume are not currently known, although progress is being made in many of these areas. The development of a holistic model of tear film structure and function, and changes that occur during dry eye will likely be forthcoming in response to current and future research.

\section{Financial disclosures}

M. Willcox, Chair: Alcon Laboratories, Allergan, Coopervision, Johnson \& Johnson Vision Care, Ophtecs (F); Allergan, Minomic International Pty., Ophtecs, Warm Contacts (C); Allergan, Optecs (R); Minomic International Pty., Ophtecs (S)

P. Argüeso: Otsuka, Santen (F)

G. Gerogiev: Menicon Co., Ltd., Otsuka Pharmaceuticals Co., Ltd., Rohto Pharmaceutical, Co., Ltd., Santen Pharmaceutical Co., Ltd., (F) J. Holopainen: None.

G. Laurie: TearSolutions, LLC (I); Ocular Tear Growth Factor-Like Protein US 7,320,870; 7,459,440; Japan 4288070; Canada
2,438,334; Use of Lacritin in Promoting Ocular Cell Survival US 7,648,964 B2; Eur 1766768; Japan 512278; Lacritin-Syndecan Interactions US 7,932,227 B1; Compositions and Methods for the Delivery of Drugs to the Ocular Surface by Contact Lenses PCT/ US2014/32412; Compositions and Methods for Detecting, Diagnosing, Preventing and Treating Dry Eye PCT/US2015/19964 (P)

T. Millar: None.

E. Papas: None.

J. Rolland-Thompson: None.

T. Schmidt: Johnson \& Jonson Vision Care, Contamac, Lubris (F); Lubris (I); Johnson \& Johnson Vision Care, Allergan, Lubris (C); Lubris (P); Johnson \& Johnson Vision Care (R)

U. Stahl: Advanced Vision Research, Alcon, Allergan, Contamac, CooperVision, Essilor, Inflamax, Johnson \& Johnson Vision Care, Ocular Dynamics, Oculus, Safilens, TearLab, TearScience (F)

T. Suarez: Bioftalmik co-founder and investor (I), (E); Coinventor of a patent related with dry eye biomarkers (EP2603797 European Patent \& US20140057307A1 USA Patent) (P)

L. Subbaraman: Advanced Vision Research, Alcon, Allergan, Contamac, CooperVision, Essilor, Inflamax, Johnson \& Johnson Vision Care, Ocular Dynamics, Oculus, Safilens, TearLab, TearScience (F); Johnson \& Johnson (C), (R)

O. Ucakhan: None.

L. Jones (Harmonisation member): Advanced Vision Research, Alcon, Allergan, Contamac, CooperVision, Essilor, Inflamax, Johnson \& Johnson Vision Care, Ocular Dynamics, Oculus, Safilens, TearLab, TearScience (F); Alcon, CooperVision, Johnson \& Johnson Vision Care $(C)(R)$

F (Financial Support), I (Personal Financial Interest), E (Employment), C (Consultant), P (Patent), R (Recipient), N (No Commercial Relationship), $\mathrm{S}$ (non-remunerative).

\section{References}

[1] Wolff E. The muco-cutaneous junction of the lid margin and the distribution of the tear fluid. Trans Ophthalmol Soc U K 1946;66:291-308.

[2] Holly FJ, Lemp MA. Tear physiology and dry eyes. Surv Ophthalmol 1977;22: 69-87.

[3] Doane MG. Abnormalities of the structure of the superficial lipid layer on the in vivo dry-eye. In: Sullivan DA, editor. Lacrimal Gland, Tear Film, and Dry Eye Syndromes. USA: Springer; 1994. p. 489-93.

[4] Yokoi N, Bron AJ, Georgiev GA. The precorneal tear film as a fluid shell: the effect of blinking and saccades on tear film distribution and dynamics. Ocul Surf 2014;12:252-66.

[5] Wang J, Aquavella J, Palakuru J, Chung S, Feng C. Relationships between central tear film thickness and tear menisci of the upper and lower eyelids. Invest Ophthalmol Vis Sci 2006;47:4349-55.

[6] Savini G, Barboni P, Zanini M. Tear meniscus evaluation by optical coherence tomography. Ophthalmic Surg Lasers Imaging 2006;37:112-8.

[7] Shen M, Li J, Wang J, Ma H, Cai C, Tao A, et al. Upper and lower tear menisci in the diagnosis of dry eye. Invest Ophthalmol Vis Sci 2009;50:2722-6.

[8] King-Smith PE, Fink BA, Hill RM, Koelling KW, Tiffany JM. The thickness af the tear film. Curr Eye Res 2004;29:357-68.

[9] King-Smith PE, Fink BA, Fogt N, Nichols KK, Hill RM, Wilson GS. The thickness of the human precorneal tear film: evidence from reflection spectra. Invest Ophthalmol Vis Sci 2000;41:3348-59.

[10] Chen Q, Wang J, Tao A, Shen M, Jiao S, Lu F. Ultrahigh-resolution measurement by optical coherence tomography of dynamic tear film changes on contact lenses. Invest Ophthalmol Vis Sci 2010;51:1988-93.

[11] King-Smith PE, Kimball SH, Nichols JJ. Tear film interferometry and corneal surface roughness. Invest Ophthalmol Vis Sci 2014;55:2614-8.

[12] Holly FJ, Lemp MA. Surface chemistry of the tear film: implications for dry eye syndromes, contact lenses, and ophthalmic polymers. Cont Lens Soc Am J $1971 ; 5: 12-9$.

[13] Holly FJ. Formation and rupture of the tear film. Exp Eye Res 1973;15: $515-25$.

[14] Mantelli F, Mauris J, Argueso P. The ocular surface epithelial barrier and other mechanisms of mucosal protection: from allergy to infectious diseases. Curr Opin Allergy Clin Immunol 2013;13:563-8.

[15] Govindarajan B, Gipson IK. Membrane-tethered mucins have multiple functions on the ocular surface. Exp Eye Res 2010;90:655-63.

[16] Gipson IK, Spurr-Michaud S, Tisdale A. Human conjunctival goblet cells express the membrane associated mucin MUC16: localization to mucin granules. Exp Eye Res 2015;145:230-4. 
[17] Gipson IK, Argueso P. Role of mucins in the function of the corneal and conjunctival epithelia. Int Rev Cytol 2003;231:1-49.

[18] Kautto L, Nguyen-Khuong T, Everest-Dass A, Leong A, Zhao Z, Willcox MD, et al. Glycan involvement in the adhesion of Pseudomonas aeruginosa to tears. Exp Eye Res 2016;145:278-88.

[19] Zhou L, Zhao SZ, Koh SK, Chen L, Vaz C, Tanavde V, et al. In-depth analysis of the human tear proteome. J Proteomics 2012;75:3877-85.

[20] Azkargorta M, Soria J, Ojeda C, Guzman F, Acera A, Iloro I, et al. Human basal tear peptidome characterization by CID, HCD, and ETD followed by in silico and in vitro analyses for antimicrobial peptide adentification. J Proteome Res 2015; 14:2649-58.

[21] Brown SH, Kunnen CM, Duchoslav E, Dolla NK, Kelso MJ, Papas EB, et al. A comparison of patient matched meibum and tear lipidomes. Invest Ophthalmol Vis Sci 2013;54:7417-24.

[22] McDonald JE, Brubaker S. Meniscus-induced thinning of tear films. Am J Ophthalmol 1971:72:139-46.

[23] Miller KL, Polse KA, Radke CJ. Black-line formation and the "perched" human tear film. Curr Eye Res 2002;25:155-62.

[24] King-Smith PE, Hinel EA, Nichols JJ. Application of a novel interferometric method to investigate the relation between lipid layer thickness and tear film thinning. Invest Ophthalmol Vis Sci 2010;51:2418-23.

[25] Peng CC, Cerretani C, Li Y, Bowers S, Shahsavarani S, Lin MC, et al. Flow evaporimeter to assess evaporative resistance of human tear-film lipid layer. Ind Eng Chem Res 2014;53:18130-9.

[26] Bron AJ, Tiffany JM, Gouveia SM, Yokoi N, Voon LW. Functional aspects of the tear film lipid layer. Exp Eye Res 2004;78:347-60.

[27] Knop E, Knop N, Millar T, Obata H, Sullivan DA. The international workshop on meibomian gland dysfunction: report of the subcommittee on anatomy, physiology, and pathophysiology of the meibomian gland. Invest Ophthalmol Vis Sci 2011;52:1938-78.

[28] Rosenfeld L, Fuller GG. Consequences of interfacial viscoelasticity on thin film stability. Langmuir 2012;28:14238-44.

[29] Georgiev GA, Yokoi N, Ivanova S, Tonchev V, Nencheva Y, Krastev R. Surface relaxations as a tool to distinguish the dynamic interfacial properties of films formed by normal and diseased meibomian lipids. Soft Matter 2014;10: 5579-88.

[30] Svitova TF, Lin MC. Racial variations in interfacial behavior of lipids extracted from worn soft contact lenses. Optom Vis Sci 2013;90:1361-9.

[31] Raju SR, Palaniappan CK, Ketelson HA, Davis JW, Millar TJ. Interfacial dilatational viscoelasticity of human meibomian lipid films. Curr Eye Res 2013;38:817-24.

[32] Dilly PN. Structure and function of the tear film. Adv Exp Med Biol 1994;350: 239-47.

[33] Cher I. A new look at lubrication of the ocular surface: fluid mechanics behind the blinking eyelids. Ocul Surf 2008;6:79-86.

[34] Goto E, Tseng SC. Kinetic analysis of tear interference images in aqueous tear deficiency dry eye before and after punctal occlusion. Invest Ophthalmol Vis Sci 2003;44:1897-905.

[35] Yokoi N, Takehisa Y, Kinoshita S. Correlation of tear lipid layer interference patterns with the diagnosis and severity of dry eye. Am J Ophthalmo 1996;122:818-24.

[36] Korb DR, Greiner JV. Increase in tear film lipid layer thickness following treatment of meibomian gland dysfunction. Adv Exp Med Biol 1994;350: 293-8.

[37] Goto E, Dogru M, Kojima T, Tsubota K. Computer-synthesis of an interference color chart of human tear lipid layer, by a colorimetric approach. Invest Ophthalmol Vis Sci 2003;44:4693-7.

[38] Wang JH, Fonn D, Simpson TL, Jones L. Precorneal and pre- and postlens tear film thickness measured indirectly with optical coherence tomography. Invest Ophthalmol Vis Sci 2003;44:2524-8.

[39] Schmoll T, Unterhuber A, Kolbitsch C, Le T, Stingl A, Leitgeb R. Precise thickness measurements of Bowman's layer, epithelium, and tear film. Opt Vis Sci 2012;89:E795-802.

[40] Werkmeister RM, Alex A, Kaya S, Unterhuber A, Hofer B, Riedl J, et al. Measurement of tear film thickness using ultrahigh-resolution optical coherence tomography. Invest Ophthalmol Vis Sci 2013;54:5578-83.

[41] Huang JX, Tankam P, Aquavella JV, Hindman HB, Clarkson E, Kupinski M, et al. Tear film thickness estimation using optical coherence tomography and maximum-likelihood estimation. Invest Ophthalmol Vis Sci 2015;56. E-Abstract 351 .

[42] dos Santos VA, Schmetterer L, Groschl M, Garhofer G, Schmidl D, Kucera M, et al. In vivo tear film thickness measurement and tear film dynamics visualization using spectral domain optical coherence tomography. Opt Express 2015;23:21043-63.

[43] Isreb MA, Greiner JV, Korb DR, Glonek T, Mody SS, Finnemore VM, et al. Correlation of lipid layer thickness measurements with fluorescein tear film break-up time and Schirmer's test. Eye (Lond) 2003;17:79-83.

[44] Zhuang H, Zhou XT, Xu JJ. A novel method for pachymetry mapping of human precorneal tear film using Pentacam with fluorescein. Invest Ophthalmol Vis Sci 2010;51:156-9.

[45] King-Smith PE, Reuter KS, Braun RJ, Nichols JJ, Nichols KK. Tear film breakup and structure studied by simultaneous video recording of fluorescence and tear film lipid layer images. Invest Ophthalmol Vis Sci 2013;54:4900-9.

[46] Su TY, Chang SW, Yang CJ, Chiang HK. Direct observation and validation of fluorescein tear film break-up patterns by using a dual thermal-fluorescent imaging system. Biomed Opt Express 2014;5:2614-9.

[47] Mishima S, Gasset A. Klyce Jr SD, Baum JL. Determination of tear volume and tear flow. Invest Ophthalmol 1966;5:264-76.

[48] Braun RJ. Dynamics of the tear film. Annu Rev Fluid Mech 2012;44. 267, 97.

[49] Dartt DA. Regulation of mucin and fluid secretion by conjunctival epithelial cells. Prog Retin Eye Res 2002;21:555-76.

[50] Maitchouk DY, Beuerman RW, Ohta T, Stern M, Varnell RJ. Tear production after unilateral removal of the main lacrimal gland in squirrel monkeys. Arch Ophthalmol 2000;118:246-52.

[51] Botelho SY, Hisada M, Fuenmayor N. Functional innervation of the lacrimal gland in the cat. Origin of secretomotor fibers in the lacrimal nerve. Arch Ophthalmol 1966;76:581-8.

[52] Sibony PA, Walcott B, McKeon C, Jakobiec FA. Vasoactive intestinal polypeptide and the innervation of the human lacrimal gland. Arch Ophthalmol 1988; 106:1085-8.

[53] Botelho SY. Tears and the lacrimal gland. Sci Am 1964:211:78-86.

[54] Craig JP, Willcox MD, Argueso P, Maissa C, Stahl U, Tomlinson A, et al. The TFOS International Workshop on Contact Lens Discomfort: report of the contact lens interactions with the tear film subcommittee. Invest Ophthalmol Vis Sci 2013:54. TFOS123-56.

[55] Belmonte C, Nichols JJ, Cox SM, Brock JA, Begley CG, Bereiter DA, et al. TFOS DEWS II Pain and Sensation report. Ocul Surf 2017;15:404-37.

[56] Brown SI, Dervichian DG. Hydrodynamics of blinking. In vitro study of the interaction of the superficial oily layer and the tears. Arch Ophthalmol 1969;82:541-7.

[57] King-Smith PE, Fink BA, Nichols JJ, Nichols KK, Braun RJ, McFadden GB. The contribution of lipid layer movement to tear film thinning and breakup. Invest Ophthalmol Vis Sci 2009;50:2747-56.

[58] Bron AJ, Yokoi N, Gaffney EA, Tiffany JM. A solute gradient in the tear meniscus. I. A hypothesis to explain Marx's line. Ocul Surf 2011;9:70-91.

[59] Bron AJ, Yokoi N, Gaffney EA, Tiffany JM. A solute gradient in the tear meniscus. II. Implications for lid margin disease, including meibomian gland dysfunction. Ocul Surf 2011;9:92-7.

[60] Maurice DM. The dynamics and drainage of tears. Int Ophthalmol Clin 1973;13:103-16.

[61] Khanal S, Millar TJ. Nanoscale phase dynamics of the normal tear film. Nanomedicine 2010;6:707-13.

[62] Kuppens EV, Stolwijk TR, de Keizer RJ, van Best JA. Basal tear turnover and topical timolol in glaucoma patients and healthy controls by fluorophotometry. Invest Ophthalmol Vis Sci 1992;33:3442-8.

[63] Kuppens EV, van Best JA, Sterk CC, de Keizer RJ. Decreased basal tear turnover in patients with untreated primary open-angle glaucoma. Am J Ophthalmol 1995;120:41-6.

[64] van Best JA, Benitez del Castillo JM, Coulangeon LM. Measurement of basal tear turnover using a standardized protocol. European concerted action on ocular fluorometry. Graefes Arch Clin Exp Ophthalmol 1995;233:1-7.

[65] Nichols JJ, Mitchell GL, King-Smith PE. Thinning rate of the precorneal and prelens tear films. Invest Ophthalmol Vis Sci 2005;46:2353-61.

[66] Rolland JP, Huang J, Hindman HB. In vivo measurement of tear film dynamics with optical coherence tomography and maximum-likelihood estimation. Invest Ophthalmol Vis Sci 2016;57. E-Abstract 6179.

[67] Craig JP, Tomlinson A. Importance of the lipid layer in human tear film stability and evaporation. Optom Vis Sci 1997;74:8-13.

[68] Gaffney EA, Tiffany JM, Yokoi N, Bron AJ. A mass and solute balance model for tear volume and osmolarity in the normal and the dry eye. Prog Retin Eye Res 2010;29:59-78.

[69] Sullivan BD, Crews LA, Messmer EM, Foulks GN, Nichols KK, Baenninger P, et al. Correlations between commonly used objective signs and symptoms for the diagnosis of dry eye disease: clinical implications. Acta Ophthalmol 2014;92:161-6.

[70] de Monchy I, Gendron G, Miceli C, Pogorzalek N, Mariette X, Labetoulle M. Combination of the Schirmer I and phenol red thread tests as a rescue strategy for diagnosis of ocular dryness associated with Sjogren's syndrome. Invest Ophthalmol Vis Sci 2011;52:5167-73.

[71] Hamano T, Mitsunaga S, Kotani S, Hamano T, Hamano K, Hamano H, et al. Tear volume in relation to contact lens wear and age. CLAO J 1990;16:57-61.

[72] Wright JC, Meger GE. A review of the Schirmer test for tear production. Arch Ophthalmol 1962;67:564-5.

[73] Mainstone JC, Bruce AS, Golding TR. Tear meniscus measurement in the diagnosis of dry eye. Curr Eye Res 1996;15:653-61.

[74] Yokoi N, Bron AJ, Tiffany JM, Kinoshita S. Reflective meniscometry: a new field of dry eye assessment. Cornea 2000;19:S37-43.

[75] Xu KP, Tsubota K. Correlation of tear clearance rate and fluorophotometric assessment of tear turnover. Br J Ophthalmol 1995;79:1042-5.

[76] Xu KP, Yagi Y, Toda I, Tsubota K. Tear function index. A new measure of dry eye. Arch Ophthalmol 1995:113:84-8.

[77] Korb DR, Greiner JV, Glonek T, Whalen A, Hearn SL, Esway JE, et al. Human and rabbit lipid layer and interference pattern observations. Adv Exp Med Biol 1998:438:305-8.

[78] King-Smith PE, Nichols JJ, Nichols KK, Fink BA, Braun RJ. Contributions of evaporation and other mechanisms to tear film thinning and break-up. Optom Vis Sci 2008;85:623-30.

[79] King-Smith PE, Ramamoorthy P, Braun RJ, Nichols JJ. Tear film images and breakup analyzed using fluorescent quenching. Invest Ophthalmol Vis Sci 2013;54:6003-11. 
[80] Papas E. Tear break-up time: clinical procedures and their effects. Ophthalmic Physiol Opt 1999;19:274-5.

[81] Cox SM, Nichols KK, Nichols JJ. Agreement between automated and traditional measures of tear film breakup. Optom Vis Sci 2015;92:e257-63.

[82] Nichols KK, Mitchell GL, Zadnik K. The repeatability of clinical measurements of dry eye. Cornea 2004;23:273-85.

[83] Cho P, Brown B, Chan I, Conway R, Yap M. Reliability of the tear break-up time technique of assessing tear stability and the locations of the tear breakup in Hong Kong Chinese. Optom Vis Sci 1992;69:879-85.

[84] Abelson R, Lane KJ, Rodriguez J, Johnston P, Angjeli E, Ousler G, et al. A singlecenter study evaluating the effect of the controlled adverse environment (CAE(SM)) model on tear film stability. Clin Ophthalmol 2012;6:1865-72.

[85] Pult H, Riede-Pult BH. A new modified fluorescein strip: its repeatability and usefulness in tear film break-up time analysis. Cont Lens Anterior Eye 2012;35:35-8.

[86] Korb DR, Greiner JV, Herman J. Comparison of fluorescein break-up time measurement reproducibility using standard fluorescein strips versus the Dry Eye Test (DET) method. Cornea 2001;20:811-5.

[87] Lamble JW, Gilbert D, Ashford JJ. The break-up time of artificial pre-ocular films on the rabbit cornea. J Pharm Pharmacol 1976;28:450-1.

[88] Mengher LS, Bron AJ, Tonge SR, Gilbert DJ. A non-invasive instrument for clinical assessment of the pre-corneal tear film stability. Curr Eye Res 1985;4:1-7.

[89] Patel S, Murray D, McKenzie A, Shearer DS, McGrath BD. Effects of fluorescein on tear breakup time and on tear thinning time. Am J Optom Physiol Opt 1985;62:188-90.

[90] Hirji N, Patel S, Callander M. Human tear film pre-rupture phase time (TPRPT)-a non-invasive technique for evaluating the pre-corneal tear film using a novel keratometer mire. Ophthalmic Physiol Opt 1989;9:139-42.

[91] Alonso-Caneiro D, Iskander DR, Collins MJ. Tear film surface quality with soft contact lenses using dynamic-area high-speed videokeratoscopy. Eye Contact Lens 2009;35:227-31.

[92] Downie LE. Automated tear film surface quality breakup time as a novel clinical marker for tear hyperosmolarity in dry eye disease. Invest Ophthalmol Vis Sci 2015;56:7260-8.

[93] Hirota M, Uozato H, Kawamorita T, Shibata Y, Yamamoto S. Effect of incomplete blinking on tear film stability. Optom Vis Sci 2013;90:650-7.

[94] Hong J, Sun X, Wei A, Cui X, Li Y, Qian T, et al. Assessment of tear film stability in dry eye with a newly developed keratograph. Cornea 2013;32:716-21.

[95] Koh S, Ikeda C, Fujimoto H, Oie Y, Soma T, Maeda N, et al. Regional differences in tear film stability and meibomian glands in patients with aqueousdeficient dry eye. Eye Contact Lens 2016;42:250-5.

[96] Kopf M, Yi F, Robert Iskander D, Collins MJ, Shaw AJ, Straker B. Tear film surface quality with soft contact lenses using dynamic videokeratoscopy. J Opt 2008;1:14-21.

[97] Gumus K, Crockett CH, Rao K, Yeu E, Weikert MP, Shirayama M, et al. Noninvasive assessment of tear stability with the tear stability analysis system in tear dysfunction patients. Invest Ophthalmol Vis Sci 2011;52: 456-61.

[98] Goto T, Zheng X, Okamoto S, Ohashi Y. Tear film stability analysis system: introducing a new application for videokeratography. Cornea 2004;23: S65-70.

[99] Wolffsohn JS, Arita R, Chalmers R, Djalilian A, Dogru M, Dumbleton K, et al. TFOS DEWS II Diagnostic Methodology report. Ocul Surf 2017;15:539-74.

[100] Su TY, Ho WT, Lu CY, Chang SW, Chiang HK. Correlations among ocular surface temperature difference value, the tear meniscus height, Schirmer's test and fluorescein tear film break up time. Br J Ophthalmol 2015;99:482-7.

[101] Szczesna DH, Jaronski J, Kasprzak HT, Stenevi U. Interferometric measurements of dynamic changes of tear film. J Biomed Opt 2006;11:34028.

[102] Szczesna DH, Kasprzak HT, Jaronski J, Rydz A, Stenevi U. An interferometric method for the dynamic evaluation of the tear film. Acta Ophthalmol Scand 2007;85:202-8.

[103] Guillon JP. Tear film structure and contact lenses. In: Holly FJ, editor. The preocular tear film in health, disease and contact lens wear. Lubbock, TX: Dry Eye Institute; 1986. p. 914-35.

[104] Doane MG. An instrument for in vivo tear film interferometry. Optom Vis Sci 1989;66:383-8.

[105] Szczesna DH, Iskander DR. Robust estimation of tear film surface quality in lateral shearing interferometry. J Biomed Opt 2009;14:064039.

[106] Szczesna DH, Alonso-Caneiro D, Iskander DR, Read SA, Collins MJ. Predicting dry eye using noninvasive techniques of tear film surface assessment. Invest Ophthalmol Vis Sci 2011;52:751-6.

[107] Benito A, Perez GM, Mirabet S, Vilaseca M, Pujol J, Marin JM, et al. Objective optical assessment of tear-film quality dynamics in normal and mildly symptomatic dry eyes. J Cataract Refract Surg 2011;37:1481-7.

[108] Kobashi H, Kamiya K, Yanome K, Igarashi A, Shimizu K. Longitudinal assessment of optical quality and intraocular scattering using the doublepass instrument in normal eyes and eyes with short tear breakup time. PLoS One 2013;8:e82427.

[109] Su TY, Ho WT, Chang SW, Chiang HK. Thermographic evaluation of tear film break-up time to study tear film stability. Int J Therm Sci 2016;99:36-40.

[110] Rieger G. The importance of the precorneal tear film for the quality of optical imaging. Br J Ophthalmol 1992;76:157-8.

[111] Goto E, Yagi Y, Matsumoto Y, Tsubota K. Impaired functional visual acuity of dry eye patients. Am J Ophthalmol 2002;133:181-6.
[112] Denoyer A, Rabut G, Baudouin C. Tear film aberration dynamics and visionrelated quality of life in patients with dry eye disease. Ophthalmology 2012;119:1811-8.

[113] Liu H, Thibos L, Begley CG, Bradley A. Measurement of the time course of optical quality and visual deterioration during tear break-up. Invest Ophthalmol Vis Sci 2010;51:3318-26.

[114] Tomlinson A, Khanal S. Assessment of tear film dynamics: quantification approach. Ocul Surf 2005;3:81-95.

[115] Lemp MA. Report of the national eye institute/industry workshop on clinical trials in dry eyes. CLAO J 1995;21:221-32.

[116] The definition and classification of dry eye disease: report of the Definition and Classification Subcommittee of the International Dry Eye Workshop (2007). Ocul Surf. 2007:5:75-92.

[117] Murube J. Tear osmolarity. Ocul Surf 2006;4:62-73.

[118] Versura P, Campos EC. TearLab(R) Osmolarity System for diagnosing dry eye. Expert Rev Mol Diagn 2013;13:119-29.

[119] Stahl U, Willcox M, Stapleton F. Osmolality and tear film dynamics. Clin Exp Optom 2012;95:3-11.

[120] Tomlinson A, Bron AJ, Korb DR, Amano S, Paugh JR, Pearce EI, et al. The international workshop on meibomian gland dysfunction: report of the diagnosis subcommittee. Invest Ophthalmol Vis Sci 2011;52:2006-49.

[121] Srinivasan S, Nichols KK. Collecting tear osmolarity measurements in the diagnosis of dry eye. Expert Rev Ophthalmol 2009;4:451-3.

[122] Messmer EM, Bulgen M, Kampik A. Hyperosmolarity of the tear film in dry eye syndrome. Dev Ophthalmol 2010;45:129-38.

[123] Khanal S, Tomlinson A, Diaper CJ. Tear physiology of aqueous deficiency and evaporative dry eye. Optom Vis Sci 2009;86:1235-40.

[124] Srinivasan S, Joyce E, Jones LW. Tear osmolality and ferning patterns in postmenopausal women. Optom Vis Sci 2007;84:588-92.

[125] Tomlinson A, McCann LC, Pearce EI. Comparison of human tear film osmolarity measured by electrical impedance and freezing point depression techniques. Cornea 2010;29:1036-41.

[126] Versura P, Profazio V, Campos EC. Performance of tear osmolarity compared to previous diagnostic tests for dry eye diseases. Curr Eye Res 2010;35: 553-64.

[127] Jacobi C, Jacobi A, Kruse FE, Cursiefen C. Tear film osmolarity measurements in dry eye disease using electrical impedance technology. Cornea 2011;30: $1289-92$.

[128] Lemp MA, Bron AJ, Baudouin C, Benitez Del Castillo JM, Geffen D, Tauber J, et al. Tear osmolarity in the diagnosis and management of dry eye disease. Am J Ophthalmol 2011;151:792-8.

[129] Szalai E, Berta A, Szekanecz Z, Szucs G, Modis Jr L. Evaluation of tear osmolarity in non-Sjogren and Sjogren syndrome dry eye patients with the TearLab system. Cornea 2012;31:867-71.

[130] Li M, Du C, Zhu D, Shen M, Cui L, Wang J. Daytime variations of tear osmolarity and tear meniscus volume. Eye Contact Lens 2012;38:282-7.

[131] Chen SP, Massaro-Giordano G, Pistilli M, Schreiber CA, Bunya VY. Tear osmolarity and dry eye symptoms in women using oral contraception and contact lenses. Cornea 2013;32:423-8.

[132] Hassan Z, Szalai E, Berta A, Modis Jr L, Nemeth G. Assessment of tear osmolarity and other dry eye parameters in post-LASIK eyes. Cornea 2013;32. e142-5.

[133] Keech A, Senchyna M, Jones L. Impact of time between collection and collection method on human tear fluid osmolarity. Curr Eye Res 2013;38: 428-36.

[134] Garcia N, Teson M, Enriquez-de-Salamanca A, Mena L, Sacristan A, Fernandez I, et al. Basal values, intra-day and inter-day variations in tear film osmolarity and tear fluorescein clearance. Curr Eye Res 2014;39:673-9.

[135] Koktekir BE, Bozkurt B, Gonul S, Gedik S, Okudan S. Effect of religious fasting on tear osmolarity and ocular surface. Eye Contact Lens 2014;40:239-42.

[136] Masmali A, Alrabiah S, Alharbi A, El-Hiti GA, Almubrad T. Investigation of tear osmolarity using the TearLab osmolarity system in normal adults in Saudi Arabia. Eye Contact Lens 2014;40:74-8.

[137] Bunya VY, Fuerst NM, Pistilli M, McCabe BE, Salvo R, Macchi I, et al. Variability of tear osmolarity in patients with dry eye. JAMA Ophthalmol 2015;133:662-7.

[138] Tomlinson A, Khanal S, Ramaesh K, Diaper C, McFadyen A. Tear film osmolarity: determination of a referent for dry eye diagnosis. Invest Ophthalmol Vis Sci 2006;47:4309-15.

[139] Caffery B, Chalmers RL, Marsden H, Nixon G, Watanabe R, Harrison W, et al Correlation of tear osmolarity and dry eye symptoms in convention attendees. Optom Vis Sci 2014;91:142-9.

[140] Fuerst N, Langelier N, Massaro-Giordano M, Pistilli M, Stasi K, Burns C, et al Tear osmolarity and dry eye symptoms in diabetics. Clin Ophthalmol 2014;8: 507-15.

[141] Eperjesi F, Aujla M, Bartlett H. Reproducibility and repeatability of the OcuSense TearLab osmometer. Graefes Arch Clin Exp Ophthalmol 2012;250: $1201-5$.

[142] Niimi J, Tan B, Chang J, Zhou Y, Ghanekar A, Wong M, et al. Diurnal pattern of tear osmolarity and its relationship to corneal thickness and deswelling. Cornea 2013;32:1305-10.

[143] Yeh TN, Graham AD, Lin MC. Relationships among tear film stability, osmolarity, and dryness symptoms. Optom Vis Sci 2015;92:e264-72.

[144] Tomlinson A, Pearce EI, Simmons PA, Blades K. Effect of oral contraceptives on tear physiology. Ophthalmic Physiol Opt 2001;21:9-16. 
[145] Vehof J, Wang B, Kozareva D, Hysi PG, Snieder H, Hammond CJ. The heritability of dry eye disease in a female twin cohort. Invest Ophthalmol Vis Sci 2014;55:7278-83.

[146] Sullivan BD, Pepose JS, Foulks GN. Progressively increased variation in tea osmolarity mirrors dry eye severity. JAMA Ophthalmol 2015;133:1481-2.

[147] Lee YB, Koh JW, Hyon JY, Wee WR, Kim JJ, Shin YJ. Sleep deprivation reduces tear secretion and impairs the tear film. Invest Ophthalmol Vis Sci 2014;55: $3525-31$.

[148] Willmann G, Schatz A, Fischer MD, Schommer K, Zrenner E, BartzSchmidt KU, et al. Exposure to high altitude alters tear film osmolarity and breakup time. High Alt Med Biol 2014;15:203-7.

[149] Khanal S, Millar TJ. Barriers to clinical uptake of tear osmolarity measurements. Br J Ophthalmol 2012:96:341-4.

[150] Fortes MB, Diment BC, Di Felice U, Gunn AE, Kendall JL, Esmaeelpour M, et al Tear fluid osmolarity as a potential marker of hydration status. Med Sci Sports Exerc 2011;43:1590-7.

[151] Walsh NP, Fortes MB, Esmaeelpour M. Influence of modest changes in whole-body hydration on tear fluid osmolarity: important considerations for dry eye disease detection. Cornea 2011;30:1517. author reply -8.

[152] Walsh NP, Fortes MB, Raymond-Barker P, Bishop C, Owen J, Tye E, et al. Is whole-body hydration an important consideration in dry eye? Invest Ophthalmol Vis Sci 2012;53:6622-7.

[153] Braun RJ, King-Smith PE, Begley CG, Li L, Gewecke NR. Dynamics and function of the tear film in relation to the blink cycle. Prog Retin Eye Res 2015;45: 132-64.

[154] Li L, Braun RJ, Driscoll TA, Henshaw WD, Banks JW, King-Smith PE. Computed tear film and osmolarity dynamics on an eye-shaped domain. Math Med Bio 2016;33:123-57.

[155] Begley C, Simpson T, Liu H, Salvo E, Wu Z, Bradley A, et al. Quantitative analysis of tear film fluorescence and discomfort during tear film instability and thinning. Invest Ophthalmol Vis Sci 2013;54:2645-53.

[156] Varikooty J, Simpson TL. The interblink interval I: the relationship between sensation intensity and tear film disruption. Invest Ophthalmol Vis Sci 2009:50:1087-92.

[157] Liu H, Begley C, Chen M, Bradley A, Bonanno J, McNamara NA, et al. A link between tear instability and hyperosmolarity in dry eye. Invest Ophthalmo Vis Sci 2009;50:3671-9.

[158] Craig JP, Singh I, Tomlinson A, Morgan PB, Efron N. The role of tear physiology in ocular surface temperature. Eye (Lond) 2000;14(Pt 4):635-41.

[159] Research in dry eye: report of the research subcommittee of the international dry eye WorkShop (2007). Ocul Surf 2007:5:179-93.

[160] Suzuki M, Massingale ML, Ye F, Godbold J, Elfassy T, Vallabhajosyula M, et al. Tear osmolarity as a biomarker for dry eye disease severity. Invest Ophthalmol Vis Sci 2010:51:4557-61.

[161] Sullivan BD, Crews LA, Sonmez B, de la Paz MF, Comert E, Charoenrook V, et al. Clinical utility of objective tests for dry eye disease: variability ove time and implications for clinical trials and disease management. Cornea 2012:31:1000-8.

[162] Sullivan BD, Whitmer D, Nichols KK, Tomlinson A, Foulks GN, Geerling G, et al. An objective approach to dry eye disease severity. Invest Ophthalmo Vis Sci 2010:51:6125-30.

[163] Tukenmez-Dikmen N, Yildiz EH, Imamoglu S, Turan-Vural E, Sevim MS. Correlation of dry eye workshop dry eye severity grading system with tea meniscus measurement by optical coherence tomography and tear osmolarity. Eye Contact Lens 2016:42:153-7.

[164] Utine CA, Bicakcigil M, Yavuz S, Ciftci F. Tear osmolarity measurements in dry eye related to primary Sjogren's syndrome. Curr Eye Res 2011;36:683-90.

[165] Gilbard JP, Farris RL, Santamaria 2nd J. Osmolarity of tear microvolumes in keratoconjunctivitis sicca. Arch Ophthalmol 1978;96:677-81.

[166] Alves M, Reinach PS, Paula JS, Vellasco e Cruz AA, Bachette L, Faustino J, et al. Comparison of diagnostic tests in distinct well-defined conditions related to dry eye disease. PLoS One 2014:9:e97921.

[167] Bunya VY, Langelier N, Chen S, Pistilli M, Vivino FB, Massaro-Giordano G Tear osmolarity in Sjogren syndrome. Cornea 2013;32:922-7.

[168] Amparo F, Jin Y, Hamrah P, Schaumberg DA, Dana R. What is the value of incorporating tear osmolarity measurement in assessing patient response to therapy in dry eye disease? Am J Ophthalmol 2014;157:69-77.

[169] Berchicci L, Iuliano L, Miserocchi E, Bandello F, Modorati G. Tear osmolarity in ocular graft-versus-host disease. Cornea 2014;33:1252-6.

[170] Na KS, Yoo YS, Hwang KY, Mok JW, Joo CK. Tear osmolarity and ocular surface parameters as diagnostic markers of ocular graft-versus-host disease. Am J Ophthalmol 2015;160:143-9. e1.

[171] Schargus M, Meyer-ter-Vehn T, Menrath J, Grigoleit GU, Geerling G. Correlation between tear film osmolarity and the disease score of the International Chronic Ocular Graft-Versus-Host-Disease Consensus Group in hematopoietic stem cell transplantation patients. Cornea 2015;34:911-6.

[172] Rolando M, Baldi F, Calabria GA. Tear mucus ferning in keratoconjunctivitis sicca. In: Holly FJ, editor. The preocular tear film in health, disease and contact lens wear. Lubbock, Tex: Dry Eye Institute; 1986. p. 203-9.

[173] Kogbe O, Liotet S, Tiffany JM. Factors responsible for tear ferning. Cornea $1991 ; 10: 433-44$.

[174] Golding TR, Brennan NA. The basis of tear ferning. Clin Exp Optom 1989;72: $102-12$

[175] Norn M. Quantitative tear ferning. Clinical investigations. Acta Ophthalmol (Copenh) 1994;72:369-72.
[176] Vaikoussis E, Georgiou P, Nomicarios D. Tear mucus ferning in patients with Sjogren's syndrome. Doc Ophthalmol 1994;87:145-51.

[177] Maragou M, Vaikousis E, Ntre A, Koronis N, Georgiou P, Hatzidimitriou E, et al. Tear and saliva ferning tests in Sjogren's syndrome (SS). Clin Rheumatol 1996;15:125-32.

[178] Masmali AM, Al-Ohtani S, Al-Gasham TM, El-Hiti GA, Purslow C, Murphy PJ. Application of a new grading scale for tear ferning in non-dry eye and dry eye subjects. Cont Lens Anterior Eye 2015;38:39-43.

[179] Bitton E, Keech A, Jones L, Simpson T. Subjective and objective variation of the tear film pre- and post-sleep. Optom Vis Sci 2008;85:740-9.

[180] Masmali AM, Al-Bahlal JM, El-Hiti GA, Akhtar S, Purslow C, Murphy PJ, et al. Repeatability and diurnal variation of tear ferning test. Eye Contact Lens 2015;41:262-7.

[181] Sharanjeet K, Ho CY, Mutalib HA, Ghazali AR. The relationship between tear ferning patterns and non-invasive tear break-up time in normal Asian population. J Optom 2016;9:175-81.

[182] Versura P, Fresina M, Campos EC. Ocular surface changes over the menstrual cycle in women with and without dry eye. Gynecol Endocrinol 2007;23: 385-90.

[183] Cennamo GL, Del Prete A, Forte R, Cafiero G, Del Prete S, Marasco D. Impression cytology with scanning electron microscopy: a new method in the study of conjunctival microvilli. Eye (Lond) 2008;22:138-43.

[184] Ravazzoni L, Ghini C, Macri A, Rolando M. Forecasting of hydrophilic contact lens tolerance by means of tear ferning test. Graefes Arch Clin Exp Ophthalmol 1998;236:354-8.

[185] Pensyl CD, Dillehay SM. The repeatability of tear mucus ferning grading. Optom Vis Sci 1998:75:600-4.

[186] Evans KS, North RV, Purslow C. Tear ferning in contact lens wearers. Ophthalmic Physiol Opt 2009;29:199-204.

[187] Julio G, Lluch S, Cardona G, Fornieles A, Merindano D. Item by item analysis strategy of the relationship between symptoms and signs in early dry eye. Curr Eye Res 2012;37:357-64.

[188] Versura P, Cellini M, Torreggiani A, Profazio V, Bernabini B, Caramazza R. Dryness symptoms, diagnostic protocol and therapeutic management: a report on 1,200 patients. Ophthalmic Res 2001;33:221-7.

[189] Julio G, Lluch S, Pujol P, Merindano MD. Effects of tear hyperosmolarity on conjunctival cells in mild to moderate dry eye. Ophthalmic Physiol Opt 2012;32:317-23.

[190] Horwath J, Ettinger K, Bachernegg M, Bodner E, Schmut O. Ocular Ferning test - effect of temperature and humidity on tear Ferning patterns. Ophthalmologica $2001 ; 215: 102-7$.

[191] Norn M. Quantitative tear ferning. Methodologic and experimental investigations. Acta Ophthalmol (Copenh) 1988;66:201-5.

[192] Jackson JA, Perrigin JA. Relationship of impression cytology and tear ferning to reports of dry eye. J Am Optom Assoc 1999;70:187-92.

[193] Versura P, Profazio V, Cellini M, Torreggiani A, Caramazza R. Eye discomfort and air pollution. Ophthalmologica 1999;213:103-9.

[194] Battaglia Parodi M, Giusto DD. Ocular fluid ferning test and fractals. Ophthalmic Res 1993;25:307-13.

[195] Versura P, Frigato M, Cellini M, Mule R, Malavolta N, Campos EC. Diagnostic performance of tear function tests in Sjogren's syndrome patients. Eye (Lond) 2007:21:229-37.

[196] Rolando M, Baldi F, Zingirian M. The effect of hyperosmolarity on tear mucus ferning. Fortschr Ophthalmol 1986;83:644-6.

[197] Tatlipinar S, Gedik S, Irkec M, Orhan M, Erdener U. Ocular ferning during the menstrual cycle in healthy women. Eur J Ophthalmol 2001;11:15-8.

[198] Puderbach S, Stolze HH. Tear ferning and other lacrimal tests in normal persons of different ages. Int Ophthalmol 1991;15:391-5.

[199] Felberg S, Cordeiro H, Sato EH, Martini Filho D, Nishiwaki-Dantas MC, Endo RM, et al. Reproducibility of the classification of ocular ferning patterns in Sjogren's syndrome patients. Arq Bras Oftalmol 2008;71:228-33.

[200] Norn MS. Diagnosis of dry eye. In: Lemp MA, Marquardt R, editors. The Dry Eye: A Comprehensive Guide. New York: Springer Verlag; 1992. p. 133-82.

[201] Wyon NM, Wyon DP. Measurement of acute response to draught in the eye. Acta Ophthalmol (Copenh) 1987;65:385-92.

[202] Kogbe O, Liotet S. An interesting use of the study of tear ferning patterns in contactology. Ophthalmologica 1987;194:150-3.

[203] Altman PL, Dittmer DS. Physical properties and chemical composition of tears. Man. Biology Data Book. Bethesda, Maryland: Federation of Americal Societies of Experimental Biology; 1974. p. 2032-40.

[204] Carney LG, Hill RM. Human tear pH. Diurnal variations. Arch Ophthalmol 1976:94:821-4.

[205] Norn MS. Tear fluid pH in normals, contact lens wearers, and pathological cases. Acta Ophthalmol (Copenh) 1988;66:485-9.

[206] Carney LG, Hill RM. Human tear buffering capacity. Arch Ophthalmol 1979;97:951-2.

[207] Abelson MB, Udell IJ, Weston JH. Normal human tear pH by direct measurement. Arch Ophthalmol 1981;99:301.

[208] Fischer FH, Wiederholt M. Human precorneal tear film $\mathrm{pH}$ measured by microelectrodes. Graefes Arch Clin Exp Ophthalmol 1982:218:168-70.

[209] McCarey BE, Wilson LA. pH, osmolarity and temperature effects on the water content of hydrogel contact lenses. Contact Intraocul Lens Med J 1982;8: 158-67.

[210] Coles WH, Jaros PA. Dynamics of ocular surface pH. Br J Ophthalmol 1984;68: 549-52. 
[211] Norn M. Tear pH after instillation of buffer in vivo. Acta Ophthalmol Suppl 1985;173:32-4.

[212] Andres S, Garcia ML, Espina M, Valero J, Valls O. Tear pH, air pollution, and contact lenses. Am J Optom Physiol Opt 1988;65:627-31.

[213] Chen FS, Maurice DM. The pH in the precorneal tear film and under a contact lens measured with a fluorescent probe. Exp Eye Res 1990;50:251-9.

[214] Khurana AK, Chaudhary R, Ahluwalia BK, Gupta S. Tear film profile in dry eye. Acta Ophthalmol (Copenh) 1991;69:79-86.

[215] Yamada M, Mochizuki H, Kawai M, Yoshino M, Mashima Y. Fluorophotometric measurement of $\mathrm{pH}$ of human tears in vivo. Curr Eye Res 1997;16: 482-6.

[216] Janszky I, Vamosi P, Orszagh I, Berta A. Demonstration of increasing standard $\mathrm{pH}$ value of lacrimal fluid with increase of flow rate. Acta Ophthalmol Scand 2001;79:180-3.

[217] Mathers WD. Ocular evaporation in meibomian gland dysfunction and dry eye. Ophthalmology 1993;100:347-51.

[218] Shimazaki J, Sakata M, Tsubota K. Ocular surface changes and discomfort in patients with meibomian gland dysfunction. Arch Ophthalmol 1995;113: 1266-70.

[219] Mathers WD, Lane JA. Meibomian gland lipids, evaporation, and tear film stability. Adv Exp Med Biol 1998;438:349-60.

[220] Khanal S, Tomlinson A, McFadyen A, Diaper C, Ramaesh K. Dry eye diagnosis. Invest Ophthalmol Vis Sci 2008;49:1407-14.

[221] Rolando M, Refojo MF, Kenyon KR. Increased tear evaporation in eyes with keratoconjunctivitis sicca. Arch Ophthalmol 1983;101:557-8.

[222] Mathers WD, Daley TE. Tear flow and evaporation in patients with and without dry eye. Ophthalmology 1996;103:664-9.

[223] Hamano H, Hori M, Mitsunaga S. Application of an evaporimeter to the field of ophthalmology. J Jpn Contact Lens Soc 1980;22:101-7.

[224] Mathers W. Evaporation from the ocular surface. Exp Eye Res 2004;78: 389-94.

[225] Herok GH, Mudgil P, Millar TJ. The effect of Meibomian lipids and tear proteins on evaporation rate under controlled in vitro conditions. Curr Eye Res 2009;34:589-97.

[226] Hamano H, Hori M, Mitsunaga S. Measurement of evaporation rate of water from the precorneal tear film and contact lenses. Contactology 1981;25: $8-14$.

[227] Cedarstaff TH, Tomlinson A. A comparative study of tear evaporation rates and water content of soft contact lenses. Am J Optom Physiol Opt 1983;60: 167-74.

[228] Rolando M, Refojo MF. Tear evaporimeter for measuring water evaporation rate from the tear film under controlled conditions in humans. Exp Eye Res 1983;36:25-33.

[229] Trees GR, Tomlinson A. Effect of artificial tear solutions and saline on tear film evaporation. Optom Vis Sci 1990;67:886-90.

[230] Tsubota K, Yamada M. Tear evaporation from the ocular surface. Invest Ophthalmol Vis Sci 1992;33:2942-50.

[231] Mathers WD, Binarao G, Petroll M. Ocular water evaporation and the dry eye. A new measuring device. Cornea 1993;12:335-40.

[232] Goto E, Endo K, Suzuki A, Fujikura Y, Matsumoto Y, Tsubota K. Tear evaporation dynamics in normal subjects and subjects with obstructive meibomian gland dysfunction. Invest Ophthalmol Vis Sci 2003;44:533-9.

[233] Arciniega JC, Wojtowicz JC, Mohamed EM, McCulley JP. Changes in the evaporation rate of tear film after digital expression of meibomian glands in patients with and without dry eye. Cornea 2011;30:843-7.

[234] Kojima T, Matsumoto Y, Ibrahim OM, Wakamatsu TH, Uchino M, Fukagawa K, et al. Effect of controlled adverse chamber environment exposure on tear functions in silicon hydrogel and hydrogel soft contact lens wearers. Invest Ophthalmol Vis Sci 2011;52:8811-7.

[235] Petznick A, Tan JH, Boo SK, Lee SY, Acharya UR, Tong L. Repeatability of a new method for measuring tear evaporation rates. Optom Vis Sci 2013;90: 366-71.

[236] Thai LC, Tomlinson A, Doane MG. Effect of contact lens materials on tear physiology. Optom Vis Sci 2004;81:194-204.

[237] Guillon M, Maissa C. Contact lens wear affects tear film evaporation. Eye Contact Lens 2008;34:326-30.

[238] Hirayama M, Murat D, Liu Y, Kojima T, Kawakita T, Tsubota K. Efficacy of a novel moist cool air device in office workers with dry eye disease. Acta Ophthalmol 2013;91:756-62.

[239] Rohit A, Ehrmann K, Naduvilath T, Willcox M, Stapleton F. Validating a new device for measuring tear evaporation rates. Ophthalmic Physiol Opt 2014;34:53-62.

[240] Yeo S, Tan JH, Acharya UR, Sudarshan VK, Tong L. Longitudinal changes in tear evaporation rates after eyelid warming therapies in meibomian gland dysfunction. Invest Ophthalmol Vis Sci 2016;57:1974-81.

[241] Alghamdi WM, Markoulli M, Holden BA, Papas EB. Impact of duration of contact lens wear on the structure and function of the meibomian glands. Ophthalmic Physiol Opt 2016;36:120-31.

[242] Peng CC, Cerretani C, Braun RJ, Radke CJ. Evaporation-driven instability of the precorneal tear film. Adv Colloid Interface Sci 2014;206:250-64.

[243] Kimball SH, King-Smith PE, Nichols JJ. Evidence for the major contribution of evaporation to tear film thinning between blinks. Invest Ophthalmol Vis Sci 2010;51:6294-7.

[244] Mathers WD, Lane JA, Zimmerman MB. Tear film changes associated with normal aging. Cornea 1996;15:229-34.
[245] Guillon M, Maissa C. Tear film evaporation-effect of age and gender. Cont Lens Anterior Eye 2010;33:171-5.

[246] Tan JH, Ng EY, Acharya UR. Evaluation of tear evaporation from ocular surface by functional infrared thermography. Med Phys 2010;37:6022-34.

[247] Craig JP, Tomlinson A. Age and gender effects on the normal tear film. Adv Exp Med Biol 1998;438:411-5.

[248] Tsubota K, Nakamori K. Effects of ocular surface area and blink rate on tear dynamics. Arch Ophthalmol 1995;113:155-8.

[249] McCulley JP, Aronowicz JD, Uchiyama E, Shine WE, Butovich IA. Correlations in a change in aqueous tear evaporation with a change in relative humidity and the impact. Am J Ophthalmol 2006;141:758-60.

[250] Uchiyama E, Aronowicz JD, Butovich IA, McCulley JP. Increased evaporative rates in laboratory testing conditions simulating airplane cabin relative humidity: an important factor for dry eye syndrome. Eye Contact Lens 2007;33: 174-6.

[251] Abusharha AA, Pearce EI. The effect of low humidity on the human tear film. Cornea 2013;32:429-34.

[252] Tomlinson A, Doane MG, McFadyen A. Inputs and outputs of the lacrimal system: review of production and evaporative loss. Ocul Surf 2009;7: 186-98.

[253] Rantamaki AH, Javanainen M, Vattulainen I, Holopainen JM. Do lipids retard the evaporation of the tear fluid? Invest Ophthalmol Vis Sci 2012;53: $6442-7$.

[254] Borchman D, Foulks GN, Yappert MC, Mathews J, Leake K, Bell J. Factors affecting evaporation rates of tear film components measured in vitro. Eye Contact Lens 2009;35:32-7.

[255] Millar TJ, Schuett BS. The real reason for having a meibomian lipid layer covering the outer surface of the tear film - a review. Exp Eye Res 2015;137: 125-38.

[256] Brown SI, Dervichian DG. The oils of the meibomian glands. Physical and surface characteristics. Arch Ophthalmol 1969;82:537-40.

[257] Cerretani CF, Ho NH, Radke CJ. Water-evaporation reduction by duplex films: application to the human tear film. Adv Colloid Interface Sci 2013;197-198 33-57.

[258] Kulovesi P, Rantamaki AH, Holopainen JM. Surface properties of artificial tear film lipid layers: effects of wax esters. Invest Ophthalmol Vis Sci 2014;55: $4448-54$.

[259] La Mer VK, Healy TW. Evaporation of water: its retardation by monolayers: spreading a monomolecular film on the surface is a tested and economical means of reducing water loss. Science 1965;148:36-42.

[260] Paananen RO, Rantamaki AH, Holopainen JM. Antievaporative mechanism of wax esters: implications for the function of tear fluid. Langmuir 2014;30: 5897-902.

[261] Rantamaki AH, Wiedmer SK, Holopainen JM. Melting points-the key to the anti-evaporative effect of the tear film wax esters. Invest Ophthalmol Vis Sci 2013;54:5211-7.

[262] Butovich IA, Lu H, McMahon A, Ketelson H, Senchyna M, Meadows D, et al Biophysical and morphological evaluation of human normal and dry eye meibum using hot stage polarized light microscopy. Invest Ophthalmol Vis Sci 2014;55:87-101.

[263] Leiske D, Leiske C, Leiske D, Toney M, Senchyna M, Ketelson H, et al. Temperature-induced transitions in the structure and interfacial rheology of human meibum. Biophys J 2012;102:369-76.

[264] Lu H, Wojtowicz JC, Butovich IA. Differential scanning calorimetric evaluation of human meibomian gland secretions and model lipid mixtures: transition temperatures and cooperativity of melting. Chem Phys Lipids 2013;170-171:55-64.

[265] Bhamla MS, Chai C, Rabiah NI, Frostad JM, Fuller GG. Instability and breakup of model tear films. Invest Ophthalmol Vis Sci 2016;57:949-58.

[266] McCulley JP, Shine W. A compositional based model for the tear film lipid layer. Trans Am Ophthalmol Soc 1997;95:79-88. discussion -93.

[267] Iwata S, Lemp MA, Holly FJ, Dohlman CH. Evaporation rate of water from the precorneal tear film and cornea in the rabbit. Invest Ophthalmol 1969;8: 613-9.

[268] de Souza GA, Godoy LM, Mann M. Identification of 491 proteins in the tear fluid proteome reveals a large number of proteases and protease inhibitors. Genome Biol 2006; 7:R72.

[269] Green-Church KB, Nichols KK, Kleinholz NM, Zhang L, Nichols JJ. Investigation of the human tear film proteome using multiple proteomic approaches. Mol Vis 2008;14:456-70.

[270] Argueso P, Balaram M, Spurr-Michaud S, Keutmann HT, Dana MR, Gipson IK. Decreased levels of the goblet cell mucin MUC5AC in tears of patients with Sjogren syndrome. Invest Ophthalmol Vis Sci 2002;43:1004-11.

[271] Spurr-Michaud S, Argueso P, Gipson I. Assay of mucins in human tear fluid. Exp Eye Res 2007;84:939-50.

[272] Butovich IA. On the lipid composition of human meibum and tears: comparative analysis of nonpolar lipids. Invest Ophthalmol Vis Sci 2008;49: 3779-89.

[273] Langmuir I, Schaefer VJ. Rates of evaporation of water through compressed monolayers on water. J Frankl Inst 1943;235:119-62.

[274] Borchman D. Does the tear film lipid layer inhibit the rate of evaporation of tears? EC Ophthalmol 2015;3:251-3.

[275] Coullerez G, Gorodyska G, Reimhult E, Textor M. Grandin HM self-assembled multifunctional polymers for biointerfaces. In: Knoll W, Advincula RC, editors. Functional Polymer Films, vol. 2. Bognor Regis: John Wiley \& Sons Ltd. 
2012. p. 855-905.

[276] Green-Church KB, Butovich I, Willcox M, Borchman D, Paulsen F, Barabino S, et al. The international workshop on meibomian gland dysfunction: report of the subcommittee on tear film lipids and lipid-protein interactions in health and disease. Invest Ophthalmol Vis Sci 2011;52:1979-93.

[277] Tiffany JM. The lipid secretion of the meibomian glands. Adv Lipid Res 1987;22:1-62.

[278] Yokoi N, Yamada H, Mizukusa Y, Bron AJ, Tiffany JM, Kato T, et al. Rheology of tear film lipid layer spread in normal and aqueous tear-deficient dry eyes. Invest Ophthalmol Vis Sci 2008;49:5319-24.

[279] Rolando M, Valente C, Barabino S. New test to quantify lipid layer behavior in healthy subjects and patients with keratoconjunctivitis sicca. Cornea 2008;27:866-70.

[280] Kulovesi P, Telenius J, Koivuniemi A, Brezesinski G, Rantamaki A, Viitala T, et al. Molecular organization of the tear fluid lipid layer. Biophys J 2010;99: 2559-67.

[281] Kulovesi P, Telenius J, Koivuniemi A, Brezesinski G, Vattulainen I, Holopainen JM. The impact of lipid composition on the stability of the tear fluid lipid layer. Soft Matter 2012;8:5826-34.

[282] Kunnen CM, Brown SH, Lazon de la Jara P, Holden BA, Blanksby SJ, Mitchell TW, et al. Influence of meibomian gland expression methods on human lipid analysis results. Ocul Surf 2016;14:49-55.

[283] Haworth KM, Nichols JJ, Thangavelu M, Sinnott LT, Nichols KK. Examination of human meibum collection and extraction techniques. Optom Vis Sci 2011;88:525-33.

[284] Pucker AD, Nichols JJ. Analysis of meibum and tear lipids. Ocul Surf 2012;10: 230-50.

[285] Pucker AD, Haworth KM. The presence and significance of polar meibum and tear lipids. Ocul Surf 2015;13:26-42.

[286] Nagyova B, Tiffany JM. Components responsible for the surface tension of human tears, Curr Eye Res 1999:19:4-11.

[287] Svitova TF, Lin MC. Dynamic interfacial properties of human tear-lipid films and their interactions with model-tear proteins in vitro. Adv Colloid Interface Sci 2016:233:4-24.

[288] Borchman D, Foulks GN, Yappert MC, Tang D, Ho DV. Spectroscopic evaluation of human tear lipids. Chem Phys Lipids 2007;147:87-102.

[289] Saville JT, Zhao Z, Willcox MD, Blanksby SJ, Mitchell TW. Detection and quantification of tear phospholipids and cholesterol in contact lens deposits: the effect of contact lens material and lens care solution. Invest Ophthalmol Vis Sci 2010;51:2843-51.

[290] Lam SM, Tong L, Duan X, Petznick A, Wenk MR, Shui G. Extensive characterization of human tear fluid collected using different techniques unravels the presence of novel lipid amphiphiles. J Lipid Res 2014;55:289-98.

[291] Rohit A, Stapleton F, Brown SH, Mitchell TW, Willcox MD. Comparison of tea lipid profile among basal, reflex, and flush tear samples. Optom Vis Sci 2014;91:1391-5.

[292] Dean AW, Glasgow BJ. Mass spectrometric identification of phospholipids in human tears and tear lipocalin. Invest Ophthalmol Vis Sci 2012:53:1773-82.

[293] Georgiev GA. Controversies regarding the role of polar lipids in human and animal tear film lipid layer. Ocul Surf 2015;13:176-8.

[294] Tiffany JM, Winter N, Bliss G. Tear film stability and tear surface tension. Curr Eye Res 1989;8:507-15.

[295] Tiffany JM. Tears in health and disease. Eye (Lond) 2003;17:923-6.

[296] Millar TJ, Tragoulias ST, Anderton PJ, Ball MS, Miano F, Dennis GR, et al. The surface activity of purified ocular mucin at the air-liquid interface and interactions with meibomian lipids. Cornea 2006;25:91-100.

[297] Miano F, Calcara M, Millar TJ, Enea V. Insertion of tear proteins into a meibomian lipids film. Colloids Surf B Biointerfaces 2005:44:49-55.

[298] Millar TJ, Mudgil P, Butovich IA, Palaniappan CK. Adsorption of human tear lipocalin to human meibomian lipid films. Invest Ophthalmol Vis Sci 2009;50:140-51.

[299] Mudgil P, Torres M, Millar TJ. Adsorption of lysozyme to phospholipid and meibomian lipid monolayer films. Colloids Surf B Biointerfaces 2006;48: 128-37.

[300] Palaniappan CK, Schutt BS, Brauer L, Schicht M, Millar T]. Effects of keratin and lung surfactant proteins on the surface activity of meibomian lipids. Invest Ophthalmol Vis Sci 2013;54:2571-81.

[301] Leiske DL, Miller CE, Rosenfeld L, Cerretani C, Ayzner A, Lin B, et al. Molecular structure of interfacial human meibum films. Langmuir 2012:28:11858-65.

[302] Rosenfeld L, Cerretani C, Leiske DL, Toney MF, Radke CJ, Fuller GG. Structural and rheological properties of meibomian lipid. Invest Ophthalmol Vis Sc 2013;54:2720-32.

[303] Borchman D, Foulks GN, Yappert MC, Bell J, Wells E, Neravetla S, et al. Human meibum lipid conformation and thermodynamic changes with meibomiangland dysfunction. Invest Ophthalmol Vis Sci 2011;52:3805-17.

[304] King-Smith PE, Bailey MD, Braun RJ. Four characteristics and a model of an effective tear film lipid layer (TFLL). Ocul Surf 2013;11:236-45.

[305] Georgiev GA, Yokoi N, Ivanova S, Dimitov T, Andreev K, Krastev R, et al. Surface chemistry study of the interactions of hyaluronic acid and benzalkonium chloride with meibomian and corneal cell lipids. Soft Matter 2013:9: 10841-56.

[306] Leiske DL, Raju SR, Ketelson HA, Millar TJ, Fuller GG. The interfacial viscoelastic properties and structures of human and animal Meibomian lipids. Exp Eye Res 2010;90:598-604.

[307] Tragoulias ST, Anderton PJ, Dennis GR, Miano F, Millar TJ. Surface pressure measurements of human tears and individual tear film components indicate that proteins are major contributors to the surface pressure. Cornea 2005;24:189-200.

[308] Millar TJ. A mechanism to explain the behaviour of spread films of meibomian lipids. Curr Eye Res 2013;38:220-3.

[309] Butovich IA. Tear film lipids. Exp Eye Res 2013;117:4-27.

[310] Wizert A, Iskander DR, Cwiklik L. Organization of lipids in the tear film: a molecular-level view. PLoS One 2014;9:e92461.

[311] Cwiklik L. Tear film lipid layer: a molecular level view. Biochim Biophys Acta 2016;1858:2421-30.

[312] Wei XE, Markoulli M, Millar TJ, Willcox MD, Zhao Z. Divalent cations in tears, and their influence on tear film stability in humans and rabbits. Invest Ophthalmol Vis Sci 2012;53:3280-5.

[313] Mudgil P, Millar TJ. Surfactant properties of human meibomian lipids. Invest Ophthalmol Vis Sci 2011;52:1661-70.

[314] Svitova TF, Lin MC. Tear lipids interfacial rheology: effect of lysozyme and lens care solutions. Optom Vis Sci 2010;87:10-20.

[315] Georgiev GA, Yokoi N, Koev K, Kutsarova E, Ivanova S, Kyumurkov A, et al. Surface chemistry study of the interactions of benzalkonium chloride with films of meibum, corneal cells lipids, and whole tears. Invest Ophthalmol Vis Sci 2011;52:4645-54.

[316] Georgiev GA, Yokoi N, Ivanova S, Krastev R, Lalchev Z. Surface chemistry study of the interactions of pharmaceutical ingredients with human meibum films. Invest Ophthalmol Vis Sci 2012;53:4605-15.

[317] Svitova TF, Lin MC. Lens-care-solution-induced alterations in dynamic interfacial properties of human tear-lipid films. Cont Lens Anterior Eye 2014;37:368-76.

[318] Ivanova S, Tonchev V, Yokoi N, Yappert MC, Borchman D, Georgiev GA. Surface properties of squalene/meibum films and NMR confirmation of squalene in tears. Int J Mol Sci 2015;16:21813-31.

[319] Georgiev GA, Kutsarova E, Jordanova A, Krastev R, Lalchev Z. Interactions of Meibomian gland secretion with polar lipids in Langmuir monolayers. Colloids Surfaces B Biointerfaces 2010;78:317-27.

[320] Schuett BS, Millar TJ. An investigation of the likely role of (O-acyl) omegahydroxy fatty acids in meibomian lipid films using (O-oleyl) omega-hydroxy palmitic acid as a model. Exp Eye Res 2013;115:57-64.

[321] Millar T], King-Smith PE. Analysis of comparison of human meibomian lipid films and mixtures with cholesteryl esters in vitro films using high resolution color microscopy. Invest Ophthalmol Vis Sci 2012;53:4710-9.

[322] Schuett BS, Millar TJ. Lipid component contributions to the surface activity of meibomian lipids. Invest Ophthalmol Vis Sci 2012:53:7208-19.

[323] Mochizuki H, Yamada M, Hatou S, Tsubota K. Turnover rate of tear-film lipid layer determined by fluorophotometry. Br J Ophthalmol 2009;93:1535-8.

[324] Sharma A, Ruckenstein E. Mechanism of tear film rupture and its implications for contact lens tolerance. Am J Optom Physiol Opt 1985;62:246-53.

[325] Craig JP, Wang MT, Kim D, Lee JM. Exploring the Predisposition of the Asian Eye to Development of Dry Eye. Ocul Surf 2016;14:385-92.

[326] Gouveia SM, Tiffany JM. Human tear viscosity: an interactive role for proteins and lipids. Biochim Biophys Acta 2005;1753:155-63.

[327] Pandit JC, Nagyova B, Bron AJ, Tiffany JM. Physical properties of stimulated and unstimulated tears. Exp Eye Res 1999;68:247-53.

[328] Tiffany JM. The viscosity of human tears. Int Ophthalmol 1991:15:371-6.

[329] Knop N, Knop E. [Meibomian glands. Part I: anatomy, embryology and histology of the Meibomian glands]. Ophthalmologe 2009;106:872-83.

[330] Blackie CA, Korb DR. The diurnal secretory characteristics of individual meibomian glands. Cornea 2010;29:34-8.

[331] Chew CK, Jansweijer C, Tiffany JM, Dikstein S, Bron AJ. An instrument for quantifying meibomian lipid on the lid margin: the Meibometer. Curr Eye Res 1993;12:247-54

[332] Chew CK, Hykin PG, Jansweijer C, Dikstein S, Tiffany JM, Bron AJ. The casual level of meibomian lipids in humans. Curr Eye Res 1993;12:255-9.

[333] Lam SM, Tong L, Reux B, Duan X, Petznick A, Yong SS, et al. Lipidomic analysis of human tear fluid reveals structure-specific lipid alterations in dry eye syndrome. J Lipid Res 2014;55:299-306.

[334] Butovich IA. The Meibomian puzzle: combining pieces together. Prog Retin Eye Res 2009;28:483-98.

[335] Butovich IA. Cholesteryl esters as a depot for very long chain fatty acids in human meibum. J Lipid Res 2009;50:501-13.

[336] Lam SM, Tong L, Yong SS, Li B, Chaurasia SS, Shui G, et al. Meibum lipid composition in Asians with dry eye disease. PLoS One 2011;6:e24339.

[337] Butovich IA, Wojtowicz JC, Molai M. Human tear film and meibum. Very long chain wax esters and (O-acyl)-omega-hydroxy fatty acids of meibum. J Lipid Res 2009;50:2471-85.

[338] Shine WE, McCulley JP. The role of cholesterol in chronic blepharitis. Invest Ophthalmol Vis Sci 1991;32:2272-80.

[339] Borchman D, Yappert MC, Milliner SE, Duran D, Cox GW, Smith RJ, et al. $13 C$ and $1 \mathrm{H}$ NMR ester region resonance assignments and the composition of human infant and child meibum. Exp Eye Res 2013;112:151-9.

[340] Sullivan BD, Evans JE, Dana MR, Sullivan DA. Influence of aging on the polar and neutral lipid profiles in human meibomian gland secretions. Arch Ophthalmol 2006;124:1286-92.

[341] Brown SH, Kunnen CM, Papas EB, Lazon de la Jara P, Willcox MD, Blanksby SJ, et al. Intersubject and Interday Variability in Human Tear and Meibum Lipidomes: A Pilot Study. Ocul Surf 2016;14:43-8.

[342] Borchman D, Yappert MC, Milliner SE, Smith RJ, Bhola R. Confirmation of the 
presence of squalene in human eyelid lipid by heteronuclear single quantum correlation spectroscopy. Lipids 2013;48:1269-77.

[343] Kelly GS. Squalene and its potential clinical uses. Altern Med Rev 1999;4: 29-36.

[344] Lam SM, Tong L, Duan X, Acharya UR, Tan JH, Petznick A, et al. Longitudinal changes in tear fluid lipidome brought about by eyelid-warming treatment in a cohort of meibomian gland dysfunction. J Lipid Res 2014;55:1959-69.

[345] Lewis BA, Engelman DM. Lipid bilayer thickness varies linearly with acyl chain length in fluid phosphatidylcholine vesicles. J Mol Biol 1983;166: $211-7$.

[346] Borchman D, Foulks GN, Yappert MC, Milliner SE. Differences in human meibum lipid composition with meibomian gland dysfunction using NMR and principal component analysis. Invest Ophthalmol Vis Sci 2012;53: $337-47$.

[347] Shrestha RK, Borchman D, Foulks GN, Yappert MC, Milliner SE. Analysis of the composition of lipid in human meibum from normal infants, children, adolescents, adults, and adults with meibomian gland dysfunction using (1) H-NMR spectroscopy. Invest Ophthalmol Vis Sci 2011;52:7350-8.

[348] Borchman D, Foulks GN, Yappert MC, Milliner SE. Changes in human meibum lipid composition with age using nuclear magnetic resonance spectroscopy. Invest Ophthalmol Vis Sci 2012;53:475-82.

[349] Borchman D, Foulks GN, Yappert MC, Kakar S, Podoll N, Rychwalski P, et al. Physical changes in human meibum with age as measured by infrared spectroscopy. Ophthalmic Res 2010;44:34-42.

[350] Borchman D, Yappert MC, Foulks GN. Changes in human meibum lipid with meibomian gland dysfunction using principal component analysis. Exp Eye Res 2010;91:246-56.

[351] Saville JT, Zhao Z, Willcox MD, Ariyavidana MA, Blanksby SJ, Mitchell TW. Identification of phospholipids in human meibum by nano-electrospray ionisation tandem mass spectrometry. Exp Eye Res 2011:92:238-40.

[352] Rantamaki AH, Seppanen-Laakso T, Oresic M, Jauhiainen M, Holopainen JM. Human tear fluid lipidome: from composition to function. PLoS One 2011;6: e19553.

[353] Strott CA, Higashi Y. Cholesterol sulfate in human physiology: what's it all about? J Lipid Res 2003;44:1268-78.

[354] Hattrup CL, Gendler SJ. Structure and function of the cell surface (tethered) mucins. Annu Rev Physiol 2008:70:431-57.

[355] Thornton DJ, Rousseau K, McGuckin MA. Structure and function of the polymeric mucins in airways mucus. Annu Rev Physiol 2008;70:459-86.

[356] Corfield AP. Mucins: a biologically relevant glycan barrier in mucosal protection. Biochim Biophys Acta 2015;1850:236-52.

[357] Carraway KL, Perez A, Idris N, Jepson S, Arango M, Komatsu M, et al. Muc4/ sialomucin complex, the intramembrane ErbB2 ligand, in cancer and epithelia: to protect and to survive. Prog Nucleic Acid Res Mol Biol 2002;71: 149-85.

[358] Dartt DA. Control of mucin production by ocular surface epithelial cells. Exp Eye Res 2004; 78:173-85.

[359] Hodges RR, Dartt DA. Tear film mucins: front line defenders of the ocular surface; comparison with airway and gastrointestinal tract mucins. Exp Eye Res 2013;117:62-78.

[360] Stephens DN, McNamara NA. Altered mucin and glycoprotein expression in dry eye disease. Optom Vis Sci 2015;92:931-8.

[361] Argueso P. Glycobiology of the ocular surface: mucins and lectins. Jpn J Ophthalmol 2013;57:150-5.

[362] Mantelli F, Argueso P. Functions of ocular surface mucins in health and disease. Curr Opin Allergy Clin Immunol 2008;8:477-83.

[363] Paulsen F, Langer G, Hoffmann W, Berry M. Human lacrimal gland mucins, Cell Tissue Res 2004;316:167-77.

[364] Yu DF, Chen Y, Han JM, Zhang H, Chen XP, Zou WJ, et al. MUC19 expression in human ocular surface and lacrimal gland and its alteration in Sjogren syndrome patients. Exp Eye Res 2008;86:403-11.

[365] Moore JE, Vasey GT, Dartt DA, McGilligan VE, Atkinson SD, Grills C, et al Effect of tear hyperosmolarity and signs of clinical ocular surface pathology upon conjunctival goblet cell function in the human ocular surface. Invest Ophthalmol Vis Sci 2011;52:6174-80.

[366] Zhang J, Yan X, Li H. Analysis of the correlations of mucins, inflammatory markers, and clinical tests in dry eye. Cornea 2013;32:928-32.

[367] Shimazaki-Den S, Dogru M, Higa K, Shimazaki J. Symptoms, visual function, and mucin expression of eyes with tear film instability. Cornea 2013;32: $1211-8$.

[368] Uchino Y, Uchino M, Yokoi N, Dogru M, Kawashima M, Okada N, et al. Alteration of tear mucin 5 AC in office workers using visual display terminals: The Osaka Study. JAMA Ophthalmol 2014;132:985-92.

[369] Dogru M, Matsumoto Y, Okada N, Igarashi A, Fukagawa K, Shimazaki J, et al. Alterations of the ocular surface epithelial MUC16 and goblet cell MUC5AC in patients with atopic keratoconjunctivitis. Allergy 2008;63:1324-34.

[370] Corrales RM, Calonge M, Herreras JM, Saez V, Chaves FJ. Human epithelium from conjunctival impression cytology expresses MUC7 mucin gene. Cornea 2003;22:665-71.

[371] Jumblatt MM, McKenzie RW, Steele PS, Emberts CG, Jumblatt JE. MUC7 expression in the human lacrimal gland and conjunctiva. Cornea 2003;22: $41-5$.

[372] Gomes GP, Assis MA, Fonseca JS, de Souza PE, Zenobio EG, Oliveira DD, et al. Genetic polymorphism of MUC7 in individuals with aggressive or chronic periodontitis. J Oral Sci 2011;53:445-9.
[373] Gururaja TL, Ramasubbu N, Venugopalan P, Reddy MS, Ramalingam K, Levine MJ. Structural features of the human salivary mucin, MUC7. Glycoconj J 1998;15:457-67.

[374] Corrales RM, Narayanan S, Fernandez I, Mayo A, Galarreta DJ, FuentesPaez G, et al. Ocular mucin gene expression levels as biomarkers for the diagnosis of dry eye syndrome. Invest Ophthalmol Vis Sci 2011;52:8363-9.

[375] Pflugfelder SC, Liu Z, Monroy D, Li DQ Carvajal ME, Price-Schiavi SA, et al Detection of sialomucin complex (MUC4) in human ocular surface epithelium and tear fluid. Invest Ophthalmol Vis Sci 2000;41:1316-26.

[376] Mantelli F, Schaffer L, Dana R, Head SR, Argueso P. Glycogene expression in conjunctiva of patients with dry eye: downregulation of Notch signaling. Invest Ophthalmol Vis Sci 2009;50:2666-72.

[377] Woodward AM, Argueso P. Expression analysis of the transmembrane mucin MUC20 in human corneal and conjunctival epithelia. Invest Ophthalmol Vis Sci 2014;55:6132-8.

[378] Singh PK, Hollingsworth MA. Cell surface-associated mucins in signal transduction. Trends Cell Biol 2006;16:467-76.

[379] Shen Q, Rahn JJ, Zhang J, Gunasekera N, Sun X, Shaw AR, et al. MUC1 initiates Src-CrkL-Rac1/Cdc42-mediated actin cytoskeletal protrusive motility after ligating intercellular adhesion molecule-1. Mol Cancer Res 2008;6:555-67.

[380] Gipson IK, Spurr-Michaud S, Tisdale A, Menon BB. Comparison of the transmembrane mucins MUC1 and MUC16 in epithelial barrier function. PLoS One 2014;9:e100393.

[381] Corrales RM, Galarreta D, Herreras JM, Saez V, Arranz I, Gonzalez MJ, et al. Conjunctival mucin mRNA expression in contact lens wear. Optom Vis Sci 2009;86:1051-8.

[382] Argueso P, Guzman-Aranguez A, Mantelli F, Cao Z, Ricciuto J, Panjwani N. Association of cell surface mucins with galectin-3 contributes to the ocular surface epithelial barrier. J Biol Chem 2009;284:23037-45.

[383] Uchino Y, Mauris J, Woodward AM, Dieckow J, Amparo F, Dana R, et al. Alteration of galectin-3 in tears of patients with dry eye disease. Am J Ophthalmol 2015;159:1027-35.

[384] Gipson IK, Spurr-Michaud SJ, Senchyna M, Ritter 3rd R, Schaumberg D. Comparison of mucin levels at the ocular surface of postmenopausal women with and without a history of dry eye. Cornea 2011;30:1346-52.

[385] Caffery B, Heynen ML, Joyce E, Jones L, Ritter 3rd R, Senchyna M. MUC1 expression in Sjogren's syndrome, KCS, and control subjects. Mol Vis 2010;16:1720-7.

[386] Caffery B, Joyce E, Heynen ML, Jones L, Ritter 3rd R, Gamache DA, et al. MUC16 expression in Sjogren's syndrome, KCS, and control subjects. Mol Vis 2008; $14: 2547-55$.

[387] Albertsmeyer AC, Kakkassery V, Spurr-Michaud S, Beeks O, Gipson IK. Effect of pro-inflammatory mediators on membrane-associated mucins expressed by human ocular surface epithelial cells. Exp Eye Res 2010;90:444-51.

[388] Li YY, Chang JW, Hsieh LL, Yeh KY. Neutralization of interleukin (IL)-10 released by monocytes/macrophages enhances the up-regulatory effect of monocyte/macrophage-derived IL-6 on expressions of IL-6 and MUC1, and migration in HT-29 colon cancer cells. Cell Immunol 2010;265:164-71.

[389] Paulsen F, Jager K, Worlitzsch D, Brauer L, Schulze U, Schafer G, et al Regulation of MUC16 by inflammatory mediators in ocular surface epithelial cell lines. Ann Anat 2008;190:59-70.

[390] Cermak JM, Krenzer KL, Sullivan RM, Dana MR, Sullivan DA. Is complete androgen insensitivity syndrome associated with alterations in the meibomian gland and ocular surface? Cornea 2003;22:516-21.

[391] Argueso P, Tisdale A, Mandel U, Letko E, Foster CS, Gipson IK. The cell-layerand cell-type-specific distribution of GalNAc-transferases in the ocular surface epithelia is altered during keratinization. Invest Ophthalmol Vis Sci 2003;44:86-92.

[392] Argueso P, Sumiyoshi M. Characterization of a carbohydrate epitope defined by the monoclonal antibody H185: sialic acid O-acetylation on epithelial cell-surface mucins. Glycobiology 2006;16:1219-28.

[393] Danjo Y, Watanabe H, Tisdale AS, George M, Tsumura T, Abelson MB, et al. Alteration of mucin in human conjunctival epithelia in dry eye. Invest Ophthalmol Vis Sci 1998;39:2602-9.

[394] Hayashi Y, Kao WW, Kohno N, Nishihara-Hayashi M, Shiraishi A, Uno T, et al. Expression patterns of sialylated epitope recognized by KL-6 monoclonal antibody in ocular surface epithelium of normals and dry eye patients. Invest Ophthalmol Vis Sci 2004;45:2212-7.

[395] Nakamura Y, Yokoi N, Tokushige H, Kinoshita S. Sialic Acid in human tear fluid decreases in dry eye. Jpn J Ophthalmol 2004;48:519-23.

[396] Vijmasi T, Chen FY, Chen YT, Gallup M, McNamara N. Topical administration of interleukin-1 receptor antagonist as a therapy for aqueous-deficient dry eye in autoimmune disease. Mol Vis 2013;19:1957-65.

[397] Schmidt TA, Sullivan DA, Knop E, Richards SM, Knop N, Liu S, et al. Transcription, translation, and function of lubricin, a boundary lubricant, at the ocular surface. JAMA Ophthalmol 2013;131:766-76.

[398] Morrison S, Sullivan DA, Sullivan BD, Sheardown H, Schmidt TA. Dosedependent and synergistic effects of proteoglycan 4 on boundary lubrication at a human cornea-polydimethylsiloxane biointerface. Eye Contact Lens 2012;38:27-35.

[399] Samsom M, Chan A, Iwabuchi Y, Subbaraman L, Jones L, Schmidt TA. In vitro friction testing of contact lenses and human ocular tissues: Effect of proteoglycan 4 (PRG4). Tribol Int 2015;89:27-33.

[400] Samsom ML, Morrison S, Masala N, Sullivan BD, Sullivan DA, Sheardown H, et al. Characterization of full-length recombinant human Proteoglycan 4 as 
an ocular surface boundary lubricant. Exp Eye Res 2014;127:14-9.

[401] Lambiase A, Sullivan BD, Schmidt TA, Sullivan DA, Jay GD, Truitt 3rd ER, et al. A Two-Week, Randomized, Double-masked Study to Evaluate Safety and Efficacy of Lubricin (150 mug/mL) Eye Drops Versus Sodium Hyaluronate (HA) $0.18 \%$ Eye Drops (Vismed(R)) in Patients with Moderate Dry Eye Disease. Ocul Surf 2017:15:77-87.

[402] Schulz BL, Oxley D, Packer NH, Karlsson NG. Identification of two highly sialylated human tear-fluid DMBT1 isoforms: the major high-molecularmass glycoproteins in human tears. Biochem J 2002;366:511-20.

[403] Prakobphol A, Xu F, Hoang VM, Larsson T, Bergstrom J, Johansson I, et al. Salivary agglutinin, which binds Streptococcus mutans and Helicobacter pylori, is the lung scavenger receptor cysteine-rich protein gp-340. J Biol Chem 2000:275:39860-6.

[404] Leito JT, Ligtenberg AJ, van Houdt M, van den Berg TK, Wouters D. The bacteria binding glycoprotein salivary agglutinin (SAG/gp340) activates complement via the lectin pathway. Mol Immunol 2011;49:185-90.

[405] Karnati R, Laurie DE, Laurie GW. Lacritin and the tear proteome as natura replacement therapy for dry eye. Exp Eye Res 2013;117:39-52.

[406] Semba RD, Enghild JJ, Venkatraman V, Dyrlund TF, Van Eyk JE. The Human Eye Proteome Project: perspectives on an emerging proteome. Proteomics 2013;13:2500-11.

[407] Zhou L, Beuerman RW, Chan CM, Zhao SZ, Li XR, Yang H, et al. Identification of tear fluid biomarkers in dry eye syndrome using iTRAQ quantitative proteomics. J Proteom Res 2009;8:4889-905.

[408] Nichols JJ, Green-Church KB. Mass spectrometry-based proteomic analyses in contact lens-related dry eye. Cornea 2009;28:1109-17.

[409] Soria J, Duran JA, Etxebarria J, Merayo J, Gonzalez N, Reigada R, et al. Tear proteome and protein network analyses reveal a novel pentamarker panel for tear film characterization in dry eye and meibomian gland dysfunction. Proteom 2013;78:94-112.

[410] Boehm N, Funke S, Wiegand M, Wehrwein N, Pfeiffer N, Grus FH. Alterations in the tear proteome of dry eye patients-a matter of the clinical phenotype. Invest Ophthalmol Vis Sci 2013;54:2385-92.

[411] Li B, Sheng M, Li J, Yan G, Lin A, Li M, et al. Tear proteomic analysis of Sjogren syndrome patients with dry eye syndrome by two-dimensional-nano-liquid chromatography coupled with tandem mass spectrometry. Sci Rep 2014;4 5772 .

[412] Tong L, Zhou XY, Jylha A, Aapola U, Liu DN, Koh SK, et al. Quantitation of 47 human tear proteins using high resolution multiple reaction monitoring (HR-MRM) based-mass spectrometry. J Proteom 2015;115:36-48.

[413] Tsai PS, Evans JE, Green KM, Sullivan RM, Schaumberg DA, Richards SM, et al. Proteomic analysis of human meibomian gland secretions. $\mathrm{Br} \mathrm{J}$ Ophthalmol 2006;90:372-7.

[414] Perumal N, Funke S, Pfeiffer N, Grus FH. Proteomics analysis of human tears from aqueous-deficient and evaporative dry eye patients. Sci Rep 2016;6: 29629.

[415] Acera A, Rocha G, Vecino E, Lema I, Duran JA. Inflammatory markers in the tears of patients with ocular surface disease. Ophthalmic Res 2008;40: $315-21$.

[416] Seifert K, Gandia NC, Wilburn JK, Bower KS, Sia RK, Ryan DS, et al. Tear lacritin levels by age, sex, and time of day in healthy adults. Invest Ophthalmol Vis Sci 2012:53:6610-6.

[417] Enriquez-de-Salamanca A, Castellanos E, Stern ME, Fernandez I, Carreno E, Garcia-Vazquez C, et al. Tear cytokine and chemokine analysis and clinica correlations in evaporative-type dry eye disease. Mol Vis 2010;16:862-73.

[418] Acera A, Vecino E, Duran JA. Tear MMP-9 levels as a marker of ocular surface inflammation in conjunctivochalasis. Invest Ophthalmol Vis Sci 2013;54 8285-91.

[419] Lopez-Miguel A, Teson M, Martin-Montanez V, Enriquez-de-Salamanca A, Stern ME, Calonge M, et al. Dry eye exacerbation in patients exposed to desiccating stress under controlled environmental conditions. Am J Ophthalmol 2014;157:788-98.

[420] Zheng X, De Paiva CS, Rao K, Li DQ, Farley WJ, Stern M, et al. Evaluation of the transforming growth factor-beta activity in normal and dry eye human tears by CCL-185 cell bioassay. Cornea 2010;29:1048-54.

[421] Chan TC, Ye C, Chan KP, Chu KO, Jhanji V. Evaluation of point-of-care test for elevated tear matrix metalloproteinase 9 in post-LASIK dry eyes. Br J Ophthalmol 2016;100:1188-91.

[422] Gonzalez N, Iloro I, Duran JA, Elortza F, Suarez T. Evaluation of inter-day and inter-individual variability of tear peptide/protein profiles by MALDI-TOF MS analyses. Mol Vis 2012;18:1572-82.

[423] Boehm N, Riechardt AI, Wiegand M, Pfeiffer N, Grus FH. Proinflammatory cytokine profiling of tears from dry eye patients by means of antibody microarrays. Invest Ophthalmol Vis Sci 2011;52:7725-30.

[424] Choi W, Li Z, Oh HJ, Im SK, Lee SH, Park SH, et al. Expression of CCR5 and its ligands CCL3, -4 , and -5 in the tear film and ocular surface of patients with dry eye disease. Curr Eye Res 2012;37:12-7.

[425] Lam H, Bleiden L, de Paiva CS, Farley W, Stern ME, Pflugfelder SC. Tear cytokine profiles in dysfunctional tear syndrome. Am J Ophthalmol 2009;147:198-205.

[426] Lambiase A, Micera A, Sacchetti M, Cortes M, Mantelli F, Bonini S. Alterations of tear neuromediators in dry eye disease. Arch Ophthalmol 2011;129: 981-6.

[427] Massingale ML, Li X, Vallabhajosyula M, Chen D, Wei Y, Asbell PA. Analysis of inflammatory cytokines in the tears of dry eye patients. Cornea 2009;28:
$1023-7$

[428] McKown RL, Wang N, Raab RW, Karnati R, Zhang Y, Williams PB, et al. Lacritin and other new proteins of the lacrimal functional unit. Exp Eye Res 2009;88:848-58.

[429] Na KS, Mok JW, Kim JY, Rho CR, Joo CK. Correlations between tear cytokines, chemokines, and soluble receptors and clinical severity of dry eye disease. Invest Ophthalmol Vis Sci 2012;53:5443-50.

[430] Ohashi Y, Ishida R, Kojima T, Goto E, Matsumoto Y, Watanabe K, et al. Abnormal protein profiles in tears with dry eye syndrome. Am J Ophthalmol 2003;136:291-9.

[431] Rao K, Farley WJ, Pflugfelder SC. Association between high tear epidermal growth factor levels and corneal subepithelial fibrosis in dry eye conditions. Invest Ophthalmol Vis Sci 2010;51:844-9.

[432] Yoon KC, Jeong IY, Park YG, Yang SY. Interleukin-6 and tumor necrosis factoralpha levels in tears of patients with dry eye syndrome. Cornea 2007;26: 431-7.

[433] Solomon A, Dursun D, Liu Z, Xie Y, Macri A, Pflugfelder SC. Pro- and antiinflammatory forms of interleukin-1 in the tear fluid and conjunctiva of patients with dry-eye disease. Invest Ophthalmol Vis Sci 2001;42:2283-92.

[434] Virtanen T, Konttinen YT, Honkanen N, Harkonen M, Tervo T, Tear fluid plasmin activity of dry eye patients with Sjogren's syndrome. Acta Ophthalmol Scand 1997;75:137-41.

[435] Huang JF, Zhang Y, Rittenhouse KD, Pickering EH, McDowell MT. Evaluations of tear protein markers in dry eye disease: repeatability of measurement and correlation with disease. Invest Ophthalmol Vis Sci 2012;53:4556-64.

[436] Yoon KC, Park CS, You IC, Choi HJ, Lee KH, Im SK, et al. Expression of CXCL9, $-10,-11$, and CXCR3 in the tear film and ocular surface of patients with dry eye syndrome. Invest Ophthalmol Vis Sci 2010;51:643-50.

[437] Sack R, Conradi L, Beaton A, Sathe S, McNamara N, Leonardi A. Antibody array characterization of inflammatory mediators in allergic and normal tears in the open and closed eye environments. Exp Eye Res 2007;85: 528-38.

[438] Sanghi S, Kumar R, Lumsden A, Dickinson D, Klepeis V, Trinkaus-Randall V, et al. cDNA and genomic cloning of lacritin, a novel secretion enhancing factor from the human lacrimal gland. J Mol Biol 2001;310:127-39.

[439] LaFrance MW, Kehinde LE, Fullard RJ. Multiple cytokine analysis in human tears: an optimized procedure for cytometric bead-based assay. Curr Eye Res 2008;33:525-44.

[440] Willcox MD, Zhao Z, Naduvilath T, Lazon de la Jara P. Cytokine changes in tears and relationship to contact lens discomfort. Mol Vis 2015;21:293-305.

[441] Ananthi S, Venkatesh Prajna N, Lalitha P, Valarnila M, Dharmalingam K. Pathogen induced changes in the protein profile of human tears from Fusarium keratitis patients. PLoS One 2013;8:e53018.

[442] Grus FH, Podust VN, Bruns K, Lackner K, Fu S, Dalmasso EA, et al. SELDI-TOFMS ProteinChip array profiling of tears from patients with dry eye. Invest Ophthalmol Vis Sci 2005;46:863-76.

[443] Koo BS, Lee DY, Ha HS, Kim JC, Kim CW. Comparative analysis of the tear protein expression in blepharitis patients using two-dimensional electrophoresis. J Proteom Res 2005;4:719-24.

[444] Lee SH, Park MY, Kim KW, Wee SW, Kim JC. Zinc finger protein in severe dry eye syndrome. Curr Eye Res 2014;39:431-8.

[445] Lei Z, Beuerman RW, Chew AP, Koh SK, Cafaro TA, Urrets-Zavalia EA, et al. Quantitative analysis of $\mathrm{N}$-linked glycoproteins in tear fluid of climatic droplet keratopathy by glycopeptide capture and iTRAQ. J Proteom Res 2009;8:1992-2003.

[446] Matheis N, Grus FH, Breitenfeld M, Knych I, Funke S, Pitz S, et al. Proteomics differentiate between thyroid-associated orbitopathy and dry eye syndrome. Invest Ophthalmol Vis Sci 2015:56:2649-56.

[447] Srinivasan S, Thangavelu M, Zhang L, Green KB, Nichols KK. iTRAQ quantitative proteomics in the analysis of tears in dry eye patients. Invest Ophthalmol Vis Sci 2012;53:5052-9.

[448] Tong L, Zhou L, Beuerman RW, Zhao SZ, Li XR. Association of tear proteins with Meibomian gland disease and dry eye symptoms. Br J Ophthalmol 2011;95:848-52.

[449] Guyette N, Williams L, Tran MT, Than T, Bradley J, Kehinde L, et al. Comparison of low-abundance biomarker levels in capillary-collected nonstimulated tears and washout tears of aqueous-deficient and normal patients. Invest Ophthalmol Vis Sci 2013;54:3729-37.

[450] Versura P, Bavelloni A, Grillini M, Fresina M, Campos EC. Diagnostic performance of a tear protein panel in early dry eye. Mol Vis 2013;19:1247-57.

[451] Versura P, Nanni P, Bavelloni A, Blalock WL, Piazzi M, Roda A, et al. Tear proteomics in evaporative dry eye disease. Eye (Lond) 2010;24:1396-402.

[452] McNamara NA, Ge S, Lee SM, Enghauser AM, Kuehl L, Chen FY, et al. Reduced Levels of Tear Lacritin Are Associated With Corneal Neuropathy in Patients With the Ocular Component of Sjogren's Syndrome. Invest Ophthalmol Vis Sci 2016:57:5237-43.

[453] Masoudi S, Stapleton FJ, Willcox MD. Contact Lens-Induced Discomfort and Protein Changes in Tears. Optom Vis Sci 2016;93:955-62.

[454] Domingo I, Coll J, Ribas-Montobio J, Marrugat J, Rubies-Prat J. Lacrimal immunoglobulins in rheumatoid arthritis patients with or without Sjogren's syndrome. Ophthalmologica 1998;212:30-3.

[455] Hamm-Alvarez SF, Janga SR, Edman MC, Madrigal S, Shah M, Frousiakis SE, et al. Tear cathepsin S as a candidate biomarker for Sjogren's syndrome. Arthritis Rheumatol 2014;66:1872-81.

[456] Posa A, Brauer L, Schicht M, Garreis F, Beileke S, Paulsen F. Schirmer strip vs. 
capillary tube method: non-invasive methods of obtaining proteins from tear fluid. Ann Anat 2013;195:137-42.

[457] Perumal N, Funke S, Wolters D, Pfeiffer N, Grus FH. Characterization of human reflex tear proteome reveals high expression of lacrimal proline-rich protein 4 (PRR4). Proteomics 2015;15:3370-81.

[458] Fullard RJ, Snyder C. Protein levels in nonstimulated and stimulated tears of normal human subjects. Invest Ophthalmol Vis Sci 1990;31:1119-26.

[459] Fullard RJ, Tucker DL. Changes in human tear protein levels with progressively increasing stimulus. Invest Ophthalmol Vis Sci 1991:32:2290-301.

[460] Willcox MD, Morris CA, Thakur A, Sack RA, Wickson J, Boey W. Complement and complement regulatory proteins in human tears. Invest Ophthalmol Vis Sci 1997;38:1-8.

[461] Masoudi S, Zhao Z, Stapleton F, Willcox M. Contact Lens-Induced Discomfort and Inflammatory Mediator Changes in Tears. Eye Contact Lens 2017;43: $40-5$.

[462] Ferguson RE, Carroll HP, Harris A, Maher ER, Selby PJ, Banks RE. Housekeeping proteins: a preliminary study illustrating some limitations as useful references in protein expression studies. Proteomics 2005;5:566-71.

[463] Opsahl JA, Vaudel M, Guldbrandsen A, Aasebo E, Van Pesch V, Franciotta D, et al. Label-free analysis of human cerebrospinal fluid addressing various normalization strategies and revealing protein groups affected by multiple sclerosis. Proteomics 2016;16:1154-65.

[464] Pflugfelder SC, Jones D, Ji Z, Afonso A, Monroy D. Altered cytokine balance in the tear fluid and conjunctiva of patients with Sjogren's syndrome keratoconjunctivitis sicca. Curr Eye Res 1999;19:201-11.

[465] Tishler M, Yaron I, Geyer O, Shirazi I, Naftaliev E, Yaron M. Elevated tear interleukin-6 levels in patients with Sjogren syndrome. Ophthalmology 1998; 105:2327-9.

[466] Danjo Y, Lee M, Horimoto K, Hamano T. Ocular surface damage and tear lactoferrin in dry eye syndrome. Acta Ophthalmol (Copenh) 1994:72:433-7.

[467] Navone R, Lunardi C, Gerli R, Tinazzi E, Peterlana D, Bason C, et al. Identification of tear lipocalin as a novel autoantigen target in Sjogren's syndrome. J Autoimmun 2005;25:229-34.

[468] Yamada M, Mochizuki H, Kawai M, Tsubota K, Bryce TJ. Decreased tear lipocalin concentration in patients with meibomian gland dysfunction. $\mathrm{Br} \mathrm{J}$ Ophthalmol 2005;89:803-5.

[469] Zhao H, Jumblatt JE, Wood TO, Jumblatt MM. Quantification of MUC5AC protein in human tears. Cornea 2001;20:873-7.

[470] Aho VV, Nevalainen TJ, Saari KM. Group IIA phospholipase A2 content of tears in patients with keratoconjunctivitis sicca. Graefes Arch Clin Exp Ophthalmol 2002;240:521-3.

[471] Chen D, Wei Y, Li X, Epstein S, Wolosin JM, Asbell P. sPLA2-IIa is an inflammatory mediator when the ocular surface is compromised. Exp Eye Res 2009;88:880-8.

[472] Acera A, Suarez T, Rodriguez-Agirretxe I, Vecino E, Duran JA. Changes in tear protein profile in patients with conjunctivochalasis. Cornea 2011;30:42-9.

[473] Aho VV, Paavilainen V, Nevalainen TJ, Peuravuori H, Saari KM. Diurnal variation in group IIa phospholipase A2 content in tears of contact lens wearers and normal controls. Graefes Arch Clin Exp Ophthalmol 2003;241: $85-8$.

[474] Maria NI, Vogelsang P, Versnel MA. The clinical relevance of animal models in Sjogren's syndrome: the interferon signature from mouse to man. Arthritis Res Ther 2015;17:172.

[475] Bian F, Barbosa FL, Corrales RM, Pelegrino FS, Volpe EA, Pflugfelder SC, et al. Altered balance of interleukin-13/interferon-gamma contributes to lacrimal gland destruction and secretory dysfunction in CD25 knockout model of Sjogren's syndrome. Arthritis Res Ther 2015;17:53.

[476] Lee SY, Han SJ, Nam SM, Yoon SC, Ahn JM, Kim TI, et al. Analysis of tear cytokines and clinical correlations in Sjogren syndrome dry eye patients and non-Sjogren syndrome dry eye patients. Am J Ophthalmol 2013;156: 247-53.

[477] Afonso AA, Sobrin L, Monroy DC, Selzer M, Lokeshwar B, Pflugfelder SC. Tear fluid gelatinase B activity correlates with IL-1alpha concentration and fluorescein clearance in ocular rosacea. Invest Ophthalmol Vis Sci 1999;40: $2506-12$.

[478] Jones L, Downie LE, Korb D, Benitez-del-Castillo JM, Dana R, Deng SX, et al. TFOS DEWS II Management and Therapy report. Ocul Surf 2017; 15:575-628.

[479] Higuchi A, Ueno R, Shimmura S, Suematsu M, Dogru M, Tsubota K. Albumin rescues ocular epithelial cells from cell death in dry eye. Curr Eye Res 2007;32:83-8

[480] Pattamatta U, Willcox M, Stapleton F, Garrett Q. Bovine lactoferrin promotes corneal wound healing and suppresses IL-1 expression in alkali wounded mouse cornea. Curr Eye Res 2013;38:1110-7.

[481] Wang N, Zimmerman K, Raab RW, McKown RL, Hutnik CM, Talla V, et al. Lacritin rescues stressed epithelia via rapid forkhead box 03 (FOXO3)associated autophagy that restores metabolism. J Biol Chem 2013;288: 18146-61.

[482] Wang W, Jashnani A, Aluri SR, Gustafson JA, Hsueh PY, Yarber F, et al. A thermo-responsive protein treatment for dry eyes. J Control Release 2015;199:156-67.

[483] Seki JT, Sakurai N, Moldenhauer S, Dam J, Atenafu EG, Yip PM, et al. Human albumin eye drops as a therapeutic option for the management of keratoconjunctivitis sicca secondary to chronic graft-versus-host disease after stem-cell allografting. Curr Oncol 2015;22. e357-63.

[484] Ashby B, Garrett Q, Willcox M. Bovine lactoferrin structures promoting corneal epithelial wound healing in vitro. Invest Ophthalmol Vis Sci 2011;52:2719-26.

[485] Pastori V, Tavazzi S, Lecchi M. Lactoferrin-loaded contact lenses: eye protection against oxidative stress. Cornea 2015;34:693-7.

[486] Kawashima M, Kawakita T, Inaba T, Okada N, Ito M, Shimmura S, et al. Dietary lactoferrin alleviates age-related lacrimal gland dysfunction in mice. PLoS One 2012;7:e33148.

[487] Kawashima M, Nakamura S, Izuta Y, Inoue S, Tsubota K. Dietary Supplementation with a Combination of Lactoferrin, Fish Oil, and Enterococcus faecium WB2000 for Treating Dry Eye: A Rat Model and Human Clinical Study. Ocul Surf 2016;14:255-63.

[488] Devendra J, Singh S. Effect of oral lactoferrin on cataract surgery induced dry eye: a randomised controlled trial. J Clin Diagn Res 2015;9:NC06-9.

[489] Vijmasi T, Chen FY, Balasubbu S, Gallup M, McKown RL, Laurie GW, et al. Topical administration of lacritin is a novel therapy for aqueous-deficient dry eye disease. Invest Ophthalmol Vis Sci 2014;55:5401-9.

[490] Feng MM, Baryla J, Liu H, Laurie GW, McKown RL, Ashki N, et al. Cytoprotective effect of lacritin on human corneal epithelial cells exposed to benzalkonium chloride in vitro. Curr Eye Res 2014;39:604-10.

[491] Samudre S, Lattanzio Jr FA, Lossen V, Hosseini A, Sheppard Jr JD, McKown RL, et al. Lacritin, a novel human tear glycoprotein, promotes sustained basa tearing and is well tolerated. Invest Ophthalmol Vis Sci 2011;52:6265-70.

[492] Wang Z, Chen Z, Yang Q, Jiang Y, Lin L, Liu X, et al. Vitelline membrane outer layer 1 homolog interacts with lysozyme $C$ and promotes the stabilization of tear film. Invest Ophthalmol Vis Sci 2014;55:6722-7.

[493] Sambursky R, Davitt 3rd WF, Latkany R, Tauber S, Starr C, Friedberg M, et al. Sensitivity and specificity of a point-of-care matrix metalloproteinase 9 immunoassay for diagnosing inflammation related to dry eye. JAMA Ophthalmol 2013;131:24-8.

[494] D'Souza S, Petznick A, Tong L, Hall RC, Rosman M, Chan C, et al. Comparative analysis of two femtosecond LASIK platforms using iTRAQ quantitative proteomics. Invest Ophthalmol Vis Sci 2014;55:3396-402.

[495] Nättinen J, Jylhä A, Aapola U, Beuerman RW, Nykter M, Kesseli J, et al. Effects of preserved and preservative free glaucoma drugs on proteomic expression levels in corneal and conjunctival epithelial cells in vitro. Invest Ophthalmol Vis Sci 2015;56. E-Abstract 221.

[496] Zimmermann N, Erb C. Immunoassay for matrix metalloproteinase-9 in the tear film of patients with pseudoexfoliation syndrome - a pilot study. Klin Monbl Augenheilkd 2013;230:804-7.

[497] Sambursky R, Davitt 3rd WF, Friedberg M, Tauber S. Prospective, multicenter clinical evaluation of point-of-care matrix metalloproteinase-9 test for confirming dry eye disease. Cornea 2014;33:812-8.

[498] Schargus M, Ivanova S, Kakkassery V, Dick HB, Joachim S. Correlation of Tear Film Osmolarity and 2 Different MMP-9 Tests With Common Dry Eye Tests in a Cohort of Non-Dry Eye Patients. Cornea 2015:34:739-44.

[499] Lanza NL, McClellan AL, Batawi H, Felix ER, Sarantopoulos KD, Levitt RC, et al. Dry Eye Profiles in Patients with a Positive Elevated Surface Matrix Metalloproteinase 9 Point-of-Care Test Versus Negative Patients. Ocul Surf 2016;14:216-23.

[500] Zhou L, Beuerman RW, Foo Y, Liu S, Ang LP, Tan DT. Characterisation of human tear proteins using high-resolution mass spectrometry. Ann Acad Med Singapore 2006;35:400-7.

[501] Wei Y, Gadaria-Rathod N, Epstein S, Asbell P. Tear cytokine profile as a noninvasive biomarker of inflammation for ocular surface diseases: standard operating procedures. Invest Ophthalmol Vis Sci 2013;54:8327-36.

[502] Laguna MF, Sanza FJ, Soria J, Jara M, Lavin A, Casquel R, et al. Label-free biosensing by means of BICELLs for dry eye. Sensors Actuators B 2014;203: 209-12.

[503] Laguna MF, Holgado M, Hernandez AL, Santamaria B, Lavin A, Soria J, et al. Antigen-antibody affinity for dry eye biomarkers by label free biosensing. Comparison with the ELISA technique. Sensors (Basel) 2015;15:19819-29.

[504] Perumal N, Funke S, Pfeiffer N, Grus FH. Characterization of lacrimal prolinerich protein 4 (PRR4) in human tear proteome. Proteomics 2014;14: 1698-709.

[505] Aragona P, Aguennouz M, Rania L, Postorino E, Sommario MS Roszkowska AM, et al. Matrix metalloproteinase 9 and transglutaminase 2 expression at the ocular surface in patients with different forms of dry eye disease. Ophthalmology 2015;122:62-71.

[506] Csosz E, Mesko B, Fesus L. Transdab wiki: the interactive transglutaminase substrate database on web 2.0 surface. Amino Acids 2009;36:615-7.

[507] Velez VF, Romano JA, McKown RL, Green K, Zhang L, Raab RW, et al. Tissue transglutaminase is a negative regulator of monomeric lacritin bioactivity. Invest Ophthalmol Vis Sci 2013:54:2123-32.

[508] Azharuddin M, Khandelwal J, Datta H, Dasgupta AK, Raja SO. Dry eye: a protein conformational disease. Invest Ophthalmol Vis Sci 2015;56:1423-9.

[509] Faheem S, Kim SH, Nguyen J, Neravetla S, Ball M, Foulks GN, et al. Wax-tea and meibum protein, wax-beta-carotene interactions in vitro using infrared spectroscopy. Exp Eye Res 2012;100:32-9.

[510] Setala NL, Holopainen JM, Metso J, Yohannes G, Hiidenhovi J, Andersson LC, 
et al. Interaction of phospholipid transfer protein with human tear fluid mucins. J Lipid Res 2010;51:3126-34.

[511] Mauris J, Mantelli F, Woodward AM, Cao Z, Bertozzi CR, Panjwani N, et al. Modulation of ocular surface glycocalyx barrier function by a galectin-3 Nterminal deletion mutant and membrane-anchored synthetic glycopolymers. PLoS One 2013;8:e72304.

[512] Jeong S, Ledee DR, Gordon GM, Itakura T, Patel N, Martin A, et al. Interaction of clusterin and matrix metalloproteinase-9 and its implication for epithelial homeostasis and inflammation. Am J Pathol 2012;180:2028-39.

[513] Bauskar A, Mack WJ, Mauris J, Argueso P, Heur M, Nagel BA, et al. Clusterin seals the ocular surface barrier in mouse dry eye. PLoS One 2015;10: e0138958.

[514] Butovich IA, Millar TJ, Ham BM. Understanding and analyzing meibomian lipids-a review. Curr Eye Res 2008;33:405-20.

[515] Gasymov OK, Abduragimov AR, Yusifov TN, Glasgow BJ. Binding studies of tear lipocalin: the role of the conserved tryptophan in maintaining structure, stability and ligand affinity. Biochim Biophys Acta 1999;1433:307-20.

[516] Glasgow BJ, Abduragimov AR, Farahbakhsh ZT, Faull KF, Hubbell WL. Tear lipocalins bind a broad array of lipid ligands. Curr Eye Res 1995;14:363-72.

[517] Glasgow BJ, Marshall G, Gasymov OK, Abduragimov AR, Yusifov TN, Knobler CM. Tear lipocalins: potential lipid scavengers for the corneal surface. Invest Ophthalmol Vis Sci 1999;40:3100-7.

[518] Glasson M, Stapleton F, Willcox M. Lipid, lipase and lipocalin differences between tolerant and intolerant contact lens wearers. Curr Eye Res 2002;25: 227-35.

[519] Caffery B, Joyce E, Boone A, Slomovic A, Simpson T, Jones L, et al. Tear lipocalin and lysozyme in Sjogren and non-Sjogren dry eye. Optom Vis Sci 2008;85:661-7.

[520] Brauer L, Johl M, Borgermann J, Pleyer U, Tsokos M, Paulsen FP. Detection and localization of the hydrophobic surfactant proteins B and C in human tear fluid and the human lacrimal system. Curr Eye Res 2007;32:931-8.

[521] Holzfeind P, Merschak P, Dieplinger H, Redl B. The human lacrimal gland synthesizes apolipoprotein D mRNA in addition to tear prealbumin mRNA both species encoding members of the lipocalin superfamily. Exp Eye Res 1995; $61: 495-500$

[522] Molloy MP, Bolis S, Herbert BR, Ou K, Tyler MI, van Dyk DD, et al. Establishment of the human reflex tear two-dimensional polyacrylamide ge electrophoresis reference map: new proteins of potential diagnostic value. Electrophoresis 1997;18:2811-5.

[523] Remington SG, Crow JM, Nelson JD. Secretoglobins: lacrimal gland-specific rabbit lipophilin mRNAs. Invest Ophthalmol Vis Sci 2008;49:2856-62.

[524] Lehrer RI, Xu G, Abduragimov A, Dinh NN, Qu XD, Martin D, et al. Lipophilin, a novel heterodimeric protein of human tears. FEBS Lett 1998;432:163-7.

[525] Jauhiainen M, Setala NL, Ehnholm C, Metso J, Tervo TM, Eriksson O, et al. Phospholipid transfer protein is present in human tear fluid. Biochemistry 2005; $44: 8111-6$.

[526] Ma P, Beck SL, Raab RW, McKown RL, Coffman GL, Utani A, et al. Heparanase deglycanation of syndecan-1 is required for binding of the epithelialrestricted prosecretory mitogen lacritin. J Cell Biol 2006;174:1097-106.

[527] Zhang Y, Wang N, Raab RW, McKown RL, Irwin JA, Kwon I, et al. Targeting of heparanase-modified syndecan-1 by prosecretory mitogen lacritin requires conserved core GAGAL plus heparan and chondroitin sulfate as a nove hybrid binding site that enhances selectivity. J Biol Chem 2013;288: 12090-101.

[528] Medina S, Dominguez-Perles R, Gil JI, Ferreres F, Gil-Izquierdo A. Metabolomics and the diagnosis of human diseases-a guide to the markers and pathophysiological pathways affected. Curr Med Chem 2014;21:823-48.

[529] Munoz-Hernandez AM, Galbis-Estrada C, Santos-Bueso E, Cuina-Sardina R Diaz-Valle D, Gegundez-Fernandez JA, et al. Human tear metabolome. Arch Soc Esp Oftalmol 2016;91:157-9.

[530] Galbis-Estrada C, Martinez-Castillo S, Morales JM, Vivar-Llopis B, Monleon D, Diaz-Llopis M, et al. Differential effects of dry eye disorders on metabolomic profile by $1 \mathrm{H}$ nuclear magnetic resonance spectroscopy. Biomed Res Int 2014;2014:542549.

[531] Galbis-Estrada C, Pinazo-Duran MD, Martinez-Castillo S, Morales JM Monleon D, Zanon-Moreno V. A metabolomic approach to dry eye disorders. The role of oral supplements with antioxidants and omega 3 fatty acids. Mol Vis 2015;21:555-67.

[532] Lindon JC, Holmes E, Bollard ME, Stanley EG, Nicholson JK. Metabonomics technologies and their applications in physiological monitoring, drug safety assessment and disease diagnosis. Biomarkers 2004;9:1-31.

[533] Nicholson JK, Lindon JC, Holmes E. 'Metabonomics': understanding the metabolic responses of living systems to pathophysiological stimuli via multivariate statistical analysis of biological NMR spectroscopic data. Xenobiotica 1999;29:1181-9.

[534] Chen L, Zhou L, Chan EC, Neo J, Beuerman RW. Characterization of the human tear metabolome by LC-MS/MS. J Proteom Res 2011;10:4876-82.

[535] Want EJ, Wilson ID, Gika H, Theodoridis G, Plumb RS, Shockcor J, et al. Global metabolic profiling procedures for urine using UPLC-MS. Nat Protoc 2010;5: 1005-18.

[536] Nicholson JK, Lindon JC. Systems biology: Metabonomics. Nature 2008;455: 1054-6.
[537] Nakatsukasa M, Sotozono C, Shimbo K, Ono N, Miyano H, Okano A, et al. Amino Acid profiles in human tear fluids analyzed by high-performance liquid chromatography and electrospray ionization tandem mass spectrometry. Am J Ophthalmol 2011;151:799-808.

[538] Choy CK, Cho P, Chung WY, Benzie IF. Water-soluble antioxidants in human tears: effect of the collection method. Invest Ophthalmol Vis Sci 2001;42: $3130-4$.

[539] Gogia R, Richer SP, Rose RC. Tear fluid content of electrochemically active components including water soluble antioxidants. Curr Eye Res 1998;17: 257-63.

[540] Baca JT, Taormina CR, Feingold E, Finegold DN, Grabowski JJ, Asher SA. Mass spectral determination of fasting tear glucose concentrations in nondiabetic volunteers. Clin Chem 2007;53:1370-2.

[541] Taormina CR, Baca JT, Asher SA, Grabowski JJ, Finegold DN. Analysis of tear glucose concentration with electrospray ionization mass spectrometry. J Am Soc Mass Spectrom 2007;18:332-6.

[542] Pescosolido N, Imperatrice B, Koverech A, Messano M. L-carnitine and short chain ester in tears from patients with dry eye. Optom Vis Sci 2009;86: E132-8.

[543] Trope GE, Rumley AG. Catecholamine concentrations in tears. Exp Eye Res 1984;39:247-50.

[544] Pintor J, Carracedo G, Alonso MC, Bautista A, Peral A. Presence of diadenosine polyphosphates in human tears. Pflugers Arch 2002;443:432-6.

[545] Speek AJ, van Agtmaal EJ, Saowakontha S, Schreurs WH, van Haeringen NJ. Fluorometric determination of retinol in human tear fluid using high-performance liquid chromatography. Curr Eye Res 1986;5:841-5.

[546] Mendelsohn ME, Abramson DH, Senft S, Servodidio CA, Gamache PH. Uric acid in the aqueous humor and tears of retinoblastoma patients. J AAPOS 1998;2:369-71.

[547] Peral A, Carracedo G, Acosta MC, Gallar J, Pintor J. Increased levels of diadenosine polyphosphates in dry eye. Invest Ophthalmol Vis Sci 2006;47: 4053-8.

[548] Carracedo G, Peral A, Pintor J. Diadenosine polyphosphates in tears of Sjogren syndrome patients. Invest Ophthalmol Vis Sci 2010;51:5452-9.

[549] Chhadva P, Lee T, Sarantopoulos CD, Hackam AS, McClellan AL, Felix ER, et al. Human tear serotonin levels correlate with symptoms and signs of dry eye. Ophthalmology 2015;122:1675-80.

[550] Barabino S, Dana MR. Animal models of dry eye: a critical assessment of opportunities and limitations. Invest Ophthalmol Vis Sci 2004;45:1641-6.

[551] Walcott B, Matthews G, Brink P. Differences in stimulus induced calcium increases in lacrimal gland acinar cells from normal and NZB/NZW F1 female mice. Curr Eye Res 2002;25:253-60.

[552] Ding C, MacVeigh M, Pidgeon M, da Costa SR, Wu K, Hamm-Alvarez SF, et al. Unique ultrastructure of exorbital lacrimal glands in male NOD and BALB/c mice. Curr Eye Res 2006;31:13-22.

[553] You IC, Bian F, Volpe EA, de Paiva CS, Pflugfelder SC. Age-Related Conjunctival Disease in the C57BL/6.NOD-Aec1Aec2 Mouse Model of Sjogren Syndrome Develops Independent of Lacrimal Dysfunction. Invest Ophthalmol Vis Sci 2015;56:2224-33.

[554] De Paiva CS, Hwang CS, Pitcher 3rd JD, Pangelinan SB, Rahimy E, Chen W, et al. Age-related T-cell cytokine profile parallels corneal disease severity in Sjogren's syndrome-like keratoconjunctivitis sicca in CD25KO mice. Rheumatology (Oxford) 2010;49:246-58.

[555] Dursun D, Wang M, Monroy D, Li DQ, Lokeshwar BL, Stern ME, et al. A mouse model of keratoconjunctivitis sicca. Invest Ophthalmol Vis Sci 2002;43: 632-8.

[556] Barabino S, Shen L, Chen L, Rashid S, Rolando M, Dana MR. The controlledenvironment chamber: a new mouse model of dry eye. Invest Ophthalmol Vis Sci 2005;46:2766-71.

[557] Coursey TG, Henriksson JT, Marcano DC, Shin CS, Isenhart LC, Ahmed F, et al. Dexamethasone nanowafer as an effective therapy for dry eye disease. J Control Release 2015;213:168-74.

[558] Coursey TG, Bohat R, Barbosa FL, Pflugfelder SC, de Paiva CS. Desiccating stress-induced chemokine expression in the epithelium is dependent on upregulation of NKG2D/RAE-1 and release of IFN-gamma in experimental dry eye. J Immunol 2014;193:5264-72.

[559] Suhalim JL, Parfitt GJ, Xie Y, De Paiva CS, Pflugfelder SC, Shah TN, et al. Effect of desiccating stress on mouse meibomian gland function. Ocul Surf 2014;12:59-68.

[560] Zhang X, De Paiva CS, Su Z, Volpe EA, Li DQ, Pflugfelder SC. Topical interferon-gamma neutralization prevents conjunctival goblet cell loss in experimental murine dry eye. Exp Eye Res 2014;118:117-24.

[561] Zhang X, Schaumburg CS, Coursey TG, Siemasko KF, Volpe EA, Gandhi NB, et al. CD8 $(+)$ cells regulate the T helper-17 response in an experimental murine model of Sjogren syndrome. Mucosal Immunol 2014;7:417-27.

[562] Henriksson JT, De Paiva CS, Farley W, Pflugfelder SC, Burns AR, Bergmanson JP. Morphologic alterations of the palpebral conjunctival epithelium in a dry eye model. Cornea 2013;32:483-90.

[563] de Paiva CS, Schwartz CE, Gjorstrup P, Pflugfelder SC. Resolvin E1 (RX-10001) reduces corneal epithelial barrier disruption and protects against goblet cell loss in a murine model of dry eye. Cornea 2012;31:1299-303.

[564] De Paiva CS, Volpe EA, Gandhi NB, Zhang X, Zheng X, Pitcher 3rd JD, et al. 
Disruption of TGF-beta signaling improves ocular surface epithelial disease in experimental autoimmune keratoconjunctivitis sicca. PLoS One 2011;6: e29017.

[565] Chang E, McClellan AJ, Farley WJ, Li DQ, Pflugfelder SC, De Paiva CS. Biodegradable PLGA-Based Drug Delivery Systems for Modulating Ocular Surface Disease under Experimental Murine Dry Eye. J Clin Exp Ophthalmol 2011;2: $1-6$.

[566] Schaumburg CS, Siemasko KF, De Paiva CS, Wheeler LA, Niederkorn JY, Pflugfelder SC, et al. Ocular surface APCs are necessary for autoreactive T cell-mediated experimental autoimmune lacrimal keratoconjunctivitis. J Immunol 2011;187:3653-62.

[567] Zhang X, Chen W, De Paiva CS, Volpe EA, Gandhi NB, Farley WJ, et al. Desiccating stress induces CD4+ T-cell-mediated Sjogren's syndrome-like corneal epithelial apoptosis via activation of the extrinsic apoptotic pathway by interferon-gamma. Am J Pathol 2011;179:1807-14.

[568] De Paiva CS, Chotikavanich S, Pangelinan SB, Pitcher 3rd JD, Fang B, Zheng X et al. IL-17 disrupts corneal barrier following desiccating stress. Mucosal Immunol 2009;2:243-53.

[569] Siemasko KF, Gao J, Calder VL, Hanna R, Calonge M, Pflugfelder SC, et al In vitro expanded $\mathrm{CD} 4+\mathrm{CD} 25+$ Foxp $3+$ regulatory $\mathrm{T}$ cells maintain a normal phenotype and suppress immune-mediated ocular surface inflammation. Invest Ophthalmol Vis Sci 2008;49:5434-40.

[570] Stewart P, Chen Z, Farley W, Olmos L, Pflugfelder SC. Effect of experimental dry eye on tear sodium concentration in the mouse. Eye Contact Lens 2005;31:175-8.

[571] Strong B, Farley W, Stern ME, Pflugfelder SC. Topical cyclosporine inhibits conjunctival epithelial apoptosis in experimental murine keratoconjunctivitis sicca. Cornea 2005;24:80-5.

[572] Li Z, Woo JM, Chung SW, Kwon MY, Choi JS, Oh HJ, et al. Therapeutic effect of topical adiponectin in a mouse model of desiccating stress-induced dry eye. Invest Ophthalmol Vis Sci 2013;54:155-62.

[573] Corrales RM, Stern ME, De Paiva CS, Welch J, Li DQ, Pflugfelder SC. Desiccating stress stimulates expression of matrix metalloproteinases by the corneal epithelium. Invest Ophthalmol Vis Sci 2006;47:3293-302.

[574] Corrales RM, Villarreal A, Farley W, Stern ME, Li DQ, Pflugfelder SC. Strainrelated cytokine profiles on the murine ocular surface in response to desiccating stress. Cornea 2007;26:579-84.

[575] Ozyildirim AM, Wistow GJ, Gao J, Wang J, Dickinson DP, Frierson Jr HF, et al. The lacrimal gland transcriptome is an unusually rich source of rare and poorly characterized gene transcripts. Invest Ophthalmol Vis Sci 2005;46: 1572-80.

[576] Zhou L, Wei R, Zhao P, Koh SK, Beuerman RW, Ding C. Proteomic analysis revealed the altered tear protein profile in a rabbit model of Sjogren's syndrome-associated dry eye. Proteomics 2013;13:2469-81.

[577] Butovich IA, Lu H, McMahon A, Eule JC. Toward an animal model of the human tear film: biochemical comparison of the mouse, canine, rabbit, and human meibomian lipidomes. Invest Ophthalmol Vis Sci 2012;53:6881-96.

[578] Li N, Deng X, Gao Y, Zhang S, He M, Zhao D. Establishment of the mild, moderate and severe dry eye models using three methods in rabbits. BMC Ophthalmol 2013;13:50.

[579] Bron AJ, de Paiva CS, Chauhan SK, Bonini S, Gabison EE, Jain S, et al. TFOS DEWS II Pathophysiology report. Ocul Surf 2017;15:438-510.

[580] Tan LL, Morgan P, Cai ZQ, Straughan RA. Prevalence of and risk factors for symptomatic dry eye disease in Singapore. Clin Exp Optom 2015;98:45-53.

[581] Paulsen AJ, Cruickshanks KJ, Fischer ME, Huang GH, Klein BE, Klein R, et al. Dry eye in the beaver dam offspring study: prevalence, risk factors, and health-related quality of life. Am J Ophthalmol 2014;157:799-806.

[582] Yang WJ, Yang YN, Cao J, Man ZH, Yuan J, Xiao X, et al. Risk Factors for Dry Eye Syndrome: A Retrospective Case-Control Study. Optom Vis Sci 2015;92: e199-205.

[583] Holly FJ. Tear film physiology and contact lens wear. II. Contact lens-tear film interaction. Am J Optom Physiol Opt 1981;58:331-41.

[584] Nichols JJ, King-Smith PE. The impact of hydrogel lens settling on the thickness of the tears and contact lens. Invest Ophthalmol Vis Sci 2004;45: 2549-54.

[585] Muselier-Mathieu A, Bron AM, Mathieu B, Souchier M, Brignole-Baudouin F, Acar $\mathrm{N}$, et al. Ocular surface assessment in soft contact lens wearers; the contribution of tear osmolarity among other tests. Acta Ophthalmol 2014:92:364-9.

[586] Rohit A, Willcox MD, Brown SH, Mitchell TW, Stapleton F. Clinical and biochemical tear lipid parameters in contact lens wearers. Optom Vis Sci 2014:91:1384-90.

[587] Muntz A, Subbaraman LN, Sorbara L, Jones L. Tear exchange and contact lenses: a review. J Optom 2015;8:2-11.

[588] McNamara NA, Polse KA, Bonanno JA. Fluorophotometry in contact lens research: the next step. Optom Vis Sci 1998:75:316-22.

[589] Paugh JR, Stapleton F, Keay L, Ho A. Tear exchange under hydrogel contact lenses: methodological considerations. Invest Ophthalmol Vis Sci 2001;42: 2813-20.

[590] Polse KA. Tear flow under hydrogel contact lenses. Invest Ophthalmol Vis Sci 1979;18:409-13.

[591] Luo L, Li DQ, Doshi A, Farley W, Corrales RM, Pflugfelder SC. Experimental dry eye stimulates production of inflammatory cytokines and MMP-9 and activates MAPK signaling pathways on the ocular surface. Invest Ophthalmol Vis Sci 2004;45:4293-301.

[592] Heimer SR, Evans DJ, Mun JJ, Stern ME, Fleiszig SM. Surfactant protein D contributes to ocular defense against Pseudomonas aeruginosa in a murine model of dry eye disease. PLoS One 2013;8:e65797.

[593] Toshida H, Nguyen DH, Beuerman RW, Murakami A. Neurologic evaluation of acute lacrimomimetic effect of cyclosporine in an experimental rabbit dry eye model. Invest Ophthalmol Vis Sci 2009:50:2736-41.

[594] Toshida H, Nguyen DH, Beuerman RW, Murakami A. Evaluation of novel dry eye model: preganglionic parasympathetic denervation in rabbit. Invest Ophthalmol Vis Sci 2007;48:4468-75.

[595] Wolffsohn JS, Mroczkowska S, Hunt OA, Bilkhu P, Drew T, Sheppard A. Crossover evaluation of silicone hydrogel daily disposable contact lenses. Optom Vis Sci 2015;92:1063-8.

[596] Bhargava R, Kumar P. Oral omega-3 fatty acid treatment for dry eye in contact lens wearers. Cornea 2015;34:413-20.

[597] Lopez-de la Rosa A, Martin-Montanez V, Lopez-Miguel A, Calonge M, Enriquez-de-Salamanca A, Gonzalez-Garcia MJ. Corneal Sensitivity and Inflammatory Biomarkers in Contact Lens Discomfort. Optom Vis Sci 2016;93: 892-900.

[598] Fukui M, Yamada M, Akune Y, Shigeyasu C, Tsubota K. Fluorophotometric Analysis of the Ocular Surface Glycocalyx in Soft Contact Lens Wearers. Curr Eye Res 2016;41:9-14.

[599] Mathers WD, Stovall D, Lane JA, Zimmerman MB, Johnson S. Menopause and tear function: the influence of prolactin and sex hormones on human tear production. Cornea 1998;17:353-8.

[600] Gagliano C, Caruso S, Napolitano G, Malaguarnera G, Cicinelli MV, Amato R, et al. Low levels of 17-beta-oestradiol, oestrone and testosterone correlate with severe evaporative dysfunctional tear syndrome in postmenopausal women: a case-control study. Br J Ophthalmol 2014;98:371-6.

[601] Scuderi G, Contestabile MT, Gagliano C, Iacovello D, Scuderi L, Avitabile T. Effects of phytoestrogen supplementation in postmenopausal women with dry eye syndrome: a randomized clinical trial. Can J Ophthalmol 2012;47: 489-92.

[602] Srinivasan S, Joyce E, Boone A, Simpson T, Jones L, Senchyna M. Tear lipocalin and lysozyme concentrations in postmenopausal women. Ophthalmic Physiol Opt 2010;30:257-66.

[603] Careba I, Chiva A, Totir M, Ungureanu E, Gradinaru S. Tear lipocalin, lysozyme and lactoferrin concentrations in postmenopausal women. J Med Life 2015;8(Spec Issue):94-8.

[604] Taner P, Akarsu C, Atasoy P, Bayram M, Ergin A. The effects of hormone replacement therapy on ocular surface and tear function tests in postmenopausal women. Ophthalmologica 2004;218:257-9.

[605] Pelit A, Bagis T, Kayaselcuk F, Dursun D, Akova Y, Aydin P. Tear function tests and conjunctival impression cytology before and after hormone replacement therapy in postmenopausal women. Eur J Ophthalmol 2003;13:337-42.

[606] Schaumberg DA, Buring JE, Sullivan DA, Dana MR. Hormone replacement therapy and dry eye syndrome. JAMA 2001;286:2114-9.

[607] Sullivan DA, Rocha EM, Aragona P, Clayton JA, Ding J, Golebiowski B, et al TFOS DEWS II Sex, Gender, and Hormones report. Ocul Surf 2017;15: 284-333.

[608] Xu N, Huang D, Yang H, Lai Z, Luo Q. Ocular surface characteristics and impression cytology in patients with active versus inactive Thyroid Eye Disease. Eye Sci 2012;27:64-8.

[609] Huang D, Xu N, Song Y, Wang P, Yang H. Inflammatory cytokine profiles in the tears of thyroid-associated ophthalmopathy. Graefes Arch Clin Exp Ophthalmol 2012;250:619-25.

[610] Gilbard JP, Farris RL. Ocular surface drying and tear film osmolarity in thyroid eye disease. Acta Ophthalmol (Copenh) 1983;61:108-16.

[611] Iskeleli G, Karakoc Y, Abdula A. Tear film osmolarity in patients with thyroid ophthalmopathy. Jpn J Ophthalmol 2008:52:323-6.

[612] Ujhelyi B, Gogolak P, Erdei A, Nagy V, Balazs E, Rajnavolgyi E, et al. Graves orbitopathy results in profound changes in tear composition: a study of plasminogen activator inhibitor-1 and seven cytokines. Thyroid 2012;22: 407-14.

[613] Yazici A, Sari ES, Sahin G, Kilic A, Cakmak H, Ayar O, et al. Change in tear film characteristics in visual display terminal users. Eur J Ophthalmol 2015;25: $85-9$.

[614] Kojima T, Ibrahim OM, Wakamatsu T, Tsuyama A, Ogawa J, Matsumoto Y et al. The impact of contact lens wear and visual display terminal work on ocular surface and tear functions in office workers. Am J Ophthalmol 2011;152:933-40.

[615] Jansen ME, Begley CG, Himebaugh NH, Port NL. Effect of contact lens wear and a near task on tear film break-up. Optom Vis Sci 2010;87:350-7.

[616] Schlote T, Kadner G, Freudenthaler N. Marked reduction and distinct patterns of eye blinking in patients with moderately dry eyes during video display terminal use. Graefes Arch Clin Exp Ophthalmol 2004;242:306-12.

[617] Freudenthaler N, Neuf H, Kadner G, Schlote T. Characteristics of spontaneous eyeblink activity during video display terminal use in healthy volunteers. Graefes Arch Clin Exp Ophthalmol 2003;241:914-20.

[618] Patel S, Henderson R, Bradley L, Galloway B, Hunter L. Effect of visual display 
unit use on blink rate and tear stability. Optom Vis Sci 1991;68:888-92.

[619] Fenga C, Aragona P, Cacciola A, Spinella R, Di Nola C, Ferreri F, et al. Meibomian gland dysfunction and ocular discomfort in video display terminal workers. Eye (Lond) 2008;22:91-5.

[620] Fenga C, Aragona P, Di Nola C, Spinella R. Comparison of ocular surface disease index and tear osmolarity as markers of ocular surface dysfunction in video terminal display workers. Am J Ophthalmol 2014;158:41-8.

[621] Cardona G, Garcia C, Seres C, Vilaseca M, Gispets J. Blink rate, blink amplitude, and tear film integrity during dynamic visual display terminal tasks. Curr Eye Res 2011;36:190-7.

[622] Abusharha AA, Pearce EI, Fagehi R. Effect of Ambient Temperature on the Human Tear Film. Eye Contact Lens 2016;42:308-12.
[623] Torricelli AA, Novaes P, Matsuda M, Alves MR, Monteiro ML. Ocular surface adverse effects of ambient levels of air pollution. Arq Bras Oftalmol 2011;74: $377-81$.

[624] Torricelli AA, Matsuda M, Novaes P, Braga AL, Saldiva PH, Alves MR, et al. Effects of ambient levels of traffic-derived air pollution on the ocular surface: analysis of symptoms, conjunctival goblet cell count and mucin 5AC gene expression. Environ Res 2014;131:59-63.

[625] Gomes JAP, Azar DT, Baudouin C, Efron N, Hirayama M, Horwath-Winter J, et al. TFOS DEWS II Jatrogenic report. Ocul Surf 2017:15:511-38.

[626] Jordan A, Baum J. Basic tear flow - does it exist? Ophthalmology 1980;87: 920-30. 